\title{
I. Der Aufbau der Deutschen Zentralverwaltung für Justiz (1945-1947)
}

\section{Die sowjetische Besatzungsmacht und das Justizwesen}

Die Machtausübung der Sowjetunion in der SBZ unterlag - ähnlich wie die der anderen alliierten Mächte in ihren Zonen auch - grundsätzlich keinen Beschränkungen und eröffnete daher äußerst weitgehende Möglichkeiten ungehemmter Einflußnahme. Dennoch nutzte die Sowjetunion diese Phase ihrer Herrschaft nur begrenzt zur Sowjetisierung der politischen und wirtschaftlichen Verhältnisse in dem von ihr beherrschten Teil Deutschlands. Zur Erklärung dieses Widerspruches bedarf es eines kurzen Blicks auf die sowjetischen Zielvorstellungen, die internationalen Rahmenbedingungen und die Sachzwänge, denen auch Moskau unterlag. Bei Kriegsende stand für die sowjetische Führung die künftige politische Struktur Deutschlands noch keineswegs fest; eine Teilung Deutschlands kam damals für Stalin, teils aus seinem (kurzfristigen) Interesse an Reparationen aus ganz Deutschland, teils aus seinen sicherheitspolitischen Bestrebungen, die Westzonen nicht dauerhaft den Westalliierten zu überlassen, nicht in Frage. Ob in Moskau die Entscheidung zwischen den Optionen, Deutschland langfristig neutral zu halten oder in das sowjetische Imperium zu integrieren, damals bereits getroffen war, ist unklar ${ }^{1}$. Entscheidend für das sowjetische Handeln als Besatzungsmacht in dieser Zeit war jedenfalls, daß aus Interesse an der Aufrechterhaltung der deutschen Einheit die Eintracht unter den Siegermächten nicht gefährdet werden durfte. Die sowjetische Führung akzeptierte daher den Alliierten Kontrollrat als Handlungsrahmen: Einerseits darauf bedacht, dessen Entscheidungen zu beeinflussen, sah sie sich andererseits verpflichtet, dessen Normativakte auch in der SBZ umzusetzen². Die Politik der sowjetischen Besatzer war jedoch nicht nur von solchen übergeordneten Zielen, sondern - wie die der anderen Besatzungsmächte auch - weitgehend von Pragmatismus geprägt, da es in der "Zusammenbruchsgesellschaft“ zunächst darauf ankam, das öffentliche Leben in Wirtschaft und Gesellschaft möglichst rasch wieder in Gang zu setzen. Dies schloß Neuerungen zwar nicht grundsätzlich aus, machte jedoch oftmals eine Anknüpfung an tradierte Strukturen notwendig. Die dritte und wohl wichtigste Zielsetzung sowjetischer Besatzungspolitik bestand in der Sicherung der Herrschaft über die eigene Zone. Während sich die Sowjetunion auch darin nicht grundsätzlich von den anderen Besatzungsmächten unterschied, bestand sehr wohl eine Differenz in den Mitteln, mit denen

1 Nach Naimark, Russians in Germany, S. 466, blieben diese und die Teilungsoption „unreconciled during the period of occupation".

2 Zur interalliierten Politik siehe Mai, Alliierter Kontrollrat. 
sie dieses Ziel anstrebte. Dazu zählten einerseits äußerst rigorose Repressionsmaßnahmen, die nur vor dem Hintergrund des brutalen deutschen Besatzungsregimes in der Sowjetunion, eines in dieser Zeit entstandenen und von der sowjetischen Propaganda geförderten Feindbildes und des stalinistischen Regimes verständlich werden. Andererseits müssen dazu präventive Maßnahmen im Hinblick auf die staatlichen und gesellschaftlichen Strukturen gerechnet werden: Herrschaftssichernd in diesem Sinne sollten die Etablierung der KPD/SED in den Schlüsselstellungen des politischen Systems, die Enteignungen in Landwirtschaft und Industrie sowie die Entnazifizierung von Verwaltung, Schule und Justiz wirken. Die sowjetische Politik in der SBZ war in diesen Jahren daher ambivalent. Einerseits wies sie äußerst repressive Züge auf und legte in vielfacher Hinsicht die Fundamente für die zweite Diktatur in Deutschland; andererseits war sie pragmatisch ausgerichtet und darauf bedacht, die Eintracht unter den Alliierten nicht zu gefährden, so daß sie durchaus demokratische und reformerische Ansätze zuließ.

Doppeldeutig waren vor allem die von der Besatzungsmacht angestoßenen Entwicklungen, die - im engeren und im weiteren Sinne - das Justizwesen und die Zentralverwaltung für Justiz (DJV) beeinflußten. Als im Zuge des allgemeinen Zusammenbruchs im Jahre 1945 auch die Rechtspflege weitgehend zum Stillstand kam, war die Besatzungsmacht vornehmlich aus pragmatischen Gründen an einer möglichst umgehenden Wiederaufnahme der Justiztätigkeit auf lokaler, regionaler und zonaler Ebene interessiert ${ }^{3}$. So wurden auf Befehl der Kommandanten vor Ort die Gerichte oft unmittelbar nach dem Einmarsch sowjetischer Truppen wieder tätig, wobei die sowjetische Seite darauf achtete, keine NS-Juristen wieder einzustellen. Nach Etablierung des Alliierten Kontrollrats und der Militärverwaltung signalisierte die SMAD mit Befehl Nr. 49 - der eine entsprechende interalliierte Regelung vorwegnahm -, daß die sowjetische Besatzungsmacht an die deutschen Gerichtsstrukturen aus der Zeit vor 1933 anknüpfen und dabei im Einvernehmen mit den Westalliierten handeln wollte. Die Entscheidung, das Schwergewicht der Verwaltung - und damit auch der Justizverwaltung - auf die Länder und Provinzen zu legen, ist ebenfalls auf diese Mischung aus Pragmatismus und deutschlandpolitischem Kalkül zurückzuführen. Dies alles und die grundsätzliche Fortgeltung der deutschen Justizgesetze - freilich ohne die NS-spezifischen Änderungen - zeigten deutlich, daß die Besatzungsmacht die traditionellen rechtsstaatlichen Strukturen für das deutsche Justizsystem wieder in Kraft setzen wollte.

Damit kontrastierten die sowjetischen Zwangsmaßnahmen gegenüber der deutschen Bevölkerung. Im Zuge ihres Vormarsches in den letzten Kriegsmonaten internierte die Rote Armee bereits jenseits von Oder und Neiße Massen ihr verdächtig erscheinender Deutsche in Lagern des NKWD. Auch in der SBZ wurden zehn solcher Speziallager errichtet, die zunächst direkt dem stellvertretenden Innenminister Iwan A. Serow und erst ab August 1948 der Hauptverwaltung für Lager des Innenministeriums (MWD) unterstellt und damit Teil des GULag-Systems wurden. Zwischen 1945 und 1950 waren darin etwa 189000 Personen inhaf-

3 Anders als beispielsweise die amerikanische Besatzungsmacht, die zunächst einmal die Gerichte in ihrer Zone schloß: siehe dazu Stolleis, Rechtsordnung und Justizpolitik, S. 255. 
tiert, darunter etwa 35000 Ausländer, in der Regel sowjetische Staatsangehörige. Die sowjetischen Sicherheitsorgane ergriffen sowohl nationalsozialistische Funktionsträger als auch vermeintliche Gegner der Besatzungsmacht, darunter zahlreiche Jugendliche, die als im Untergrund aktive „Werwölfe“ galten. Daß es sich dabei mehr um ein Phantom als um eine reale Gefahr handelte, kümmerte die sowjetischen Geheimpolizisten nicht; die Verhaftungspraxis war weitgehend von stalinistischer Willkür geprägt. Von den insgesamt 154000 internierten Deutschen starben aufgrund der in den Lagern herrschenden Bedingungen, vor allem der völlig unzureichenden Ernährung und der katastrophalen hygienischen Zustände, nach neuesten Forschungen 43645. Im Unterschied zu den Konzentrationslagern des Dritten Reiches und den Lagern in der Sowjetunion während der Stalin-Zeit sind die Todesfälle nicht auf eine direkte Vernichtungsabsicht der sowjetischen Verantwortlichen zurückzuführen ${ }^{4}$. Wenngleich auch die westlichen Alliierten in ihren Besatzungszonen Internierungslager für verdächtige und NS-belastete Deutsche unterhielten, wurde schon bald ein entscheidender Unterschied deutlich: Während sich in den Westzonen die Haftbedingungen allmählich besserten und nach eingehenden Einzelfalluntersuchungen bereits ab November 1945 Entlassungen vorgenommen wurden, änderte sich an den Zuständen in den sowjetischen Lagern nichts; wenn sich die Lagertore, wie 1948, einmal öffneten, geschah dies aus Gründen politischer Opportunität und nicht nach juristischen Überprüfungen 5 . Die Inhaftierungspraxis in der SBZ änderte sich mit einer Anweisung des MWD, ab Januar 1947 Lagereinweisungen nur bei Vorliegen eines vom Militärstaatsanwalt ausgestellten Haftbefehls vorzunehmen: Die der sowjetischen Rechtspraxis entsprechende staatsanwaltschaftliche Aufsicht führte $1947 \mathrm{zu}$ einer praktischen Einstellung der Internierungen 6 . Sie betraf freilich nicht den sowjetischen Staatssicherheitsdienst (MGB), der weiterhin willkürliche Verhaftungen vornehmen durfte und dadurch unter der deutschen Bevölkerung nach wie vor Angst und Schrecken verbreitete. Wie ein Memorandum des Chefs der SMA in Thüringen, Iwan S. Kolesnitschenko, zeigt, kritisierten auch Teile der Militärverwaltung diese Praxis, da damit ein wesentliches Ziel sowjetischer Politik, „die Sympathien der deutschen Bevölkerung für die UdSSR zu gewinnen“, konterkariert wurde?.

Auch wenn die von der Geheimpolizei gefaßten Deutschen vor ein Sowjetisches Militärtribunal (SMT) gestellt wurden, kann von einer Verrechtlichung des Verfahrens nur in einem sehr formellen Sinne gesprochen werden. Die Zuständigkeit der SMT, die primär innerhalb der sowjetischen Streitkräfte wirken sollten, ergab sich zum einen aus sowjetischen Rechtsvorschriften und zum anderen, sofern es Verfahren wegen NS-Belastung betraf, aus Gesetz Nr. 10 des Alliierten

4 Vgl. dazu insgesamt den Überblick über den neuesten Forschungsstand von Plato, Zur Geschichte des Speziallagersystems.

5 Zum Ost-West-Vergleich siehe Knigge-Tesche/Spirek/Ritscher, Internierungspraxis in Ost- und Westdeutschland.

6 Petrov, Apparate, S. 148 f.; Possekel, Einleitung, zu: Sowjetische Speziallager, Bd. 2, S. 69, und die Dokumente 65 (S. 277 f.), 68 (281), 71 (285), ebenda.

7 Das Memorandum vom 29.11. 1948 in: Bonwetsch/Bordjugov/Naimark, Sowjetische Politik in der SBZ, S. 183-198, hier 193-198 (das Zitat S. 198). 
Kontrollrats vom 20. November 19458. Die Grundlage für nach dem 8. Mai 1945 begangene Straftaten bildete vor allem Artikel 58 des russischen Strafgesetzbuches, der weitgefaßte Straftatbestände wie konterrevolutionäre Handlungen, Spionage sowie antisowjetische Propaganda und Agitation enthielt ${ }^{9}$. Die Voruntersuchungen und die Rechtsprechung der Tribunale waren durch Willkür, Brutalität und das Fehlen von rechtsstaatlichen Verfahrensregeln gekennzeichnet. Insgesamt verurteilten die Militärgerichte nach neuesten, von russischer Seite genannten Zahlen 40000 deutsche Zivilpersonen, von denen über die Hälfte in die Sowjetunion transportiert, die anderen in die Speziallager eingeliefert wurden: Im September 1948 befanden sich unter den Lagerhäftlingen der SBZ 13873 SMTVerurteilte ${ }^{10}$. Wenngleich bis 1955 in der DDR tätig, verhängten die SMT die meisten Urteile gegen Deutsche in den Jahren 1947 bis 1949. Aber auch danach waren sie noch aktiv und zeichneten sich durch eine harte Urteilspraxis aus: 1950 verhängten sie 128, 1951 102, 195293 und 195375 Todesurteile ${ }^{11}$. In den ersten Jahren nach 1945 waren SMT-Verfahren wegen NS-Belastung weit verbreitet, handelte es sich doch bei den Militärgerichten bis zum August 1947 um die einzige dafür zuständige Instanz. Hinzu kam die Strafverfolgung der Personen, die „konterrevolutionärer Verbrechen " beschuldigt wurden, also gegen jene, die politisch unangepaßt waren, gegen die Zustände in der SBZ opponierten und aus Sicht der Besatzungsmacht ein Sicherheitsrisiko darstellten. Vor allem mit der weitgehenden Übergabe der NS-Strafverfolgung an deutsche Instanzen mit SMAD-Befehl Nr. 201 stiegen die politischen SMT-Verfahren sprunghaft an. Im November 1949 waren nach einer NKWD-Statistik über die in den Speziallagern einsitzenden SMT-Verurteilten 28 Prozent wegen Tätigkeit im NS-Regime, 48 Prozent wegen „antisowjetischer Agitation“, "Spionage“ und "Sabotage“, 16 Prozent wegen „illegalen Waffenbesitzes“ und acht Prozent wegen krimineller Delikte verurteilt worden ${ }^{12}$. Auch andere sich auf 1949 beziehende Archivfunde bestätigen die Dominanz der politischen SMT-Verfahren ${ }^{13}$; ob dies auch für 1945 bis 1947 gilt, ist zweifelhaft.

Durch die Internierungen, die sowjetischen Militärtribunale und die Eingriffe lokaler Militärkommandanten sowie Geheimpolizisten in laufende Verfahren vor deutschen Gerichten ${ }^{14}$ wurde deutlich, daß rechtsstaatliche Grundsätze in der SBZ nur dort galten, wo die - weit ausgelegten - Interessen der Besatzungsmacht nicht berührt waren. Indem diese die politische Strafjustiz an sich zog, entlastete

8 Amtsblatt des Kontrollrats, Nr. 3, 31. 1. 1946, S. 50-55.

9 In deutscher Übersetzung in: Fricke, Politik und Justiz, S. 106-109. Dort (S. 100-129) auch der nach wie vor gültige Überblick zu den SMT, der jüngst von Erler, Zum Wirken der Sowjetischen Militärtribunale, mit Hilfe sowjetischer Akten ergänzt worden ist. Zu den SMT in Brandenburg siehe Pohl, Justiz in Brandenburg (Manuskript), S. 80-82.

10 Erler, Zum Wirken der Sowjetischen Militärtribunale, S. 173, 181.

1 Zahlen nach Evans, Rituals of Retribution, S. 845. Die Todesurteile wurden jedoch bei weitem nicht alle vollstreckt.

12 Angaben nach Morré, Speziallager des NKWD, S. 20.

13 Vgl. Oleschinski/Pampel, Feindliche Elemente, S. 40f.; Kersebom/Niethammer, Kompromat 1949.

14 In Ausnahmefällen drangen Berichte darüber auch an die DJV: siehe u. a. Vermerk Hartwigs, 4. 12. 1946, und DJV an SMAD-Rechtsabteilung, 29. 4. 1948, BAB, DP1 VA Nr. 330, Bl. 10 f., 3 f.; vgl. dazu auch Wentker, Justiz im Übergang, S. 173. Zu einigen dieser Vorfälle in Thüringen siehe Weber, Justiz und Diktatur, S. 53-56. 
sie jedoch gleichzeitig die deutschen Justizorgane: Eine Wiederanknüpfung an die justitielle Praxis des Dritten Reiches in Staatsschutzverfahren wurde unmöglich, ja, die deutsche Gerichtsbarkeit profitierte von der Ausklammerung der politischen Fälle insofern, als ihr dadurch die Beibehaltung rechtsstaatlicher Verfahrensweisen ermöglicht wurde. Auch wenn deutsche Gerichte aufgrund sowjetischer Eingriffe unangemessene Urteile fällten, waren letztlich nicht die Staatsanwälte und Richter, sondern die zuständigen sowjetischen Organe dafür verantwortlich. Die justitiellen und außerjustitiellen Eingriffe der sowjetischen Besatzungsmacht durchlöcherten daher den Rechtsstaat, trugen aber gleichzeitig zu seiner Erhaltung durch die deutschen Justizorgane in ihrem Tätigkeitsbereich bei.

Es waren jedoch nicht nur derartige Repressionsmaßnahmen, die dem übersteigerten sowjetischen Sicherheitsinteresse dienten. Hinzu kamen Eingriffe in die innenpolitische Struktur der SBZ, insbesondere über die KPD und, ab 1946, die SED. Bereits das Wirken der aus Moskau entsandten kommunistischen Initiativgruppen Ulbricht, Sobottka und Ackermann verdeutlichte, daß die Sowjetunion mit Hilfe der deutschen Kommunisten eine ihren Interessen zuwiderlaufende Entwicklung schon im Keim verhindern wollte ${ }^{15}$. Freilich mußte nach der - ebenfalls auf sowjetische Anweisungen zurückgehenden - Zwangsvereinigung von KPD und SPD im April 1946 aus der sozialistischen Massenpartei erst eine stalinistische Kaderpartei werden. Der umfassende gesamtgesellschaftliche Lenkungsanspruch von KPD und SED stand daher in diesen Jahren vielfach nur auf dem Papier ${ }^{16}$. Wesentliche Kennzeichen der Stalinisierung der SED waren die Beseitigung der innerparteilichen Demokratie und die damit einhergehende Einengung von Handlungsspielräumen der ehemaligen SPD-Mitglieder ${ }^{17}$. Wenngleich die innerparteiliche Repression von prominenten Sozialdemokraten in den Landesvorständen bereits im Sommer 1946 einsetzte, begann die eigentliche Stalinisierung der SED erst 1947, insbesondere mit dem II. SED-Parteitag im September dieses Jahres ${ }^{18}$.

Der Hegemonialanspruch der SED wurde unmittelbar nach 1946 zudem von den neu gegründeten Parteien CDU und LDP begrenzt. Indem die SMAD deren Gründung zuließ, erweckte sie den Eindruck, als befürworte sie ein pluralistisches Parteiensystem in der SBZ und in ganz Deutschland ${ }^{19}$. Eine offene Konkurrenz zwischen den bürgerlichen Parteien und der KPD/SED verhinderte die Besatzungsmacht jedoch durch deren Einbindung in die sogenannte „Einheitsfront der antifaschistisch-demokratischen Parteien“, in der diese auf Konsenslösungen verpflichtet wurden ${ }^{20}$. Außerdem zeigte sich vor und nach den halbfreien Wahlen von 1946, daß die SMAD sich deutlich zugunsten der SED engagierte und deren Konkurrenten aus dem bürgerlichen Lager erheblich benachteiligte ${ }^{21}$. Die Union und

15 Zur Gruppe Ulbricht vgl. Keiderling, Gruppe Ulbricht; zum Wirken der Gruppe Sobottka van Melis, Entnazifizierung in Mecklenburg-Vorpommern, S. 28-51.

16 Vgl. Kubina, Aufbau des zentralen Parteiapparates.

17 Vgl. dazu insgesamt neben der älteren Literatur neuerdings Bouvier, Ausgeschaltet, und Hurwitz, Stalinisierung der SED.

18 Vgl. Malycha, Partei von Stalins Gnaden, S. 193, 71.

19 Vgl. dazu Keiderling, Scheinpluralismus.

20 Vgl. Suckut, Blockpolitik.

21 Vgl. dazu Creuzberger, Sowjetische Besatzungsmacht. 
die Liberalen waren keineswegs von Anfang an gefügige Partner der SED: Als eigenständige Parteien gegründet, wurden sie vielmehr, gerade unter den spezifischen Bedingungen in der SBZ, zu Mitgliederparteien, in denen jene sich vertreten fühlen konnten, die nicht zur SED tendierten ${ }^{22}$. Trotz sowjetischer Einflußnahmen auf innerparteiliche Entscheidungsprozesse in CDU und LDP handelte es sich somit um politische Formationen, über deren Ansprüche SMAD und SED nicht einfach hinweggehen konnten.

Unter dem Gesichtspunkt der Herrschaftssicherung war das Justizressort für die sowjetische Besatzungsmacht zunächst von untergeordneter Bedeutung. Die Besatzungsmacht glaubte, auf eine massive Einflußnahme im deutschen Justizwesen verzichten zu können, weil sie sich die strafrechtliche Sanktionierung politischen Fehlverhaltens selbst vorbehielt und zudem von Anfang an die Besetzung der Innenressorts für sehr viel wichtiger erachtete. Bereits die KPD-Initiativgruppen hatten darauf geachtet, daß vornehmlich Kommunisten mit der Leitung der für die Polizei zuständigen Führungspositionen betraut wurden. Beim Aufbau der Innenressorts der Länder hielten SED und Besatzungsmacht an diesem Prinzip ebenfalls fest; die auf zentraler Ebene am 30. Juli 1946 mit Geheimbefehl Nr. 0212 von der SMAD gegründete Deutsche Verwaltung des Innern bildete keine Ausnahme23. Der Anteil an SED-Mitgliedern war hier Ende 1946 mit 87,1 Prozent erheblich höher als in allen anderen Zentralverwaltungen; der CDU gehörten nur 1,0, der SPD 2,4 Prozent der 276 Mitarbeiter an ${ }^{24}$. Nicht nur in der Besetzung der DVdI spiegelt sich die Tatsache wider, daß der Polizei als herrschaftssicherndem Instrument eine weitaus größere Bedeutung zukam als der Justiz. Denn der Aufbau der Polizeistrukturen erfolgte unter direkter Anleitung sowjetischer Stellen ${ }^{25}$, die festlegten, daß die Polizeichefs der Länder „in operativen Angelegenheiten nur der Deutschen Verwaltung des Innern“ und nur „administrativ" den Länderverwaltungen unterstehen sollten ${ }^{26}$. Nur durch die Zentralisierung der „von uns in der SBZ organisierten Polizei“, so Geheimpolizeichef Serow am 26. Juni 1946 gegenüber dem sowjetischen Innenminister Sergej N. Kruglow, könne sich die zu gründende DVdI „unter unserer Führung die notwendigen Erfahrungen aneigne[n] und das künftige Innenministerium bilden" 27 . Wie aus dem Protokoll der ersten Konferenz dieser Zentralverwaltung mit den Polizeichefs der Länder und Provinzen am 30. Oktober 1946 hervorgeht, herrschte Konsens darüber, die Polizei als „Machtinstrument unseres neuen Staates“ zu betrachten, das in die Lage versetzt werden sollte, ,alle Errungenschaften und jede von uns bereits politisch und wirtschaftlich vollzogene Tatsache zu sichern“28.

22 Vgl. Wentker, Anfänge der bürgerlichen Parteien.

23 Vgl. u. a. Laufer, Ursprünge, S. 150; Wenzke, Auf dem Wege zur Kaderarmee, S. 210.

24 Vgl. Personalstruktur der DVdI, ebenda, S. 211. Für die parteipolitische Besetzung des Personals der anderen Zentralverwaltungen am 21.9. 1946 siehe das Dokument bei Amos, Justizverwaltung, S. 239-244.

25 Die engen Anleitungsstrukturen auf allen Ebenen veranlassen Foitzik dazu, von einer „gemischten deutsch-sowjetischen Verwaltung" mit sowjetischer Prädominanz zu sprechen (Sowjetische Militäradministration in Deutschland, S. 346).

26 Protokoll über die Besprechung zwischen Lapenkow, Smirnow, Reschke, Wagner und Mielke, 12. 9. 1946, in: Glaser, Reorganisation, S. 85.

27 Zit. nach Foitzik, Sowjetische Militäradministration in Deutschland, S. 346.

28 Beide Zitate nach Laufer, Anfänge, S. 157. 
Die Organisationsstruktur und Besetzung der Innenverwaltung verhinderte zwar die für die anderen Verwaltungszweige damals typischen Kompetenzstreitigkeiten zwischen Zentrale und Ländern; dennoch war die Effektivität der Polizei in den ersten Jahren ihrer Existenz begrenzt. Dies hing vor allem damit zusammen, daß sie kaum auf professionelles, durch seine Tätigkeit im Dritten Reich belastetes Personal zurückgriff. Die flächendeckende Entnazifizierung wurde dazu genutzt, möglichst viele SED-Mitglieder und Angehörige der Arbeiterklasse einzustellen, die weitgehende politische Loyalität gewährleisten sollten. Aufgrund mangelnder Qualifikation, unzulänglicher Ausbildung und unzureichender Ausrüstung konnten die Volkspolizisten ihren Aufgaben kaum gerecht werden. Die massive Zunahme der Kriminalität in der unmittelbaren Nachkriegszeit tat ein übriges, um diese hoffnungslos zu überfordern. Auch deren rasches zahlenmäßiges Wachstum von 39009 Mann im Jahre 1946 auf 64587 im Jahre $1948^{29}$ führte nicht zu einer effektiveren Kontrolle der Gesellschaft, sondern verstärkte vielmehr die inneren Probleme der Polizei, zu denen insbesondere eine extrem hohe Personalfluktuation zählte ${ }^{30}$.

In ihrem Bestreben, die Besatzungsherrschaft abzusichern, beschränkte sich die sowjetische Politik nicht auf repressive Maßnahmen und Eingriffe in die politisch-administrativen Strukturen. Ihr kam es auch darauf an, diejenigen Kräfte zu beseitigen, die - nach kommunistischen Vorstellungen - die NS-Diktatur ermöglicht und maßgeblich getragen hatten. Hintergrund dieser Vorstellungen war ein verzerrter Faschismusbegriff, der den Spezifika der NS-Diktatur kaum gerecht wurde. Gleichwohl bestimmte er das Denken und Handeln der sowjetischen und deutschen Kommunisten, die daran gingen, die traditionellen deutschen Eliten in Landwirtschaft, Industrie und Verwaltung aus ihren Positionen zu entfernen. Die von der Besatzungsmacht initiierten und von der KPD vorangetriebenen Maßnahmen sollten die sozioökonomisch bedingten Machtverhältnisse grundlegend ändern und dadurch eine von Deutschland ausgehende Bedrohung der Sowjetunion ein für alle Mal verhindern ${ }^{31}$.

Dies wird bereits an der ersten Enteignungswelle in der Landwirtschaft der SBZ deutlich. Initiiert von der Sowjetunion, wurde die Bodenreform in der SBZ nach einer zentral vorgegebenen Verordnung durchgeführt. Bis zum 1. Oktober 1947 konnten 7049 Güter mit jeweils mehr als 100 Hektar und 3430 kleinere Objekte ihren Besitzern auf dieser Rechtsgrundlage entzogen und weitgehend an landlose Bauern, Flüchtlinge und ehemalige Landarbeiter verteilt werden ${ }^{32}$. Der Verwendungszweck des enteigneten Landes darf freilich nicht zu falschen Schlüssen über den Ursprung dieser Maßnahme führen. Noch im März 1949 machte der Leiter der Zentralen Kontrollkommission (ZKK), Fritz Lange, rückblickend deutlich: „Die Bodenreform war für uns nicht allein ein Umsiedlerproblem, son-

29 Zahlen nach Lindenberger, Deutsche Volkspolizei, S. 100.

30 Vgl. dazu neben den Ausführungen von Lindenberger, ebenda, S. 97-102, Bessel, Polizei zwischen Krieg und Sozialismus, sowie ders., Grenzen des Polizeistaats.

31 Zum Antifaschismusbegriff in der DDR siehe Herbert, Zweierlei Bewältigung, sowie die Beiträge von Groehler, Danyel, Faulenbach und Frei in: Danyel, Geteilte Vergangenheit.

32 Zahlen nach Bauerkämper, Auf dem Weg zum „Sozialismus auf dem Lande“, S. 249. 
dern vor allen Dingen ein politisches Problem, um damit die festesten Stützen der Reaktion, Boden und Schlösser zu zertrümmern"33.

Ein ähnliches zentrales Vorhaben betraf die Umgestaltung der Besitzverhältnisse in der Industrie, um die "Monopolbourgeoisie“ zu entmachten. Nachdem in den Ländern bereits im Sommer 1945 Enteignungen von Industrievermögen vorgenommen worden waren, wurde das Vorgehen durch die SMAD-Befehle Nr. 124 und 126 Ende Oktober 1945 vereinheitlicht. Im Vordergrund stand in den Befehlstexten zwar das Eigentum von NS-belasteten Personen und Organisationen, aber durch großzügige Auslegung in den Ausführungsbestimmungen konnten auch andere größere Betriebe enteignet werden. Mit Befehl Nr. 154/181 vom 21. Mai 1946 übereignete die Besatzungsmacht die Betriebe größtenteils vorläufig den Landesverwaltungen; nachdem am 30. Juni ein Volksentscheid in Sachsen diese Aktion legitimiert hatte, zogen die anderen Länder mit entsprechenden Gesetzen nach, und führten die enteigneten Betriebe endgültig in Landeseigentum über. Der Rechtsstaat fand bei diesen Eingriffen freilich eine durch Besatzungsrecht vorgegebene Grenze, da für die Betroffenen der Rechtsweg ausgeschlossen blieb $^{34}$. Wenngleich Bodenreform und Sequestrationen rückblickend die Ausgangspunkte der sozioökonomischen Umgestaltung der SBZ/DDR darstellen, ist damit die Frage nach einer entsprechenden Zielsetzung im Jahre 1945 noch nicht beantwortet. Die Umstrukturierung der Verhältnisse auf dem Lande führte jedenfalls vorerst nicht zur Kollektivierung, sondern sollte die Klein- und Einzelbauern gegen die ehemaligen Gutsbesitzer stärken und der SED eine Klientel verschaffen. In der Industrie hingegen ergab sich aus der engen Verknüpfung von Konfiskationen und der Schaffung von „Volkseigentum“ bereits 1946 die Dominanz eines staatseigenen Sektors in der SBZ-Wirtschaft. Das kleinere und mittlere Unternehmertum wurde dadurch zwar geschwächt, aber noch nicht vernichtet, so daß auch in diesem Zusammenhang nicht von einer zwangsläufigen Entwicklung hin zur Eigentumsordnung der DDR die Rede sein kann.

Das dritte, gesellschaftliche wie staatliche Strukturen betreffende Vorhaben bildete die Entnazifizierung in Verwaltung, Schule und Justiz. Diese stellt insofern eine Besonderheit dar, als sich darin alliierte Vorgaben und das sowjetische Bestreben trafen, die alten Machteliten aus den Bastionen ihres Einflusses zu entfernen. Vor allem aufgrund dieser Zielsetzung Moskaus wurde in der SBZ die Entnazifizierung sehr viel rigoroser durchgeführt als in den anderen Besatzungszonen. Überspitzt formuliert war für die sowjetische Besatzungsmacht der personelle Bruch nicht eine in Kauf genommene Folge der Entlassungen von ,belasteten" Personen, sondern ein vorrangiges Ziel ihrer Personalpolitik, das unter Verweis auf die von allen Alliierten beschlossene Entnazifizierung legitimiert wurde. Der Ersatz dieser Funktionseliten ${ }^{35}$ durch neu rekrutierte Personengruppen stellt

33 Zit. nach Laufer, UdSSR und Einleitung der Bodenreform, S. 33. Zu Durchführung und Auswirkungen der Bodenreform in der SBZ siehe den Sammelband von Bauerkämper, Junkerland in Bauernhand.

34 Vgl. zu den Sequestrationen die DDR-offiziöse Darstellung Schöneburgs, Errichtung, S. 156-172; siehe auch die juristische Dissertation von der Becks, Konfiskationen in der SBZ, S. 89-110.

35 Zur Begrifflichkeit siehe vor allem Stammer, Elitenproblem, S. 9. Freilich geht Stammer dabei von pluralistisch-demokratisch verfaßten Gemeinwesen aus, in denen der Zugang zu den Führungsgruppen grundsätzlich allen offen ist und diese nicht nur bestimmte Funktionen in der sozialen 
strenggenommen keinen Elitenwechsel dar: Denn an die Stelle der traditionalen und nationalsozialistischen Eliten traten auf lange Sicht große, hierarchisch geordnete Apparate, die von einer relativ kleinen politischen Führungsgruppe angeleitet wurden ${ }^{36}$. Freilich mußten sich diese Apparate erst formieren, weil weder für die Verwaltung, noch für Schule und Justiz hinreichend qualifiziertes und loyales Personal zur Verfügung stand. Da diese Staatsfunktionen jedoch aufrechterhalten werden mußten, wurde zunächst vielfach auf Personal zurückgegriffen, das den kommunistischen Anforderungen nicht entsprach. Indem KPD-Mitglieder die Personalabteilungen in den Verwaltungen übernommen hatten, waren zwar die notwendigen Voraussetzungen für die Umsetzung ihrer Vorstellungen geschaffen worden; der Mangel an geeigneten "Kadern“ in den genannten Bereichen behinderte jedoch den Personalwechsel teilweise erheblich. Dabei ist zwischen den drei genannten Zweigen des öffentlichen Lebens sorgfältig zu differenzieren. In der staatlichen Bürokratie wurde Wert darauf gelegt, rasch und unter weitgehenden Abstrichen an der fachlichen Qualifikation möglichst loyale Angestellte aus Arbeiter- und Bauernkreisen zu gewinnen; binnen relativ kurzer Zeit war auch ein solcher Personalwechsel erreicht ${ }^{37}$. Die Entnazifizierung der Lehrerschaft ließ sich nicht so rasch und umfassend realisieren wie in der Verwaltung; außerdem mußten die einzustellenden Pädagogen erst in zunächst acht-, ab Herbst 1946 in zwölfmonatigen "Neulehrerkursen“ ausgebildet werden. Deren methodische Leitung lag bei der Abteilung Schulwesen der DVV, wo bis Dezember 1946 zwei aus der SPD stammende Fachleute für diese Aufgabe verantwortlich waren. Ein vollständiger Personalaustausch erfolgte somit an den Schulen nur mit mehrï̈hriger Verzögerung ${ }^{38}$. Auch die Entnazifizierung der Justiz wurde äußerst rigoros betrieben. Bis neu ausgebildete, dem System treu ergebene Justizjuristen die Personallücken füllen konnten, vergingen jedoch mehrere Jahre ${ }^{39}$.

Die DJV und das deutsche Justizwesen standen somit nicht im Mittelpunkt der sowjetischen Besatzungspolitik der Jahre 1945 bis 1947/48. Wenngleich sie keineswegs von kommunistischen Machtansprüchen unberührt blieben, war dort, anders als in anderen Teilen des Herrschaftssystems, die Ausbildung diktatorischer Strukturen noch kaum absehbar.

oder politischen Ordnung einer Gesellschaft, sondern auch eine Repräsentationsrolle übernehmen. In totalitären Staaten ist der Begriff daher auf seine Führungsrolle reduziert: vgl. Bauerkämper u. a., Funktionäre des schaffenden Volkes, S. 22-25.

36 Ebenda, S. 50.

37 Vgl. beispielsweise die Zahlen bei van Melis, Entnazifizierung in Mecklenburg-Vorpommern, S. 356-361: Bereits Anfang Mai 1946 gehörten von 821 Mitarbeitern der Landesverwaltung 345 der SED, 88 CDU und LDP an, während 388 parteilos waren; am 30.4. 1947 waren von 1292 Mitarbeitern 660 SED-, 127 CDU und LDP-Mitglieder und 505 parteilos.

38 Vgl. Hohlfeld, Neulehrer in der SBZ/DDR; Welsh, Deutsche Zentralverwaltung für Volksbildung, S. 233.

39 Siehe dazu Kap. A.III, A.IV, B.IV. 


\section{Die SMAD-Rechtsabteilung und die SED-Justizabteilung als Anleitungsinstanzen für das Justizwesen und die DJV}

Das zentrale Herrschaftsorgan in der SBZ war die sowjetische Militärverwaltung, zu deren Oberstem Chef Stalin am 7. Mai 1945 Marschall Georgi K. Schukow ernannte. Einen Tag nach der gemeinsamen Erklärung der Alliierten zur Übernahme der Regierungsgewalt in Deutschland am 5. Juni erging eine Anordnung des Rats der Volkskommissare der UdSSR zur Bildung der Sowjetischen Militäradministration in Deutschland (SMAD), die von Schukow im Befehl Nr. 1 vom 9. Juni offiziell bekanntgegeben wurde ${ }^{40}$. Die Besatzungsmächte herrschten in ihren Besatzungszonen unumschränkt mit Hilfe ihrer Militärverwaltungen, die sich zur Durchführung ihrer Anordnungen deutscher Hilfsorgane bedienten. Die Entscheidung, zur Unterstützung der SMAD auf zonaler Ebene Zentralverwaltungen zu schaffen, wurde nicht, wie vielfach vermutet, getroffen, um damit die Gestalt der in der Potsdamer Erklärung anvisierten „zentrale[n] deutsche[n] Verwaltungsabteilungen" ${ }^{41}$ zu präjudizieren ${ }^{42}$. Als Schukow mit Befehl Nr. 17 am 27. Juli 1945 die Bildung von elf deutschen Zentralverwaltungen - unter anderem eine für das Justizwesen - anordnete ${ }^{43}$, standen vielmehr pragmatische Gesichtspunkte im Vordergrund. Denn die Zentralabteilungen der Militärverwaltung in Berlin benötigten deutsche Hilfsorgane, die sie bei der Koordinierung der bisher geschaffenen Landes- und Provinzialverwaltungen unterstützten.

In der SMAD-Zentrale in Berlin-Karlshorst kam die Verantwortung für Anleitung und Kontrolle des deutschen Justizwesens vor allem zwei Abteilungen zu. Es handelte sich dabei zum einen um die dem Stellvertreter für Zivilfragen unterstellte Abteilung für innere Angelegenheiten, die ab April $1947 \mathrm{zu}$ einer Verwaltung aufgewertet wurde. Sie unterstand Generalmajor Pawel M. Malkow, einem ehemaligen NKWD-Distriktleiter ${ }^{44}$, der von sich selbst im März 1948 behauptete, laut Regierungsbeschluß kontrolliere er die deutsche Staatsanwaltschaft, Justiz und Polizei und sei unmittelbar gegenüber der SMAD-Führung rechenschaftspflichtig ${ }^{45}$. Zum anderen zeichnete die dem Politischen Berater der SMAD unterstellte Rechtsabteilung für die Justizkontrolle verantwortlich. Die DJV arbeitete ihrer Überlieferung zufolge ausschließlich der SMAD-Rechtsabteilung zu, bei der somit auch die unmittelbare Anleitung dieser Zentralverwaltung lag. Dies ändert freilich nichts daran, daß die Innenverwaltung für die Justiz insgesamt zuständig war, also bei der Kontrolle der deutschen Justiz ein faktisches Unterstellungsverhältnis der Rechtsabteilung unter die Innenverwaltung vermutet werden muß. Die SMAD-Justizabteilung handelte Jan Foitzik zufolge „als Dienstaufsichtsinstanz für die Justiz in der SBZ [...] nur mittelbar [...] für die sachlich zuständige

40 Vgl. Foitzik, Sowjetische Militäradministration in Deutschland, S. $32 \mathrm{f}$.

41 Mitteilung über die Dreimächtekonferenz von Berlin, 2. 8. 1945, in: Amtsblatt des Kontrollrats, Ergänzungsblatt Nr. 1, S. 15.

42 Vgl. zu dieser Diskussion Kraus, Ministerien für das ganze Deutschland, S. 51-60.

43 Gedruckt in: Um ein antifaschistisch-demokratisches Deutschland, S. 100-102.

44 Vgl. Foitzik, Sowjetische Militäradministration in Deutschland, S. 135, 443.

45 Ebenda, S. 245; vgl. auch S. 285 f. 
SMAD-Innenverwaltung “46. Trotz dieses Unterstellungsverhältnisses steht im folgenden ausschließlich die SMAD-Rechtsabteilung im Mittelpunkt, da sie aus der Perspektive der DJV die in Karlshorst zuständige Stelle war.

In den Aufgabenbereich der SMAD-Rechtsabteilung fielen dem Abteilungsstatut zufolge die Entnazifizierung der deutschen Gesetze, die Reorganisation des deutschen Gerichtswesens, die interalliierte Korrespondenz über die Frage der interzonalen Auslieferung von NS-Verbrechern, Kontrollaufgaben im Hinblick auf die Tätigkeit der deutschen Justizorgane in der SBZ und juristische Hilfe für sowjetische Bürger in Deutschland47. Die im Juli 1945 gebildete Rechtsabteilung war, dieser Aufgabenbeschreibung entsprechend, in zwei Unterabteilungen gegliedert, von denen die eine für die Vorbereitung von Gesetzesentwürfen des Kontrollrats und die andere für die deutsche Justiz zuständig zeichnete ${ }^{48}$. Im Alliierten Kontrollrat wurde sie im Direktorat Rechtswesen tätig: Sowohl dessen sowjetischer Leiter, Jakow Afanessewitsch Karassjow, als auch drei von vier der sowjetischen Komiteemitglieder arbeiteten gleichzeitig in der Rechtsabteilung49.

Die SMAD-Rechtsabteilung hatte unmittelbar nach ihrer Gründung zunächst 19 und im Januar 194635 Personalstellen, von denen bis Dezember acht vakant blieben; zum 31. Januar 1947 wurden ihre Stellen auf 24 reduziert ${ }^{50}$ - angesichts der Fülle ihrer Aufgaben eine im Vergleich zu den anderen Fachgebieten geringe Zahl, die zusammen mit ihrer untergeordneten Stellung innerhalb der Militärverwaltung erklärt, warum manche von der DJV angemahnten Entscheidungen entweder gar nicht oder nur sehr verzögert getroffen wurden. Zuständig für ihre personelle Besetzung war das Volkskommissariat bzw., ab März 1946, das Ministerium für Justiz der UdSSR, das für diese Aufgabe offensichtlich ausschließlich juristische Fachleute auswählte, die entweder als „Militärjuristen“ (in Uniform gekleidete Zivilisten) oder als Zivilisten ohne militärischen Dienstgrad ihren Dienst verrichteten ${ }^{51}$. Letzteres traf sogar auf Professor Karassjow, den Chef der Rechtsabteilung, einen Spezialisten für Zivilrecht und Universitätsdozenten ${ }^{52}$, zu, der zur Nomenklatur des Sekretariats des ZK der KPdSU zählte und seinen Dienst seit dem 2. Juli 1945 ausübte. Er war im Januar/Februar und Juni 1948 angesichts angeblich niedriger fachlicher und politischer Qualifikation sowie mangelnder Initiative und Führungsqualitäten zwar innersowjetischer Kritik ausgesetzt, blieb aber bis zum Juni 1949 auf seinem Posten ${ }^{53}$. Nach seiner Verwen-

46 Ebenda, S. 108, 112f., 29 (Zitat).

47 Vgl. Bordjugow, Rechtsabteilung, S. 57f.; Nikitin, Sowjetische Militäradministration und die Justiz (Manuskript), S. 1 f.

48 Vgl. Bordjugow, Rechtsabteilung, S. 58 f.; Foitzik, Sowjetische Militäradministration in Deutschland, S. 141.

49 Im Komitee für Änderung der deutschen Gesetze saß Alexandr K. Lyssjak, im Redaktionskomitee F.K. Dozenko und im Komitee für minderjährige Straftäter Martyn F. Jeroma - alles Offiziere der Rechtsabteilung. Nur A.F. Tarabanow im Komitee Industrievermögen kam nicht aus der Rechtsabteilung. Für die Besetzung des Direktorats siehe ebenda, S. 438.

50 Ebenda, S. 141; vgl. auch Nikitin, Sowjetische Militäradministration und die Justiz (Manuskript), S. 1; Bordjugow, Rechtsabteilung, S. 60 f.

51 Vgl. Foitzik, Sowjetische Militäradministration in Deutschland, S. 223; zur Kategorisierung der SMAD-Mitarbeiter ebenda, S. 216.

52 Nikitin, Sowjetische Militäradministration und die Justiz (Manuskript), S. 1.

$53 \mathrm{Vgl}$. Bordjugow, Rechtsabteilung, S. 63-65. Bordjugow geht irrtümlicherweise davon aus, daß er bis November 1949 in Berlin blieb. 
dung bei der SMAD kehrte er in den juristischen Lehr- und Ausbildungsbetrieb zurück; Hilde Benjamin traf ihn im Juni 1952 am Moskauer Juristischen Institut an, wo er die Abteilung für Fernunterricht leitete ${ }^{54}$. Auch Karassjows erster Stellvertreter, Professor Boris S. Mankowski, der bis ins Jahr 1946 hinein in der Rechtsabteilung tätig war ${ }^{55}$, trug keinen militärischen Titel. Am 23. August 1946 trat Oberst Wassili W. Bukanow an dessen Stelle56; später wurde sowjetischen Akten zufolge auch Oberst F.K. Dozenko als Stellvertreter geführt ${ }^{57}$. Als weitere Fachjuristen der SMAD-Rechtsabteilung ohne militärischen Rang sind Sinizyn und Abdul-Shagi A. Korobow zu nennen; von letzterem wurde der DJV bekannt, daß er vor seiner Verwendung in der Militärverwaltung als Rechtsanwalt tätig gewesen war $^{58}$. Als Unterabteilungsleiter für die Vorbereitung der Gesetzgebung des Kontrollrates fungierte Oberstleutnant F.K. Dozenko; Oberstleutnant Abdul-Shagi A. Jakupow leitete die für die Kontrolle der deutschen Justizorgane zuständige Unterabteilung, so daß er, wie er am 15. Juni 1946 dem DJV-Präsidenten Eugen Schiffer mitteilte, „für alle Angelegenheiten der Deutschen Justizverwaltung der zuständige Sachbearbeiter sei“59. Für alle anderen Kompetenzzuweisungen $^{60}$ gibt es keine Belege, so daß die weiteren gegenüber der DJV und anderen deutschen Dienststellen auftretenden Offiziere hier lediglich genannt sein sollen. Es handelte sich um die Oberstleutnante Nikolai A. Wassilkow, Alexandr K. Lyssjak und Martyn F. Jeroma sowie um die Majore Wiktor W. Nikolajew, Nikolai M. Solotajew, Schitomirsky, Schur und Nikolai J. Kurbatow, sowie den späteren Leiter der Rechtsabteilung bei der Berliner Kommandantur, Prochor F. Paschkewitsch, und Uschakow, der in den Stab des Politischen Beraters wechselte ${ }^{61}$.

Nicht nur die SMAD in Berlin-Karlshorst, sondern auch die sowjetischen Militärverwaltungen in den Ländern verfügten nach einer Verordnung vom 15. November 1947 über Rechtsabteilungen, die jeweils sechs bis acht Personen umfaßten $^{62}$. Diese waren, wie alle Struktureinheiten der SMAD, sowohl den Chefs der Landesverwaltungen als auch der entsprechenden zentralen Fachabteilung unterstellt. Deren Mitarbeiter, die alle zentral vom Obersten Chef der SMAD ernannt wurden, hatten zuvor teilweise in der zentralen Rechtsabteilung Funktionen innegehabt ${ }^{63}$. Gegenüber den deutschen Dienststellen in Sachsen traten sie ab Herbst

54 Benjamin, Deutsche Juristen, S. 347.

${ }_{55}$ Mankowski wird u.a. in einem Vermerk Rosenthal-Pelldrams vom 1. 12. 1945, BAB, DP1 VA Nr. 2, Bl. 115, und in einem Vermerk Kleikamps vom 27. 5. 1946, BAB, DP1 SE Nr. 3478, erwähnt.

56 Bordjugow, Rechtsabteilung, S. 63.

57 Vgl. Foitzik, Sowjetische Militäradministration in Deutschland, S. 443. In der deutschen Aktenüberlieferung tritt Dozenko fast durchgehend als Oberstleutnant und nicht als Oberst auf.

58 Sinizyn wird nur als "Referent" genannt, siehe Aktenvermerke vom 9.12. 1946 und 27.9. 1947, BAB, DP1 VA Nr. 11, Bl. 86, 123. Zu Korobow, der ab Anfang 1949 gegenüber der DJV tätig wurde, siehe Vermerk von Gentz über eine Unterredung mit Dozenko am 18. 6. 1949, BAB, DP1 HAS III/145.

59 Aktenvermerk von Stackelbergs, 17. 6. 1946, BAB, DP1 SE Nr. 2221, Bl. 110.

$60 \mathrm{Vgl}$. die Funktionszuweisungen anhand der Gesprächsgegenstände in den deutschen Akten bei Lorenz, Zentralverwaltung, S. 142.

61 Die Namen entstammen hauptsächlich der Akte BAB, DP1 VA Nr. 11, Bordjugow, Rechtsabteilung, S. 63 f., sowie Nikitin, Sowjetische Militäradministration und die Justiz (Manuskript), S. 8.

62 Vgl. Bordjugow, Rechtsabteilung, S. 63.

63 Dies trifft für Major Schitomirsky und Oberstleutnant Lyssjak zu, die beide nach ihrer Verwendung in der Zentrale nach Sachsen versetzt wurden: siehe Lorenz, Zentralverwaltung, S. 142, Vermerk Langes, 8. 1. 1948, BAB, DP1 VA Nr. 11, Bl. 127. Major Schur wurde unter Beförderung 
1947 in Erscheinung64; in Thüringen wurde das SMA-Justizressort Ende 194765, in Brandenburg offiziell erst Anfang $1948^{66}$ geschaffen. Bisweilen nahm die SMADRechtsabteilung daher in den Jahren vor 1948 auch Aufgaben in den Ländern wahr: Belegt sind Kontrollen zur Überprüfung der Durchführung von SMADBefehl Nr. 49 im Herbst 194567, Gerichtsrevisionen Jakupows in Brandenburg im Sommer ${ }^{68}$ und eine Reise von zwei SMAD-Vertretern nach Jena im Oktober 1946, um sich über die dortige Verwaltungsgerichtsbarkeit zu informieren ${ }^{69}$. Aufgrund der Nähe zu Berlin kam es 1946 offensichtlich wiederholt zu Arbeitskontakten der Rechtsabteilung in Karlshorst und der brandenburgischen Justizverwaltung 70 . Solange die Rechtsabteilungen in den Ländern noch nicht eingerichtet waren, wurde die Justiz offensichtlich von den Innenressorts direkt kontrolliert ${ }^{71}$, so daß dort auch die sowjetischen Verantwortlichkeiten klarer als in Berlin erkennbar waren.

Die Kontrolle der Justiz lag darüber hinaus bei der sowjetischen Geheimpolizei: dem NKWD/MWD bzw. NKGB/MGB. Daraus ergaben sich oftmals direkte Interventionen sowjetischer Geheimpolizisten in Verfahren vor deutschen $\mathrm{Ge}$ richten ${ }^{72}$. Auf Landesebene übte der in die Besatzungsverwaltung integrierte Leiter der Geheimpolizei die Oberaufsicht über Justiz und Polizei aus ${ }^{73}$. Auch in der DJV erschienen am 5. Juli 1946 unangemeldet zwei Herren in Zivil, die sich als Kapitän Kartoschkin und Oberleutnant Jermakow von der SMAD-Rechtsabteilung ausgaben, durch ihre Unkenntnis über die Kompetenzen der DJV jedoch zeigten, daß dies nicht der Fall sein konnte. Sie beanspruchten ein Zimmer in der Justizverwaltung und wollten von allen Personalentscheidungen unterrichtet werden: Es handelte sich somit höchstwahrscheinlich um sowjetische Geheimpolizisten, die die DJV, wie jede andere deutsche Dienststelle auch ${ }^{74}$, hinsichtlich ihrer Personalpolitik überprüften ${ }^{75}$. Fortan saß somit ein Geheimpolizist im Gebäude der DJV, der als „Verbindungsoffizier im Hause“ firmierte und im Herbst 1947 nicht nur über Personalentscheidungen, sondern auch über Erlasse der DJV im Zusammenhang mit SMAD-Befehl Nr. 201 sowie über Zahl und Stand der nach diesem Befehl durchgeführten Gerichtsverfahren informiert werden wollte ${ }^{76}$.

zum Oberstleutnant Ende 1947/Anfang 1948 Leiter der thüringischen Rechtsabteilung und im März 1949 durch Jakupow abgelöst: siehe Vermerk Walters, 20. 3. 1948, ebenda, Bl. 136, und Weber, Justiz und Diktatur, S. 151.

64 Vgl. Foitzik, Sowjetische Militäradministration in Deutschland, S. 151.

65 Vgl. ebenda, S. 148, und Weber, Justiz und Diktatur, S. 53.

$66 \mathrm{Vgl}$. Pohl, Justiz in Brandenburg (Manuskript), S. 32.

67 Karassjow an Wyschinski, 4. 11. 1945. Die Kopie des Berichts wurde dem Vf. freundlicherweise von Dr. Jochen Laufer zur Verfügung gestellt. Vgl. auch Nikitin, Sowjetische Militäradministration und die Justiz (Manuskript), S. 8.

68 Aktenvermerk Stackelbergs über Besuch Schiffers in Karlshorst am 31.7. 1946, BAB, DP1 VA Nr. 11, Bl. 62 .

69 Vgl. Weber, Justiz und Diktatur, S. $60 \mathrm{f}$.

70 Vgl. Pohl, Justiz in Brandenburg (Manuskript), S. 32.

71 Vgl. Weber, Justiz und Diktatur, S. 53.

72 Beispiele aus den Jahren 1946/47 nennt Löwenthal, Geist, S. 14, 156.

73 Vgl. Foitzik, Sowjetische Militäradministration in Deutschland, S. 166, Anm. 344.

74 Ebenda, S. 167.

75 Aktenvermerk Schiffers, 5. 7. 1946, BAB, DP1 VA Nr. 11, Bl. 57 f.; vgl. dazu Amos, Justizverwaltung, S. $87 \mathrm{f}$.

76 Vgl. Chef der DJV an Abteilungsleiter I, II, III und V, 4. 9. 1947, BAB, DP1 VA Nr. 840, BI. 8; Ver- 
Während die Kontroll- und Einflußmöglichkeiten der SMAD über Justiz und DJV unbegrenzt waren, machte sich 1945 der Anspruch der deutschen Kommunisten, den Aufbau staatlicher Strukturen wesentlich mitzugestalten, dort noch kaum bemerkbar. Die im sowjetischen Exil angestellten Nachkriegsplanungen der KPD hatten andere Schwerpunkte, bezogen sich nur am Rande auf das Justizwesen und waren mit ihren Forderungen etwa nach Bestrafung der NS-Verbrecher und Entnazifizierung der Gesetze äußerst allgemein gehalten und konsensfähig77. Auch für die Gruppen Ulbricht, Ackermann und Sobottka besaß die Justiz eine sehr viel geringere Bedeutung als etwa die Polizei und das Personalwesen in den Verwaltungen. Hinzu kam ein weiteres: Aufgrund ihrer sozialen Basis und der weitgehenden Rekrutierung ihrer Führungsschicht aus Arbeiterkreisen verfügte sie kaum über studierte Rechtswissenschaftler. Dies gilt insbesondere für die bevorzugt für den SBZ-Einsatz ausgewählten „Moskau-Kader"78.

Der Personalmangel in diesem Bereich zeigte sich unter anderem bei der Rekrutierung entsprechender Mitarbeiter für den Parteiapparat. So wurde am 22. Oktober 1945 vom Sekretariat der KPD der ehemalige Polizistenmörder und Spanienkämpfer Erich Mielke als Mitarbeiter der kommunalpolitischen Abteilung eingestellt, um dort künftig als Referent für Polizei und Justiz zu fungieren ${ }^{79}$. $\mathrm{Da} ß$ er sich in letzterem Arbeitsgebiet weitaus weniger engagieren würde als in Polizeiangelegenheiten, war bereits damals absehbar ${ }^{80}$. Auch als die KPD-Führung im August und Oktober 1945 Kommissionen beim Sekretariat bildete, die die "Fachkompetenz der Kommunisten auf Zonenebene“ bündeln und als Schnittstellen zwischen Parteiapparat und Staatsverwaltung dienen sollten ${ }^{81}$, fand sich für den Ausschuß für juristische Fragen kein Sekretär; dessen einziges Mitglied, DJV-Vizepräsident Paul Bertz, hatte nicht studiert ${ }^{82}$. Zwar beschloß das KPD-Sekretariat am 8. Oktober, als Sekretär den ehemaligen Anwalt Fritz Löwenthal „aus M[oskau] telegrafisch anzufordern“, doch erhielt dieser erst Ende 1946 die Genehmigung zur Rückkehr nach Deutschland ${ }^{83}$. Die KPD-Führung verfügte vorerst nicht über einen kompetenten Beraterstab in Justizangelegenheiten, so daß sie vor allem mit den Genossen aus der DJV, allen voran Ernst Mels-

merk Benjamins, 17. 11. 1947, BAB, DP1 VA Nr. 580, Bl. 73. Der „Verbindungsoffizier im Hause“ nannte sich Kapitän Smirnow; zu SMAD-Befehl Nr. 201 siehe Kap. B.VI.

$77 \mathrm{Vgl}$. etwa das Aktionsprogramm des Blockes der kämpferischen Demokratie, 3. Entwurf, Oktober 1944, in: Erler/Laude/Wilke, Nach Hitler, S. 265-269, hier 266 f.; vgl. dazu auch Amos, Justizverwaltung, S. 21-23.

78 Vgl. dazu insgesamt Erler, Moskau-Kader.

79 Protokoll der Sekretariatssitzung, 22.10. 1945, in: Dokumente zur Geschichte der kommunistischen Bewegung, Bd. 1, S. 108. Vgl. dazu Kubina, In einer solchen Form, S. 356, sowie ders., Aufbau des zentralen Parteiapparates, S. 83, 110.

so Nur eine Ausarbeitung Mielkes für Ulbricht zur Reform des Justizwesens vom 23. 2. 1946 ist bekannt (in: BStU, MfS AS 399/66, Bl. 187-192). Sie basiert auf einer Ausarbeitung Melsheimers vom Februar 1946 (vgl. Anm. 84).

81 Vgl. Kubina, Aufbau des zentralen Parteiapparates, S. $81 \mathrm{f}$.

82 Protokoll der Sekretariatssitzung, 1. 10. 1945, in: Dokumente zur Geschichte der kommunistischen Bewegung, Bd. 1, S. 94; die Anlage zu dem Protokoll über die Besetzung der Ausschüsse trägt das Datum vom 18. 10. 1945, ebenda, S. 95.

83 Protokoll der Sekretariatssitzung, 8.10. 1945, ebenda, S. 103. Zu Löwenthal siehe unten, Kap. A.I.4. 
heimer ${ }^{84}$, eng zusammenarbeitete, während für die Angelegenheiten des Berliner Justizwesens auch die von der Besatzungsmacht als Staatsanwalt bzw. als Senatspräsident am Kammergericht eingesetzten Max Berger und Erich Rochler ${ }^{85}$ eine gewisse Rolle spielten ${ }^{86}$. Bis zum Frühjahr 1946 entfaltete die KPD-Führung daher keine größeren Aktivitäten auf dem Gebiet der Justiz. Eine Ausnahme bildete der mit Sekretariatsbeschluß vom 8. Oktober 1945 unternommene Versuch, Art und Zusammensetzung der in Strafsachen tätigen Gerichte, die Ernennung der Richter und die Justizausbildung zu beeinflussen ${ }^{87}$. Karassjow, dem der Beschluß zuging, begrüßte zwar den Grundgedanken der Heranziehung von „Personen aus Volkskreisen, um das Justizsystem zu demokratisieren“, lehnte aber die vorgeschlagenen „Volksgerichte“ zur Aburteilung von gegen die "demokratische Ordnung " gerichteten Straftaten und NS-Verbrechen $a b^{88}$. Trotz des begrenzten Erfolgs dieses Vorstoßes zeigt sich darin, daß die KPD-Führung in Justizfragen ihre Kontakte zur SMAD gegebenenfalls aktivieren konnte, um die Entwicklungen in ihrem Sinne zu beeinflussen.

Seit Herbst 1945 wurde für alle erkennbar, daß die KPD-Führung eine möglichst rasche Vereinigung mit der SPD anstrebte. Im Unterschied zu den Kommunisten verfügte diese über etliche Juristen und Justizangestellte in ihren Reihen, deren parteipolitisches Engagement zur Bildung eines Rechtsausschusses führte. Auf die Initiative des 2. DJV-Vizepräsidenten Karl Kleikamp gegründet ${ }^{89}$, hielt dieser eine erste Vollversammlung am 18. Oktober ab. Der Ausschuß umfaßte an die 70 Mitglieder, vornehmlich aus Berlin, die sich in fünf Arbeitsausschüssen betätigten, und entfaltete eine rege Tätigkeit ${ }^{90}$. Seine politische Ausrichtung und Rechtsauffassung geht eindeutig aus der Entschließung zu den „Grundlagen der Rechtspolitik" hervor. Am 18. Oktober hatte sich die Vollversammlung des Ausschusses nach einem Referat von Erich Rosenthal-Pelldram über „Die Erneuerung des Rechtsdenkens als Forderung unserer politischen Tätigkeit" auf drei Resolutionsentwürfe geeinigt, über die sie am 31. Oktober abstimmen wollte91. Nachdem Rosenthal-Pelldram zu Beginn dieser Sitzung seinen Entwurf zurückgezogen hatte, entschieden sich die Ausschußmitglieder einstimmig für den leicht umgearbeiteten Entwurf Kleikamps, demzufolge das Recht den Zweck hatte, „neben der Sicherheits- und Schutzfunktion des Staates die Bedürfnisse und Interes-

84 Siehe u.a. die Ausarbeitung Melsheimers zur Reform des Justizwesens für Ulbricht, o.D. [Februar 1946], SAPMO, NY 4105/3, Bl. 18-20.

85 Beide waren KPD-Mitglieder ohne juristische Ausbildung. Siehe deren Erinnerungsberichte in: SAPMO, SgY 30 Nr. 56, 773. Rochler wurde von den Amerikanern abgesetzt und verblieb als Verwaltungsdezernent am Kammergericht.

86 Vgl. die Sitzung der Genossen der Berliner Justiz und der DJV bei Ulbricht, 19. 1. 1946, SAPMO, DY 30 IV 2/13/404.

87 Vorschlag des Sekretariats des ZK der KPD „Zur Frage der Justizreform“, 5. 10. 1945, SAPMO, NY 4182/1118, Bl. 63 f.; Protokoll der Sekretariatssitzung, 8.10. 1945, in: Dokumente zur Geschichte der kommunistischen Bewegung, Bd. 1, S. 104. Vgl. dazu auch Kap. A.IV.2.

88 Karassjow an Ulbricht, 27. 10. 1945, SAPMO, NY 4182/1185, Bl. $4 \mathrm{f}$.

89 Siehe dazu Fechner an Kleikamp, 10. 7. 1945, SAPMO, NY 4101/13, Bl. 2.

90 Zwischen dem 17. 10. 1945 und dem 30.3.1946 fanden acht Vollversammlungen und neun Ausschußsitzungen statt: siehe Übersicht über die Einladungen des rechtspolitischen Ausschusses, SAPMO, DY 30 IV 2/13/404; vgl. auch Anders, Demokratisierung, Anmerkungen zu Kap. I, S. 6.

91 Niederschrift über die Vollversammlung des rechtspolitischen Ausschusses, 18. 10. 1945, SAPMO, DY $302 / 13 / 404$. 
sen der Gesamtheit und der Einzelnen sowie der Einzelnen untereinander in Einklang zu bringen“. Daraus ergaben sich für Kleikamp unter anderem als Grundsätze die Unabhängigkeit der richterlichen Gewalt, die Zurückweisung der „Irrlehre von der Allmacht des Staates“ und die Forderung nach „Stärkung der Unabhängigkeit des Staatsbürgers"92. Die Vorlage Dr. Siegfrieds, der die Abhängigkeit des Rechtsdenkens und Rechtsempfindens von den gesellschaftlichen Verhältnissen betonte und daher auch die Erneuerung des Rechtsdenkens als „Produkt der gesellschaftlichen Umwälzung" bezeichnete, hatte demgegenüber keine Chance ${ }^{93}$. Das hier anklingende "sozialistische" Rechtsdenken, das eine unabhängige Justiz nur dann befürwortete, „wenn sie das Streben nach einer gerechten Gesellschaftsverfassung fördert", war im sozialdemokratischen Rechtsausschuß offensichtlich nicht mehrheitsfähig. Obwohl auch Erich Gniffke und Otto Grotewohl dem Papier in der Fassung Kleikamps zugestimmt hatten, äußerte Helmut Lehmann vom SPD-Zentralausschuß „Bedenken teils politisch-weltanschaulicher, teils praktischer Natur"94. Eine entsprechende Überarbeitung war geplant, erwies sich aber angesichts anderer Probleme im Zusammenhang mit der bevorstehenden Vereinigung von SPD und KPD als undurchführbar ${ }^{95}$.

Wie in anderen Bereichen auch, ging die Initiative zu einer engeren Kooperation der Juristen und Justizangestellten - die letztlich in eine Fusion münden sollte - von den Kommunisten aus. Angesichts der personellen und organisatorischen Schwäche der KPD auf diesem Gebiet verfolgten diese damit offensichtlich die Strategie, die SPD-Juristen zunächst auf verbindliche gemeinsame Beschlüsse zu verpflichten und anschließend für sich zu vereinnahmen. Auf Einladung Rochlers kam es am 10. Dezember $1945 \mathrm{zu}$ einem Treffen von Berliner Justizangestellten beider Parteien, das dieser im Anschluß als einen „gute[n] Anfangserfolg“ bezeichnete ${ }^{96}$. Kleikamp hingegen beklagte den „ausgesprochen demagogische[n]“ Charakter des Eingangsreferats von Hilde Benjamin sowie der Äußerungen von Max Berger und bescheinigte der Tagung ein insgesamt „subalterne[s] Niveau" 97 . Dennoch setzte der Rechtspolitische Ausschuß der SPD vorerst die Zusammenarbeit fort: Am 9. Januar 1946 trafen sich mit Rochler, Berger, Melsheimer, Benjamin, Kleikamp, Corsing und Rosenthal-Pelldram vier KPD- und drei SPD-Vertreter, die sich als „vorläufiger Aktionsausschuß“ für die rechtspolitische Zusam-

92 Der überarbeitete und mit einer Ergänzung angenommene Entwurf Kleikamps in: SAPMO, DY 30 II 2/1, Bl. 68; zit. in: Anders, Demokratisierung, Anmerkungen zu Kap. I, S. 7 f. Zur Ausschußsitzung siehe Niederschrift über die Vollversammlung des rechtspolitischen Ausschusses, 31. 10. 1945, SAPMO, DY 30 IV 2/13/404.

93 Die ursprünglichen Entwürfe Rosenthal-Pelldrams, Kleikamps und Siegfrieds in: ebenda. Der von Amos, Justizverwaltung, S. 28, zitierte Entwurf stammt nicht, wie sie schreibt, von Kleikamp, sondern von Rosenthal-Pelldram.

94 Niederschrift über die Vollversammlung des rechtspolitischen Ausschusses, 31.10. 1945; Kleikamp an die Volljuristen der SPD, 9. 2. 1946 (darin das Zitat), SAPMO, DY 30 IV 2/13/404. Zur Ablehnung der Entschließung durch Lehmann siehe Anders, Demokratisierung, Anmerkungen zu Kap. I, S. 9 f.

95 Vgl. Kleikamp an die Mitglieder des rechtspolitischen Ausschusses, 25.2., 4. 3. 1946, SAPMO, DY 30 IV $2 / 13 / 404$.

96 Die Einladung Rochlers stammte vom 1. 12. 1945; dies geht aus dem Antwortschreiben des rechtspolitischen Ausschusses der SPD vom 8. 12. 1945 hervor, ebenda. Zur Versammlung vom 10.12. 1945 siehe den Bericht Rochlers an die KPD-Bezirksleitung Groß-Berlin, 13. 12. 1945, SAPMO, NY 4182/1118.

97 Kleikamp an SPD-Bezirksvorstand Berlin, 14. 12. 1945, SAPMO, DY 30 IV 2/13/404. 
menarbeit der SPD- und KPD-Justizangestellten konstitutierten: Der erste Schritt hin zu einer institutionalisierten Zusammenarbeit schien vollzogen ${ }^{98}$.

Daß die Gräben zwischen Kleikamp auf der einen und Bertz und Berger auf der anderen Seite jedoch unüberwindlich waren, zeigte die heftige Reaktion des SPDJuristen auf zwei Artikel der kommunistischen Funktionäre in der "Deutschen Volkszeitung" vom 12. Januar 1946. Berger kritisierte darin, daß an Stelle der entlassenen nationalsozialistischen Richter pensionierte Juristen reaktiviert worden seien, deren Tätigkeit demonstriere, „daß die Justiz bereits heute wieder zum

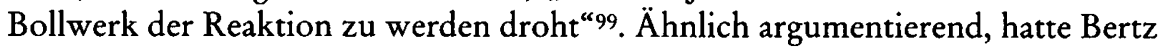
die nur mit einer juristischen Kurzausbildung ausgestatteten Volksrichter verteidigt, die allein gewährleisteten, daß im demokratischen Deutschland „nur Menschen mit demokratischer Gesinnung das hohe Amt eines Richters ausüben"100. Das ging Kleikamp als Vertreter dieser reaktivierten Juristen, die als Sozialdemokraten für ihre demokratischen Überzeugungen beruflich benachteiligt worden waren, entschieden zu weit. Die Angriffe gegen die Justiz wertete er als "glatte Infamie" und warf Berger vor, durch die Verallgemeinerung von Einzelvorgängen und eine verzerrende Darstellungsweise „den Eindruck zu erwecken, als seien die Justiz als Ganzes und die gesamte Juristenschaft rettungslos reaktionär fortschrittsfeindlich, so daß nur durch ihre Beseitigung der Weg für die demokratische Erneuerung der Justiz freigemacht werden könne“. Bei den Volksrichtern handle es sich zudem nur um „eine neue Art von Berufsrichtern" mit einer schlechteren Ausbildung als bisher ${ }^{101}$.

Angesichts dieser Mißstimmung bedurfte es einiger Überredungskunst Rochlers und Melsheimers, um Kleikamp zur Teilnahme an der zweiten gemeinsamen Versammlung der KPD- und SPD-Justizangestellten am 18. Februar zu bewegen. Im Anschluß an sein Referat wurde er von Melsheimer, Berger und Bertz scharf angegriffen, so daß die Versammlung ohne greifbares Ergebnis auseinanderging 102 . Wenn die Kommunisten gehofft hatten, den Rechtspolitischen Ausschuß der SPD zu spalten, so sahen sie sich getäuscht: Dieser stellte sich am 23. Februar mit einer Erklärung hinter ihren Vorsitzenden und beschloß, die Kooperation mit den Kommunisten auszusetzen ${ }^{103}$. Auch die Form der Vereinigung von SPD und KPD lehnte der SPD-Rechtsausschuß konsequenterweise ab. Unter Berufung auf die Berliner Funktionärskonferenz vom 1. März ${ }^{104}$ schlug dieser weitgehende Modifikationen im Parteistatut, unter anderem die Umbenennung der Partei in „Sozialistisch-demokratische Partei Deutschlands“ vor ${ }^{105}$. Diese Ânderungsvor-

98 Vgl. die von Melsheimer und Kleikamp unterzeichnete Niederschrift der Besprechung am 9.1. 1946, ebenda.

${ }_{99}$ Max Berger, Wer sind die Richter von heute? in: Deutsche Volkszeitung, 12. 1. 1946.

100 Paul Bertz, Im Namen des Volkes. Für und gegen den Volksrichter, ebenda.

101 Kleikamp an Grotewohl, 22. 1. 1946, SAPMO, DY 30 IV 2/13/404.

102 Bericht Rochlers von der 2. gemeinsamen Versammlung der KPD- und SPD-Juristen vom 18. 2. 1946, ebenda. Vgl. dazu auch Amos, Justizverwaltung, S. 29 f.

${ }^{103}$ Entschließung des Rechtspolitischen Ausschusses, 23. 2. 1946, SAPMO, DY 30 IV 2/13/404; Kleikamp an die Mitglieder des Rechtspolitischen Ausschusses, 25.2., 4. 3. 1946, ebenda. Am 2. 3.1946 fand nicht, wie Amos, Justizverwaltung, S. 29, schreibt, eine weitere Zusammenkunft von SPDund KPD-Juristen, sondern eine interne Tagung des Ausschusses statt.

104 Vgl. dazu Hurwitz, Anfänge, S. 1022-1030.

${ }_{105}$ Entschließung des Rechtspolitischen Ausschusses der SPD zum Entwurf eines Partei-Statuts der 
schläge hatten zwar nur äußerst begrenzte Auswirkungen auf die endgültigen Formulierungen des Parteistatuts, zeigen jedoch eindrücklich, daß der Rechtspolitische Ausschuß der SPD nicht von den Kommunisten instrumentalisiert werden konnte.

Das unprofessionelle Agieren der KPD in dieser Sache war vor allem auf mangelnde Anleitung durch einen erfahrenen KPD-Justizfachmann im Parteiapparat zurückzuführen. Dies änderte sich erst mit der Begründung einer Justizabteilung unter Karl Polak unmittelbar vor der Zwangsvereinigung. Geboren 1905 in einem Dorf bei Oldenburg, entstammte er „dem jüdischen Kleinbürgertum“. Nach seinem Jura-Studium in Heidelberg und Frankfurt am Main ging er zur Ableistung seines Referendardienstes 1929 nach Berlin. Bereits als Student betätigte er sich in Frankfurt in einer linken Studentenorganisation, der „Roten Studentengruppe“, und in Berlin besuchte er die "Marxistische Arbeiterschule“. 1933 promoviert, wurde er zum 1. April als „Nichtarier“ aus dem Justizdienst entlassen. Rückblikkend bezeichnete er sich damals „als bürgerlichen Intellektuellen mit starkem theoretischen Interesse für den Marxismus“. Angesichts seiner Gefährdung durch die neuen Machthaber emigrierte er in die Sowjetunion, wo er aufgrund der Vermittlung des Vizepräsidenten der sowjetischen Akademie der Wissenschaften an deren Rechtsinstitut in Moskau eine Anstellung erhielt. Dort war er auch ,an der Unionsprokuratur" tätig, also unter dem berüchtigten Generalstaatsanwalt der UdSSR, Andrej Wyschinski106. „In dieser Zeit“, so Polak 1951, „begann meine politische Entwicklung. Ich wurde durch meine Arbeit in alle Fragen des Sowjetrechts und des Sowjetstaates hineingezogen - erhielt ein breites, sehr fruchtbares Betätigungsfeld - kam in den Kreis der sowjetischen Rechtsgelehrten - erlernte die russische Sprache, erhielt eine Dozentur am juristischen Institut und erwarb einen wissenschaftlichen Grad ,Kandidat der Rechtswissenschaft'."107 Als kommunistischer Jurist mit einer deutschen akademischen Ausbildung, der im Exil intensiv mit Rechtspraxis und Rechtsdenken in der Sowjetunion in Berührung gekommen war, eignete er sich wie kein zweiter für die Stellung des juristischen ,Chefideologen' bei der KPD.

Dort jedoch wußte man vorerst nichts über diesen hochbegabten, scharfsinnigen Stalinisten, der seit November 1941 am Juristischen Institut in Taschkent gearbeitet hatte und im August 1945 nach Moskau zurückkehrte, um seine in den vorangegangenen Jahren angefertigte Dissertation einzureichen und zu verteidigen. Damals bekundete er gegenüber dem KPD-Vertreter Paul Försterling seine Absicht, nach Deutschland zurückzukehren, wo er eine akademische Laufbahn anstrebte. Die KPD-Kaderleiterin Grete Keilson erfuhr davon im Oktober 1945 in Moskau und informierte im Anschluß an ihre Rückkehr Ulbricht ${ }^{108}$, der sich

SEP [sic], 16. 3. 1946; von Kleikamp am 18.3. 1946 an den Geschäftsführenden SPD-Vorstand übermittelt, SAPMO, DY 30 IV 2/13/404. Das kritisierte Parteistatut der SED vom 26. 2. 1946 in: Einheitsdrang, S. 268-276. Zur Kritik des SPD-Rechtsausschusses vgl. Moraw, Parole, S. $171 \mathrm{f}$.

106 Vgl. auch die Aussage Götz Bergers, derzufolge Polak „einer der Mitarbeiter von Wyschinski [gewesen war], auf den er auch schwor", zit. nach Schöneburg, Berger, S. 466.

107 Lebenslauf Polaks, 1. 2. 1951, SAPMO, DY 30 2/11/V353, Bl. 40 f. Der sowjetische Kandidatentitel entsprach dem deutschen Doktortitel.

108 Lebenslauf Polaks, 6. 3. 1946, ebenda, Bl. 22; Vermerk Keilsons, 12. 11. 1945, SAPMO, NY 4182/ 1118 , Bl. 79. Nach seinem Lebenslauf vom 1.2. 1951 erfuhr er im Oktober von einem KPD-Be- 
Polak für die Justizabteilung sichern wollte. Unmittelbar nach seiner Ankunft in Berlin am 2. März 1946 wurde er daher für Ulbricht in Justizangelegenheiten tätig ${ }^{109}$, noch bevor das KPD-Sekretariat ihn am 11. März formell zum „Leiter der Rechtsabteilung" ernannte ${ }^{110}$. In dieser Position begann er bereits Ende des Monats, auch die Partei zu aktivieren. In einem Rundschreiben bat er die Bezirksleitungen der KPD um Informationen über die personelle Zusammensetzung der Justizorgane und der bereits angelaufenen Volksrichterkurse; außerdem sollten sie der Auswahl der neuen Volksrichterschüler „die nötige Aufmerksamkeit zuwenden“; schließlich empfahl er, bei jeder Bezirksleitung einen Sachbearbeiter für Justizangelegenheiten zu ernennen, der dann unmittelbar mit ihm in Kontakt treten könne'11.

Der Ausbau der Justizabteilung erfolgte erst nach der Zwangsvereinigung. Als stellvertretender Abteilungsleiter wurde Ende April/Anfang Mai das ehemalige SPD-Mitglied Reinhold Schäfermeyer eingestellt, um auch hier die Parität zwischen beiden Arbeiterparteien zu wahren. Über die Vergangenheit des promovierten Juristen ist wenig bekannt, außer daß er im Dritten Reich einer Reihe von NSOrganisationen angehört hatte, was er bei seiner Einstellung indes verschwieg ${ }^{112}$. Von Fechner protegiert, wurde er auf dessen Antrag Ende 1947 zum mit Polak gleichberechtigten Abteilungsleiter befördert ${ }^{113}$. Ende April 1946 stellte die Parteiführung zudem Götz Berger als Hauptreferenten in die Justizabteilung ein. Geboren 1905 als Sohn eines zur SPD bzw. USPD/KPD sich orientierenden Studienrats, hatte er nach Jura-Studium und Promotion bis 1932 seinen Vorbereitungsdienst absolviert. Der Schüler und Student engagierte sich zunächst in der Sozialistischen Proletarierjugend und ab 1925 im Kommunistischen Jugendverband und trat 1927 der KPD bei. Im Referendariat kam er in Kontakt mit einer Reihe von kommunistischen Rote-Hilfe-Anwälten, darunter Hilde Benjamin, deren Sozius er Ostern 1932 wurde. 1933 verlor er seine Anwaltszulassung, ging ins Exil nach Frankreich und Spanien und nahm auf seiten der Volksfront am Bürgerkrieg teil. Nach anschließender Internierung in Frankreich und Algerien (1939-1943) war er kurzzeitig in der britischen Armee, begab sich aber im November 1943 in die Sowjetunion, wo er in Turkmenistan lebte und arbeitete. Nach Kriegsende wandte er sich an Pieck und Erich Weinert vom Nationalkomitee Freies Deutschland, um wieder nach Deutschland heimkehren zu können. Seine Initiative war erfolgreich: Über Moskau kam er wenige Tage nach dem Vereinigungsparteitag vom 21./22. April 1946 nach Berlin zurück. Hilde Benjamin rekrutierte ihn für

schluß, ihn „zur Arbeit nach Deutschland in das ZK einzuladen“ (zit. auch bei Amos, Justizverwaltung, S. 79). Ein solcher Beschluß liegt nicht vor. Zu Keilsons Moskauaufenthalt siehe Kubina, Aufbau des zentralen Parteiapparates, S. 86 f., Erler, Moskau-Kader, S. 253 f. Mollnau, Sozialistische Gesetzlichkeit, S. 64, schreibt - ohne Beleg -, daß Polaks Berufung auf die Empfehlung eines SMAD-Mitarbeiters zurückging.

109 Lebenslauf Polaks, 6. 3. 1946, SAPMO, DY 30 2/11/V353, Bl. 22. Er konzipierte einen Brief Ulbrichts an den Chef der SMAD-Rechtsabteilung vom 9.3. 1946: siehe Wentker, Volksrichter, Dok. 13, S. 124.

110 Protokoll der Sekretariatssitzung, 11.3. 1946, in: Dokumente zur Geschichte der kommunistischen Bewegung, Bd. 1, S. 184.

111 Rundschreiben und zwei beigefügte Fragebögen, 28. 3. 1946, ebenda, Bd. 3, S. 467-470.

112 Vgl. Dreier u. a., Rechtswissenschaft, S. 37, Anm. 7.

${ }^{113}$ Fechner an Gehaltskommission, 23. 12. 1947, BAB, DP1 VA Nr. 6596, Bl. 104. 
den SED-Justizapparat, wo er umgehend seine Tätigkeit aufnahm ${ }^{114}$. Etwa zur selben Zeit muß Mielke aus der Justizabteilung ausgeschieden sein ${ }^{115}$, so daß diese vorerst nur mit drei Personen besetzt war. Erst ein Jahr später kam mit Hilde Neumann eine weitere Hauptreferentin dazu, die aus demselben Umfeld wie Berger stammte. Ebenfalls 1905 geboren, war sie die Tochter des jüdischen Rechtsanwalts Kurt Rosenfeld, der 1917 die USPD und 1931 die SAP mitgegründet hatte. Nach Jura-Studium (1924-1927) und Referendariat verteidigte die Sozialdemokratin als Anwältin im Auftrag der Roten Hilfe KPD-Mitglieder. Seit dem Entzug ihrer Anwaltszulassung im Frühjahr 1933 im französischen Exil, schloß sie sich 1936 der KPD an. Im Frühjahr 1941 gelang ihr die Ausreise in die Vereinigten Staaten, von wo aus sie nach Mexiko übersiedelte. Dort heiratete sie den kommunistischen Arzt Rudolf Neumann, mit dem sie im Frühjahr 1947 nach Deutschland zurückkehrte ${ }^{116}$.

Nach ihrem Eintritt in die SED-Justizabteilung im April 1947 verfügte die SED dort über vier juristisch gut qualifizierte Mitarbeiter, deren politische Loyalität außer Zweifel stand. Der Abteilung waren einschließlich der beiden Leiterposten sechs Stellen zugewiesen worden, von denen zwei jedoch nie besetzt wurden. Berger war für "Gesetzgebung und Information “ und Neumann für „Gerichtsaufbau und Schulung“ zuständig. Vakant blieben das Hauptreferat Gesetzgebung sowie das Polizeireferat, das zunächst von Mielke eingenommen worden war; ein Antrag Polaks, letzteres in ein Referat „Internationales Recht und ausländisches Staatsrecht" umzuwandeln, hatte keinen Erfolg117. Damit handelte es sich um eine der kleineren Abteilungen im Parteiapparat, die dem Zuständigkeitsbereich von Walter Ulbricht und Max Fechner zugeordnet war118.

Die SED-Justizabteilung versuchte, ihren Einfluß in Personalangelegenheiten auf zentraler und Landesebene geltend zu machen ${ }^{119}$. Ähnliche Bestrebungen galten der Zeitschrift der DJV, der „Neuen Justiz“. Sie schaltete sich unter anderem im Zusammenhang mit der Vereinheitlichung der Justizverwaltung und der Einschränkung der Verwaltungsgerichtsbarkeit mit eigenen Stellungnahmen ein, die durchaus Gewicht besaßen ${ }^{120}$; auch drängte sie die DJV in einzelnen Fragen, wie etwa der Schöffenschulung, zu verstärkter Aktivität ${ }^{121}$. Dabei nutzte sie zum

114 Zur Biographie Bergers bis 1946 siehe Schöneburg, Berger, S. 461-466; Götz Berger erinnert sich, in: Ein Jurist mit aufrechtem Gang, S. 21-44 (diese Erinnerungen enden mit dem Jahr 1946); Lebenslauf Berger, o.D., BStU, MfS AIM 2528/61, T.I., Bl. $14 \mathrm{f}$.

115 Dies geht daraus hervor, daß auf der Gehaltsliste des SED-Parteiapparats vom Mai 1946 in der Abteilung Justiz nur Polak, Schäfermeyer und Berger aufgeführt wurden: siehe SAPMO NY 4036/ 661, Bl. 64 .

$116 \mathrm{Zu}$ ihrer Biographie siehe die Begründung zum Antrag auf Verleihung des Vaterländischen Verdienstordens an Hilde Neumann zum 7. 10. 1958, BAB, DP1 VA Nr. 6699; Biographisches Handbuch, S. 530; dort auch die Angaben zu Kurt Rosenfeld, S. 614.

117 Vgl. Polak an Ulbricht/Fechner, 10. 3. 1947, BAB, DP1 VA Nr. 6596, Bl. 195.

118 Siehe Kap. B.I.

119 Zur Personalpolitik in der DJV siehe Kap. A.I.3. Zur Einflußnahme auf die Landesjustiz siehe die Überlegungen über Rolf Helm als Nachfolger für den verstorbenen sächsischen Generalstaatsanwalt John Ulrich Schroeder: Polak an Ulbricht, 7. 3. 1947, 16. 5. 1947, SAPMO, NY 4182/1120, B1. 22, BAB, DP1 VA Nr. 6596, Bl. 165.

120 Zur Verwaltungsgerichtsbarkeit siehe Kap. A.V.3.; zur Vereinheitlichung der Landesjustizverwaltungen siehe Kap. A.II.2.

121 Melsheimer an Polak, 2. 5. 1947, BAB, DP1 VA Nr. 6596, Bl. 164. 
einen den Kommunikationskanal zu den Kommunisten in der DJV ${ }^{122}$, die freilich auch von sich aus tätig wurden und gegebenenfalls an die SED-Führung herantraten, und zum anderen den zur SMAD-Rechtsabteilung, die somit in Einzelfragen gezielt die SED-Justizabteilung und nicht die DJV zu Rate zog ${ }^{123}$. Bisweilen wurden Polak und Melsheimer gemeinsam in Karlshorst vorstellig, so daß die SEDGenossen in der DJV über die Vereinbarungen der SED und der SMAD von Anfang an informiert waren. Insgesamt hielt sich der Parteieinfluß auf die DJV und die kommunistische Ausrichtung ihrer Justizpolitik jedoch noch in Grenzen, da sich die Justizabteilung des Zentralsekretariats nicht in alle zentralen Fragen einschalten konnte und da die SED in dem von SMAD, Zentral- und Länderverwaltungen geprägten Machtgefüge zwar einen gewichtigen, nicht aber den bestimmenden Faktor darstellte.

Dies hing nicht nur mit der Unterbesetzung, sondern auch mit den anderen Aktivitäten der SED-Justizabteilung zusammen. 1946 befaßte sich Polak, der wichtigste Verfassungsjurist der SED, vor allem mit der Ausarbeitung der "Grundrechte des deutschen Volkes" vom 19. September 1946 sowie den SED-Entwürfen für eine Landesverfassung und eine gesamtdeutsche Verfassung ${ }^{124}$. Auch für die Ausarbeitung der SED- „Grundsätze zur Erneuerung der Justiz“ zeichnete die Justizabteilung verantwortlich. Unter der eingängigen Leitlinie „Demokratisierung der Justiz“ wurden zunächst als Voraussetzung für den „Umbau des Justizapparats" radikale ,Säuberungen', ein neues juristisches Ausbildungswesen zur Heranbildung von Justizjuristen "aus allen Schichten des schaffenden Volkes“ und eine stärkere Beteiligung von Laienrichtern an der Rechtsprechung genannt. An zweiter Stelle stand eine Reihe politischer Forderungen (Kampf gegen die faschistische und militaristische Reaktion), individueller Freiheitsrechte (Schutz der Freiheit der Person, der Meinungsäußerung, der Wissenschaft, der Religionsausübung) und gruppenspezifischer sozialer Rechte (Schutz der Arbeitskraft der Werktätigen, der Bauern, des Mittelstandes, der Jugend), die nur lose miteinander verbunden waren. Der dritte Abschnitt schließlich beinhaltete einige zentrale Vorhaben auf dem Gebiet der Gesetzgebung: Dazu zählten neben einer gründlichen Entnazifizierung der Gesetze vor allem die Neugestaltung des Strafrechts und des Strafvollzugs, die gesetzliche Untermauerung der Gleichstellung der Frau, der Ausbau des Betriebsräterechts und die Ausarbeitung eines neuen Bodenrechts auf der Grundlage der Bodenreform ${ }^{125}$. Dies war kein Programm zur revolutionären Umgestaltung der Justiz, sondern ein Konglomerat von recht unbestimmten, teils demokratischen, teils sozialistischen Forderungen, denen auch bürgerliche Justiz-

122 Siehe u. a. die Besprechung Fechners, Melsheimers, Schäfermeyers und Polaks am 23. 5. 1947 über die Organisation der Koordination der Gesetzgebung, Abt. Justiz an Ulbricht/Fechner, 23. 5. 1947, ebenda, Bl. 153.

${ }^{123}$ So rief Major Nikolajew beispielsweise am 1.7.1947 Polak an, um seine Auffassung über die Vereinheitlichung der Justizverwaltung im gesamtdeutschen Rahmen - einer Idee des hessischen Ministerpräsidenten Karl Geiler - in Erfahrung zu bringen: Polak an Fechner/Ulbricht, 1. 7. 1947, ebenda, Bl. 139.

124 Siehe Arbeitsbericht der Abt. Justiz, 30. 5. 1947, SAPMO, NY 4182/1120, Bl. 101. Vgl. auch Braas, Entstehung der Länderverfassungen, S. $57 \mathrm{f}$.

125 Die "Grundsätze“ existieren in mehreren, nur leicht voneinander abweichenden Fassungen; die der SED-Juristenkonferenz vom 1./2. 3. 1947 vorliegende Fassung gedruckt bei Amos, Justizverwaltung, S. 227-230 (dort auch die Zitate). 
reformer zustimmen konnten. In der Präambel der „Grundsätze“ wurde die Aufgabe der Justiz jedoch ausschließlich im Hinblick auf „die politischen, sozialen und wirtschaftlichen Errungenschaften unseres demokratischen Gemeinwesens" wie etwa die Verstaatlichung wichtiger Wirtschaftsbetriebe und die Bodenreform definiert, die "als leitende Rechtsprinzipien anzuerkennen“"waren. Die dilatorische Behandlung der „Grundsätze“ in den unterschiedlichsten Gremien der Partei zeigt indes ihre untergeordnete Bedeutung für die SED-Programmatik. Nach einer ersten Diskussion auf einer SED-Juristenkonferenz am 3./4. August 1946126 wurden sie erst auf der Nachfolgekonferenz vom 1./2. März 1947 verabschie$\operatorname{det}^{127}$. Das Zentralsekretariat, dem sie anschließend als „Grundsätze der SED zur Rechtserneuerung " zur Stellungnahme zugeleitet wurden ${ }^{128}$, hielt es jedoch nicht für nötig, darüber zu beraten, sondern überließ Ulbricht die Endredaktion ${ }^{129}$. In ihrer endgültigen, verbindlichen Fassung wurden sie erst 1948 veröffentlicht ${ }^{130}$.

$\mathrm{Zu}$ einer sehr viel wichtigeren Aufgabe als die Festlegung der justizpolitischen Linie der Partei wurde deren Aktivierung auf diesem Arbeitsgebiet. Da der Schwerpunkt der deutschen Verwaltung in den Ländern liegen sollte ${ }^{131}$, galt es zunächst, bei den SED-Landesleitungen Justizreferate zu errichten. Wenngleich Polak bereits Ende März 1946 dazu die Initiative ergriffen hatte, mußte er im August immer noch feststellen: „Die Justizabteilungen der Landesleitungen sind ein sehr dunkles Kapitel und arbeiten, mit Ausnahme von Sachsen, sehr schlecht." ${ }^{132} \mathrm{Um}$ dies zu ändern, sah sich die zentrale Justizabteilung der Partei genötigt, im Januar 1947 deren Arbeitsgebiete genauer zu beschreiben: Dazu zählten vor allem die Beratung der Landesleitung in Gesetzgebungs- und Justizfragen, die Sammlung politisch wesentlicher Urteile sowie die Auswahl und Betreuung der Volksrichterschüler ${ }^{133}$. Insgesamt bemühte sich die zentrale Justizabteilung 1947 sehr viel mehr als zuvor um die Arbeit der Justizreferate in den Landesverbänden: Inspektionsreisen nach Halle, Weimar und Dresden sowie die Teilnahme an einer Reihe von Justizkonferenzen in den Ländern dienten der zentralen Kontrolle und Anleitung ${ }^{134}$. Dennoch blieben die Erfolge der justizpolitischen Arbeit auf Landesebene mehr als bescheiden. Insgesamt konstatierte die Zentrale im Herbst 1947, „daß abgesehen vom Justizreferat bei der Landesleitung Sachsen überall die Arbeit recht schleppend und mit wenig eigener Initiative durchgeführt

126 Stenographische Niederschrift der Juristenkonferenz, 3./4. 8. 1946, SAPMO, DY 30 IV 2/1.01/13, Bl. 4-8.

${ }_{127}$ Stenographische Niederschrift der 1. Juristenkonferenz der SED, 1./2. 3. 1947, SAPMO, DY 30 IV 2/1.01/37, Bl. 35-42.

128 Protokoll der Zentralsekretariatssitzung, 13.3. 1947, SAPMO, DY 30 IV 2/2.1/71, TOP 19d.

129 Protokoll der Zentralsekretariatssitzung, 24. 3. 1947, SAPMO, DY 30 IV 2/2.1/73, TOP 17.

130 Fechner, Beiträge zur Demokratisierung, S. 325-327. Vgl. zu dem Vorgang insgesamt Amos, Justizverwaltung, S. 55-57.

131 Vgl. dazu Kap. A.II.1.

132 Stenographische Niederschrift der Juristenkonferenz, 3./4. 8. 1946, SAPMO, DY 30 IV 2/1.01/13, B1. 99.

133 Rundschreiben des SED-Zentralsekretariats an die Landesvorstände, 21. 1. 1947, SAPMO, NY $4182 / 1120$, Bl. 7-9, hier 9 .

13+ Vgl. die Berichte über die Reisen nach Halle, Weimar und Dresden (10.-15. 2. 1947), nach Schwerin und Kühlungsborn (31. 10. - 2. 11. 1947) BAB, DP1 VA Nr. 6596, Bl. 198-209, 121-125; nach Dresden, Halle und Weimar (5. 5.-9. 5. 1947) und nach Weimar (20.-24. 11. 1947), SAPMO, NY 4182/1120, Bl. 43-47, 127-139. Zu den Fortbildungsveranstaltungen im Herbst 1947 siehe Kap. A.IV.2. 
wird“. Dies hing vor allem mit der schlechten personellen Besetzung der Referate zusammen, was - wie in der Zentrale auch - auf den Mangel an politisch und fachlich geeigneten Genossen zurückzuführen war; hinzu kam die Geringschätzung des Justizreferats durch die Landesleitung, was sich in fehlender politischer und materieller Unterstützung für dessen Arbeit ausdrückte ${ }^{135}$.

Eine Möglichkeit, um den Personalmangel auf juristischem Gebiet zumindest teilweise zu beheben, bestand in der Bündelung des juristischen Sachverstands innerhalb der SED zur Beratung der Parteiführung auf diesem Gebiet. Dazu wurde erstmals zum 3./4. August 1946 eine Konferenz von rund 20 Genossen aus Berlin und der SBZ einberufen. Sie bildete eine geeignete Plattform zur ersten Besprechung der Grundsätze zur Erneuerung der Justiz, diente aber darüber hinaus der Vorbereitung einer größeren SED-Juristentagung ${ }^{136}$, die nach einer weiteren Vorbesprechung schließlich am 1./2. März 1947 stattfand ${ }^{137}$. Das von Ulbricht gehaltene Einleitungsreferat beschränkte sich auf einige gängige Gemeinplätze, hinter denen sich noch kein festes justizpolitisches Konzept verbarg. Er verdeutlichte lediglich, daß es bei der Umgestaltung der Justiz nun darauf ankomme, frühere Gesetzesbestimmungen im Lichte der Erfahrungen der Gegenwart anzuwenden und vor allem mit Hilfe der Volksrichterschulen, die „eine ständige Einrichtung im demokratischen Staat sein" müßten, „neue[.], demokratische[.] Juristen“ heranzubilden ${ }^{138}$. Die zahlreichen unterschiedlichen juristischen Themen wurden von jeweils dafür kompetenten Genossen abgehandelt, die in der Regel in einer Landes- oder Zentralverwaltung beschäftigt waren ${ }^{139}$.

Um auch weiterhin die Beratung des Zentralsekretariats „in allen wesentlichen Rechtsfragen" sicherzustellen, beschloß die Konferenz auf Antrag Polaks, einen rechtspolitischen Ausschuß aus 24 SED-Juristen zu bilden, von denen 16 in Berlin und acht in den Ländern und Provinzen tätig waren. Nach dem Vorbild des zentralen Ausschusses sollten auch bei den SED-Landesleitungen rechtspolitische Ausschüsse aus den dortigen Juristen rekrutiert werden; als Verbindungsglieder zwischen beiden Gremien sollten die acht SED-Mitglieder aus den Ländern im zentralen Ausschuß fungieren ${ }^{140}$. Die rechtspolitischen Ausschüsse waren also auch zur Erfassung der führenden SED-Juristen aus der gesamten Zone gedacht ${ }^{141}$. Das Zentralsekretariat bestätigte in seiner Sitzung vom 13. März den

135 Siehe die Aufstellung "Justizreferate bei den Landesleitungen“, o.D. [Herbst 1947], BAB, DP1 VA Nr. 2, Bl. 334-336, hier 335f.; vgl. Amos, Justizverwaltung, S. 81 f.; Pohl, Justiz in Brandenburg (Manuskript), S. 42.

136 Protokoll der Zentralsekretariatssitzung, 25. 7. 1946, SAPMO, DY 30 IV 2/2.1/20, TOP 11; Stenographische Niederschrift der Juristenkonferenz am 3./4. 8. 1946, SAPMO, DY 30 IV 2/1.01/37, insbesondere Bl. 2.

137 Siehe Abt. Justiz an Pieck/Grotewohl, 18. 2. 1947, gedruckt in: Amos, Justizverwaltung, S. 227; Protokoll der Zentralsekretariatssitzung, 25. 2. 1947, SAPMO, DY 30 IV 2/2.1/69, TOP 16.

138 Teilweise gedruckt in: Ulbricht, Zur Geschichte der Arbeiterbewegung, Bd. III, S. 106-109, hier $107 \mathrm{f}$.

139 Stenographische Niederschrift über die 1. Juristenkonferenz der SED, am 1./2.3. 1947, SAPMO, DY IV 2/1.01/37.

140 Ausführungen Polaks, ebenda, Bl. $224 \mathrm{f}$.

141 Dies im Gegensatz zu Amos, Justizverwaltung, S. 57, die im rechtspolitischen Ausschuß ein Gremium der SED-Spitze „zur Kontrolle und Beeinflussung der Justizentwicklung “ sieht. Dies war er nur in einem indirekten Sinne. 
Rechtspolitischen Ausschuß unter dem Vorsitz Polaks ${ }^{142}$. Wirksam wurde der Ausschuß freilich nur auf der zentralen Ebene, indem er im Juni 1947 und im Januar 1948 zu zwei Sitzungen zusammentrat, die letztlich der Ausweitung des SED-Einflusses im Justizwesen dienten ${ }^{143}$.

Der Einfluß der KPD/SED auf das Justizwesen im allgemeinen und auf die DJV im besonderen war in den Jahren 1945 bis 1947 noch äußerst begrenzt. Denn es mangelte nicht nur an geeignetem Personal, sondern auch an tiefergehendem Interesse für dieses Betätigungsfeld. Der seit Frühjahr 1946 im Aufbau befindliche Justizapparat der SED war zudem mit den zahlreichen an ihn herangetragenen Aufgaben tendenziell überfordert; erst zu Beginn des Jahres 1947 wurden die innerparteilichen Bemühungen zur Aktivierung der SED in Justizangelegenheiten verstärkt. Hinzu kam, daß die sowjetische Entscheidung, den Schwerpunkt der Verwaltung zunächst auf die Länder zu legen, gleichzeitig aber für die gesamte Zone zuständige Zentralverwaltungen zu bilden, auch von der SED verlangte, auf beiden Ebenen justizpolitisch zu wirken. Der gesamtgesellschaftliche Lenkungsanspruch der Partei ließ sich daher im Justizwesen vorerst nicht erfüllen. Die Einrichtung besonderer Kommunikationslinien zur DJV wie zur SMAD-Rechtsabteilung sowie der Aufbau innerparteilicher Beratungsgremien und Anleitungsstrukturen sollten sich jedoch in der Justizentwicklung nach 1947/48 als vorteilhaft erweisen.

\section{Struktur und Aufgaben der DJV}

SMAD-Befehl Nr. 17 vom 27. Juli 1945 legte fest, daß die DJV „zur Leitung sämtlicher Staatsanwaltschaften, Gerichte und Justizorgane " 144 vorgesehen war. Da die SMAD keine weiteren Vorgaben zu Aufgaben und Struktur der Justizverwaltung machte, war die DJV selbst gefordert, entsprechende Vorschläge zu unterbreiten. Melsheimers Organisationsplan mit sechs Abteilungen lehnte sich eng an den des preußischen Justizministeriums aus der Zeit vor 1932 an $^{145}$. Eine Abweichung betraf die Abteilung I, die im preußischen Justizministerium sowohl mit der Gerichtsorganisation als auch mit den Personalangelegenheiten der Richter, Staatsanwälte, Rechtsanwälte und Notare betraut gewesen war. In der DJV wollte Melsheimer die Organisations- und die Personalfragen in zwei unterschiedlichen Abteilungen behandelt sehen - ein Hinweis auf die herausgehobene Bedeutung der Personalfrage für die Kommunisten. Sonst blieben die Zuständigkeiten der Abteilungen erhalten, nur die Numerierung änderte sich: Geplant waren eine für bürgerliches und öffentliches Recht (Abt. IV DJV, Abt. III preußisches Justizministe-

142 Protokoll der Zentralsekretariatssitzung, 13.3. 1947, SAPMO, DY 30 IV 2/2.1/71, TOP 19. Am 17. 3. 1947 wurde er in "Ausschuß für Justiz- und Rechtsfragen“ umbenannt: SAPMO, DY 30 IV $2 / 2.1 / 72$, TOP 7 .

${ }_{143}$ Vgl. zur mangelnden Wirksamkeit auf Landesebene den Arbeitsplan für die Abt. Justiz für Oktober bis Dezember 1947, 8. 10. 1947, BAB, DP1 VA Nr. 6596, Bl. 133. Zu den zentralen Ausschußsitzungen vom Juni 1947 und Januar 1948 siehe Kap. B.I.

144 Zit. nach: Um ein antifaschistisch-demokratisches Deutschland, S. 101.

145 Aufgrund $\$ 7$ der Verordnung zur Vereinfachung und Verbilligung der Verwaltung vom 19.10. 1932 wurden die sechs Abteilungen auf vier reduziert: vgl. Gruchmann, Justiz, S. 223. 
rium), eine für Strafrecht (Abt. V DJV, Abt. VI preußisches Justizministerium), eine für den Strafvollzug (Abt. VI DJV, Abt.V preußisches Justizministerium) und eine für die Ausbildung des juristischen Nachwuchses (Abt. III DJV, Abt. VI preußisches Justizministerium). Die Abteilungen I, II und III sollten Schiffers erstem Stellvertreter Bertz, die anderen dem zweiten Stellvertreter Kleikamp unterstellt werden ${ }^{146}$. Auch Schiffer orientierte sich am preußischen Justizministerium, seine Vorstellungen wichen von denen Melsheimers jedoch vor allem in dreierlei Hinsicht ab: Er sah für das Etat- und Kassenwesen, das Melsheimer von der Abteilung I bearbeiten lassen wollte, eine selbständige Abteilung (Abt. VI) vor, Abteilung IV sollte für Strafrecht und Strafvollzug zuständig sein, und er beabsichtigte, eine Abteilung VII einzurichten, die sich ausschließlich mit der Justizreform auf zivilrechtlichem und strafrechtlichem Gebiet zu befassen hatte. Die Zusammenlegung der Strafrechts- und der Strafvollzugsabteilung läßt sich auf die Rationalisierungsabsichten Schiffers zurückführen ${ }^{147}$, und die geplante Einrichtung der neuen Abteilung zeigt, wie wichtig ihm die Justizreform war. Denn diese sollte nicht in den Zuständigkeitsbereich eines der beiden Vizepräsidenten fallen, sondern vom ehemaligen preußischen Justizminister Hermann Schmidt geleitet und Schiffer unmittelbar unterstellt werden ${ }^{148}$.

Bei der Besprechung am 21. August $1945 \mathrm{kam}$ es vor allem über diese beiden Vorhaben Schiffers zu heftigen Auseinandersetzungen mit den kommunistischen Vertretern. Werner Gentz trat nachdrücklich für die Behandlung des Strafrechts und des Strafvollzugs in zwei getrennten Abteilungen ein. Zum einen hielt er den Abteilungsleiter angesichts der Fülle der unterschiedlichen Aufgaben, die bei der Reform des Strafrechts und des Strafvollzugs anfallen würden, für überfordert, und zum anderen machte er fachliche Gründe geltend. Der Strafvollzug sei „dem Gebiet der öffentlichen Fürsorge mit ihrer an den Notwendigkeiten des Einzelfalles orientierten Tätigkeit viel näher verwandt [...] als mit der mehr paragraphengebundenen, mehr generalisierenden Tätigkeit des Strafrichters". Eine Reform des Strafvollzugs ließ sich nach der Auffassung von Gentz also nur durchführen, wenn die dafür zuständige Abteilung selbständig blieb ${ }^{149}$. Melsheimer hielt die Errichtung der Abteilung VII zunächst aus fachlichen Gründen für unzweckmäßig, da die Justizreform in den Abteilungen erarbeitet werden müsse, die in ihrer täglichen Arbeit mit Angelegenheiten des Zivil- und Strafrechts befaßt seien. Er erblickte in diesem Vorhaben Schiffers vor allem eine Arbeitsbeschaffungsmaßnahme für Schmidt, der zudem keine besonderen Qualifikationen für diese Aufgabe mitbringe. Ein weiterer, wohl ausschlaggebender Grund zur Ablehnung des Projekts bestand in dem damit verbundenen Kompetenzverlust für die kommunistischen Vertreter in der DJViso.

146 Melsheimers Organisationsplan in: Amos, Justizverwaltung, S. 214. Zum preußischen Justizministerium siehe: "Justizverwaltung in Deutschland vor dem 30. Januar 1933“, o.D., BAB, DP1 VA Nr. 7479.

147 Bereits 1932 waren beide Abteilungen im preußischen Justizministerium aus Rationalisierungsgründen zusammengelegt worden: vgl. Gruchmann, Justiz, S. 223.

148 Die Vorstellungen Schiffers sind nur indirekt in dem Bericht Melsheimers von der Besprechung vom 21. 8. 1945 überliefert, in: Amos, Justizverwaltung, S. 215.

149 Vermerk zum Thema: Strafvollzugsabteilung, 21. 8. 1945, SAPMO, NY 4182/1118, Bl. 52.

150 Bericht Melsheimer, in: Amos, Justizverwaltung, S. 215. 
Aus dem von Generaloberst Wladimir Kurassow, dem Chef des Stabes der SMAD, am 31. August unterzeichneten und von Schukow am 4. September 1945 bestätigten Organisationsplan geht hervor, daß keine der beiden Seiten ihre Positionen ohne Abstriche durchgesetzt hatte und daß bis zur Entscheidungsfindung auch einige inhaltliche Änderungen erfolgt waren. So gab es neben der mit der Gerichtsorganisation betrauten "Abteilung für Bestandsaufnahme und Neubau“ (Abt. I) und der Personalabteilung (Abt. II) nunmehr eine „Abteilung für die Angelegenheiten der Gerichte" (Abt. III). In der Abteilung IV waren Staatsanwaltschaft und Strafvollzug zusammengefaßt, Abteilung V war für "Gesetzgebung und Kodifikation“, Abteilung VI für das „Ausbildungs- und Prüfungswesen“ und die Abteilung VII für „allgemeine Angelegenheiten“, unter anderem für das Etatund Kassenwesen, zuständig151. Während Paul Bertz als erster Stellvertreter den Abteilungen II, III und VII vorstand, waren die anderen vier Abteilungen Kleikamp unterstellt ${ }^{152}$. Zwar war damit Schiffers Plan einer Reformabteilung gescheitert; er hatte sich indes mit seinen Vorstellungen hinsichtlich des Strafvollzugs und der allgemeinen Abteilung zumindest vorläufig durchgesetzt. Am 28. September wurde jedoch bereits das Strafvollzugswesen aus der Abteilung IV ausgegliedert und eine selbständige Abteilung IV A zur Bearbeitung dieses Aufgabengebiets unter der Leitung von Gentz errichtet, was als nachträglicher Erfolg der Kommunisten gewertet werden kann ${ }^{153}$. Zu diesen Abteilungen kam im Herbst 1945 das zentrale Justizprüfungsamt für die SBZ hinzu, das zur Abnahme der zweiten juristischen Staatsprüfung bei der DJV eingerichtet wurde ${ }^{154}$. Es unterstand dem Leiter der Abteilung für Ausbildungswesen, der nunmehr den Titel „Präsident des Prüfungsamtes" trug.

$\mathrm{Zu}$ den Aufgaben der einzelnen Abteilungen äußerten sich deren Leiter Ende Oktober 1945. Den Vorhaben der Abteilung I lag eine Verfügung Schiffers vom 27. August zugrunde, in der dieser angeordnet hatte, zunächst eine generelle $\mathrm{Be}$ standsaufnahme hinsichtlich der Gerichte, Staatsanwaltschaften, Rechtsanwälte und Notare anzufertigen und im Anschluß daran durch Aufteilung oder Zusammenlegung neue Gerichtsbezirke zu schaffen, wobei - ganz im Sinne des von ihm angestrebten "Abbaus der Hypertrophie des Rechts“ - auch an die „Abgabe von Geschäften an andere Behörden (Grundbuch, Register, freiw. Gerichtsbarkeit, Konkurs, Entmündigung) und der Einbeziehung anderer Behörden (Arbeitsgerichte, Sondergerichte, Verwaltungsgerichte)“ gedacht werden sollte ${ }^{155}$. In der stichwortartigen Aufzählung der Arbeitsgebiete wurden als wichtigste Aufgaben neben der Organisation des gesamten Gerichtswesens und der Statistik das Strafregister und die Verwaltungsgerichtsbarkeit genannt ${ }^{156}$.

151 Organisationsplan und Postenbesetzung der DJV, BAB, DP1 VA Nr. 1, Bl. 17-19.

$152 \mathrm{Vgl}$. Amos, Justizverwaltung, S. 14.

153 Verfügung Schiffers, 28. 9. 1945, BAB, DP1 VA Nr. 1, Bl. 15. Über die Hintergründe dieser Entscheidung ist nichts bekannt.

$154 \mathrm{Vgl}$. Schiffers Mitteilung an die Zentralfinanzverwaltung vom 18.10. 1945, daß er „die baldige Wiedereinrichtung" des Prüfungsamtes beabsichtige, BAB, DP1 VA Nr. 7076. In der „Ordnung der Assessorprüfung für Referendare" vom 16.1. 1946, BAB, DP1 VA Nr. 7854, wurde in $\$ 1$ vorgeschrieben, daß die Assessorprüfung „vor dem bei der Deutschen Zentralen Justizverwaltung gebildeten Prüfungsamt in Berlin" abzulegen sei.

155 Verfügung Schiffers, 27. 8. 1945, BAB, DP1 VA Nr. 2, Bl. 12.

156 Arbeitsgebiet der Abteilung I, o.D. [vermutlich Oktober 1945], BAB, DP1 VA Nr. 1043, Bl. 3 f. 
Die Abteilung II, die prinzipiell für die Personalangelegenheiten aller Justizangestellten (den Strafvollzug ausgenommen) zuständig war, fühlte sich unter Legitimationszwang. Denn am 22. Oktober hatte die SMAD mit Befehl Nr. 110 die Kompetenzen der Länder und Provinzen durch die Ermächtigung, Gesetze und Verordnungen mit Gesetzeskraft zu erlassen, gestärkt ${ }^{157}$. Damit wurde es für die Zentralverwaltungen schwieriger, Eingriffe in die Länderpolitik - einschließlich der Personalpolitik - zu rechtfertigen. Abteilungsleiter Paul Winkelmann reklamierte für die DJV die Oberaufsicht über Personalentscheidungen der Länder und Provinzen und begründete dies mit der Notwendigkeit einer „einheitlichen politischen Ausrichtung " der Personalpolitik; auch sollte seine Abteilung verhindern, daß in einem Land abgelehnte Bewerber in einem anderen eingestellt würden; schließlich sah er in der DJV ein Gegengewicht gegen einen „übertriebenen Partikularismus" bei der Einstellungspraxis. Ganz im Sinne der Reformvorstellungen Schiffers wies Winkelmann zudem auf die geplante Einstellung von Laienrichtern hin, deren Auswahl und Ausbildung "sich nur nach einheitlichen Gesichtspunkten treffen“ lasse. Insgesamt hielt er daher nicht nur ein „Vorschlagsund Beratungsrecht gegenüber den Landes- und Provinzialbehörden", sondern ein "Mitwirkungs- und Aufsichtsrecht“ in Personalangelegenheiten für wünschenswert ${ }^{158}$.

Der Abteilung III kam neben der Presse- und Rundfunkarbeit als Hauptaufgabe „die Überwachung der Tätigkeit der Gerichte auf den Gebieten der Strafgerichtsbarkeit, der Zivilgerichtsbarkeit und der freiwilligen Gerichtsbarkeit" zu. Auch diese Arbeit sollte nach dem Willen ihres Leiters Fritz Corsing von einem reformerischen Impetus getragen werden: „Die Überwachung erstreckt sich unbeschadet der Unabhängigkeit der Gerichte auf ihre gesamte Tätigkeit einschließlich des Geschäftsganges und zielt auf Sicherung und Verankerung des neuen demokratischen Staates hin." Freilich war die Abteilung noch weit entfernt von den späteren Versuchen einer umfassenden Steuerung der Rechtsprechung: 1945 wollte man sich noch auf die Prüfung von Eingaben und Anfragen sowie auf einzelne Nachprüfungen vor Ort beschränken ${ }^{159}$.

Während die Abteilung IV mit ihrer Zuständigkeit für die Staatsanwaltschaft, die Rechtsanwaltschaft und das Gerichtsvollzieherwesen unter Hermann Kuenzer keine nennenswerten Neuerungsvorschläge unterbreitete ${ }^{160}$, war das von Gentz niedergelegte „Strafvollzugsprogramm“ der Abteilung IV A eine Reformschrift ersten Ranges. Seinen Ausgangspunkt bildete der Gedanke, daß die zentrale Aufgabe des Strafvollzuges die „Erziehung der ihm unterworfenen Menschen" sei, es dabei also darum ging, die Persönlichkeitsentwicklung der Strafgefangenen zu korrigieren. Daraus ergaben sich für Gentz eine Fülle von Schlußfolgerungen, die alle auf eine „Humanisierung des Strafvollzuges“ hinausliefen:

157 Gedruckt in: Um ein antifaschistisch-demokratisches Deutschland, S. $183 \mathrm{f}$.

158 Künftige Aufgaben der Abteilung II, 27. 10. 1945, BAB, DP1 VA Nr. 1043, Bl. 5-9.

159 Aufgabenkreis des Direktors Corsing, o.D. [vermutlich Oktober 1945], ebenda, Bl. $10 \mathrm{f}$.

160 Aufgabengebiet der Abteilung IV, o.D. [vermutlich Oktober 1945], ebenda, Bl. 13-15; zu nennen wären hier lediglich das Vorhaben, die Kriminalpolizei der Staatsanwaltschaft als Hilfsbeamte zu unterstellen, die Überlegung, ob angesichts des Mangels an Anwälten der Anwaltszwang weiter beibchalten und ob Wirtschaftsanwälte und Sozialanwälte als neue "Anwaltsstände“ geschaffen werden sollten. 
möglichst weitgehender Verzicht auf physischen Zwang, begrenzte Selbstverwaltung für die Gefangenen, sinnvolle handwerkliche oder gärtnerische Arbeiten, Erleichterung des Brief- und Besucherverkehrs. Als erste konkrete Aufgaben nannte Gentz eine Bestandsaufnahme der Anstalten, die Erörterung des Strafvollzugsprogramms mit den Strafvollzugsreferenten in den Länderverwaltungen sowie die Einrichtung einer oder mehrerer Musteranstalten. Obwohl der Strafvollzug eine Länderangelegenheit war, betonte Gentz abschließend, daß angesichts „der Neuartigkeit der Aufgaben und [des] Versagen[s] der alten Beamtenschaft" der Strafvollzug „der ständigen einheitlichen Überwachung und Lenkung durch die Zentralinstanz" bedürfe ${ }^{161}$.

Die Aufgaben der Gesetzgebungsabteilung unter Melsheimer beschränkten sich auf die Anwendung und Auslegung der Kontrollratsgesetze und der einschlägigen SMAD-Befehle sowie auf die Beratung der Besatzungsmacht bei ihrer Gesetzgebungstätigkeit im Kontrollrat. Hier standen vor allem die Bereinigung des Strafgesetzbuches, der Strafprozeßordnung, der Zivilprozeßordnung, des Familienrechts und des Erbhofrechts auf der Tagesordnung; die Gesetzgebungsabteilung der DJV unterstützte in diesen Fragen die SMAD-Rechtsabteilung durch Gutachten, Entwürfe und Vorschläge. Darüber hinaus beriet sie die übrigen Zentralverwaltungen in ihren gesetzgeberischen Arbeiten ${ }^{162}$.

Während bei diesem Arbeitsprogramm eine über die Entnazifizierung der Gesetze hinausgehende Reformperspektive nicht erkennbar ist, griff Erich Wende als Leiter der Abteilung VI ein zentrales Thema Schiffers auf: die Überwindung der Kluft zwischen „Volksempfinden und Rechtsprechung“. Dazu wollte er durch entsprechende Veranstaltungen in der Schule größeres Verständnis für die Rechtspflege im Volk wecken und durch eine besondere Schulung der Schöffen und Geschworenen sowie durch die Aufnahme und kurzfristige Ausbildung geeigneter Laien für den juristischen Staatsdienst - Wende schwebte eine einjährige ,Lehrzeit' in Theorie und Praxis vor - die Laien stärker an der Rechtsprechung beteiligen. Eine verbesserte Ausbildung der professionellen Richter, Staatsanwälte und Rechtsanwälte sollte ebenfalls zu „einer lebensvollen Gesetzgebung und Rechtsprechung" beitragen. Seine Forderungen für die juristische Ausbildung beschränkten sich darauf, das Studium auf eine möglichst breite Grundlage zu stellen, „eine ausreichende Kenntnis der sozialen Funktion des Rechts im Leben des Volkes" zu vermitteln und durch Praktika einen stärkeren Praxisbezug herzustellen. Auch am Referendariat wollte er grundsätzlich festhalten und das Schwergewicht der Ausbildung auf die beiden Amtsgerichtsstationen legen ${ }^{163}$.

Der Leiter der Abteilung VII schließlich, die sich in die Unterabteilungen Haushaltswesen, Kassen- und Rechnungswesen und Bauwesen gliederte, nannte als allgemeine Aufgabe seiner Abteilung, die „für die Rechtspflege bereitgestellten Mittel zweckmäßig zu verwalten“. Er reklamierte eine Oberaufsicht über alle Justizbehörden in Haushaltsangelegenheiten und hielt es für erforderlich, daß die

161 Das Strafvollzugsprogramm, 24. 10. 1945, ebenda, BI. 16-21 (Hervorhebung im Original).

162 Aufgaben der Abt. V (Gesetzgebung), 30. 1. 1946, ebenda, Bl. 33-73, hier $33 \mathrm{f}$. Ein entsprechendes

Papier vom Oktober 1945 liegt nicht vor.

${ }_{163}$ Ausführungen von Wende, 24. 10. 1945, ebenda, Bl. 39-47. 
DJV „bei allen Vorgängen wirtschaftlichen Charakters von wesentlicher Bedeutung beteiligt" werde164.

Aus den meisten dieser Aufzeichnungen läßt sich entnehmen, daß die DJV im Herbst 1945, ganz im Sinne ihres Präsidenten Schiffer, mit einer klaren Reformperspektive antrat. Inwieweit sich die teilweise mehr, teilweise weniger deutlich formulierten Vorhaben und Aufgaben realisieren ließen, war zu dieser Zeit noch offen. Bereits damals war jedoch abzusehen, daß die Länder sich aufgrund ihrer Gesetzgebungskompetenz der Politik der DJV widersetzen konnten. Die Zentralverwaltung war daher darauf angewiesen, daß die SMAD-Rechtsabteilung sie in ihrer Politik vorbehaltlos unterstützte.

\section{Die personelle Besetzung der DJV im Jahre 1945}

Bereits vor Erlaß des Befehls Nr. 17 trat die SMAD an die im Gemeinsamen Ausschuß der Einheitsfront vertretenen vier "antifaschistisch-demokratischen“ Parteien heran, unterrichtete sie von der bevorstehenden Begründung der Zentralverwaltungen und bat, insbesondere für die Präsidenten- und Vizepräsidentenstellen, um Personalvorschläge ${ }^{165}$. Somit erwies sich der am 14. Juli 1945 auf Initiative der KPD begründete „antifaschistisch-demokratische Block“ 166 als eine wesentliche Voraussetzung für die sowjetische Militärverwaltung, um die deutschen Auftragsverwaltungen mit Vertretern aller Parteien zu besetzen und damit zu verdeutlichen, daß sie dazu keineswegs nur auf die Arbeiterparteien zurückgreifen wollte. Gleichzeitig waren bürgerliche Politiker wie der CDU-Vorsitzende Andreas Hermes bestrebt, den Block als ein Instrument zu nutzen, um ein Übergewicht der beiden Linksparteien bei der Besetzung von Verwaltungsstellen - nicht nur der Zentralverwaltungen - zu verhindern ${ }^{167}$.

\section{Der Präsident der DJV: Eugen Schiffer}

Am 27. Juli 1945 waren die Personalabsprachen zwischen den sowjetischen und den deutschen Instanzen schon so weit vorangeschritten, daß die Leiter von neun der elf Zentralverwaltungen feststanden, unter anderem Eugen Schiffer, der nach Befehl Nr. 17 als Präsident der DJV einzusetzen war. Warum griff die Militärverwaltung auf diesen bereits 85 jährigen zurück, und warum ließ sich dieser trotz seines hohen Alters auf eine derartige Aufgabe ein?

Geboren 1860 als Sohn eines jüdischen Kaufmanns, blieb Eugen Schiffer nach Studium und Referendariat bis 1899 Amtsrichter im oberschlesischen Zabrze (Hindenburg). Erst nachdem er 1896 zum Protestantismus konvertiert war,

164 Aufgaben der Haushaltsabteilung, 24. 10. 1945, ebenda, Bl. 48-52, hier 48.

165 Merker, Zentralverwaltungen, S. 29f. Vgl. Weber, Geschichte der DDR, S. 99-101 zu den Ver-

handlungen mit der SPD-Führung. Friedensburg, Deutschlands Einheit, S. $61 \mathrm{f}$. , berichtet,

Freunde aus der Leitung der CDU hätten ihm Ende Juli mitgeteilt, daß sie ihn nach einer sowjetischen Anfrage auf ihre Vorschlagsliste gesetzt hätten. Für die LDP siehe Aktennotiz von Külz,

26. 7. 1945, in: Weber, DDR. Dokumente, S. $43 \mathrm{f}$.

166 Vgl. dazu Suckut, Blockpolitik, S. 16 ff., zur Gründungssitzung S. 62-65.

167 Ebenda, S. 68, Anm. 17, S. 570 f. 
wurde er 1899 nach Magdeburg versetzt und dort ein Jahr später zum Landgerichtsrat befördert. Auf der juristischen Karriereleiter folgten die Ernennungen zum Kammergerichtsrat (1906) und zum Oberverwaltungsgerichtsrat (1910) in Berlin. 1903 begann seine politische Laufbahn, als er nach dem Beitritt zur Nationalliberalen Partei ein Mandat für den preußischen Landtag erhielt. Seit 1912 Mitglied des Reichstages, gehörte er im Ersten Weltkrieg dem Interfraktionellen Ausschuß an und leitete ab Herbst 1916 die Rechtsabteilung des Kriegsamtes im preuBischen Kriegsministerium. Das Kriegsende erlebte er als Unterstaatssekretär im Reichsschatzamt, dessen Leitung er nach der Novemberrevolution übernahm. Schiffer zählte zu den Mitbegründern der linksliberalen Deutschen Demokratischen Partei (DDP), als deren Mitglied er in die Weimarer Nationalversammlung gewählt wurde. Von seinem Posten als Finanzminister im Kabinett Scheidemann trat er aus persönlichen Gründen bereits im April 1919 zurück. Von sehr viel größerer Bedeutung wurde für ihn das Justizministerium, das er von Oktober 1919 bis April 1920 und von Mai bis Oktober 1921 leitete. Damit hatte er freilich den Höhepunkt seiner politischen Karriere in der Weimarer Republik erreicht. Bis 1924 blieb er Abgeordneter im Preußischen Landtag und im Reichstag (hier auch als Fraktionsführer seiner Partei) und galt als „heimlicher Parteiführer der DDP“. 1924 zog er sich, nach seinem Austritt aus der DDP und dem mißlungenen Experiment einer Parteineugründung, der „Liberalen Vereinigung“, aus der Politik zurück und widmete sich seiner Arbeit als Leiter der Berliner Verwaltungsakademie und als Mitherausgeber der „Deutschen Juristenzeitung“ ${ }^{168}$.

Seitdem er 1909 Mitglied der Immediatkommission für die Reform der Inneren Verwaltung im Preußischen Abgeordnetenhaus geworden war, ließ ihn das Thema einer Justizreform nicht mehr los. Aufgrund der äußerst kurzen Amtszeiten als Justizminister konnte er seine Reformvorhaben nicht verwirklichen, sondern mußte sich darauf beschränken, diese in dem 1928 erschienenen Werk „Die deutsche Justiz. Grundzüge einer durchgreifenden Reform" darzulegen. Sein Buch, ein „Bestseller unter den Juristen "169, beeinflußte die Politik insofern, als Reichsjustizminister Erich Koch-Weser unter Bezug auf die Ideen Schiffers erste Schritte zur Verwirklichung der sogenannten "großen Justizreform" unternahm. Mit dem Rücktritt Koch-Wesers im April 1929 fanden auch diese Aktivitäten ein Ende ${ }^{170}$.

Schiffers Ausgangspunkt bildete die nicht nur von ihm konstatierte Vertrauenskrise der Justiz, die er zum einen als "Augenblickskrise“ und zum anderen als „Dauerkrise“ begriff. Den Vertrauensschwund der Justiz in der Weimarer Republik machte er an der Stimmung weiter - vornehmlich, aber nicht ausschließlich linker - Kreise gegen die Unabhängigkeit der Justiz fest, die angesichts der zahlreichen Fehlurteile in politischen Strafsachen vielen nur noch als Floskel erschien. Die Justizkrise der Weimarer Zeit erschien Schiffer jedoch nur als Ausdruck der "Dauerkrise der deutschen Justiz“, deren Wurzeln er in der Rezeption des römischen Rechts erblickte. Dadurch habe eine Entfremdung zwischen Volk und

${ }_{168} \mathrm{Zu}$ Schiffers Karriere in dieser Zeit siehe Ramm, Schiffer und die Reform, S. 9-64, und ders., Schif-

fer. Wegbereiter der Justizreform, S. 456-462, sowie Kuhn, Deutsche Justizminister, S. 57.

169 Hattenhauer, Reichsjustizamt, S. 54.

170 Vgl. ebenda, S. 55-58. 
Recht eingesetzt, die er mit den Schlagworten „Rechtsfremdheit des Volkes Volksfremdheit des Rechts - Weltfremdheit der Richter" 171 umschrieb. Zur Überwindung dieser Kluft mußten Reformen in dreierlei Hinsicht erfolgen. Erstens wollte er die „Hypertrophie des Rechts“ durch die unterschiedlichsten Maßnahmen abbauen: Dazu zählten unter anderem eine Verringerung der gesetzlichen Vorschriften, eine Beschränkung der Rechtsmittel, die Heraufsetzung der Rechtsmittelsummen, die Einschränkung der Privatklage sowie die Übertragung von richterlichen Geschäften auf mittlere Beamte. Zweitens plante er, das Gerichtswesen durch einen einheitlichen dreistufigen Gerichtsaufbau (Bezirksgericht, Obergericht, Reichsgericht), durch die Aufhebung kleinerer Amtsgerichte und die „Verreichlichung der Justiz“ (der Überführung der Justizverwaltung auf das Reich) zu vereinfachen. Drittens faßte er Reformen im Hinblick auf die Richter ins Auge: Ihre Zahl sollte verringert, ihre Qualifikation indes erhöht und das Laienelement in der Richterschaft verstärkt werden. Mit Justizabbau auf der einen und mehr Rationalität im Justizwesen auf der anderen Seite hoffte Schiffer, die Akzeptanz für Recht und Justiz im Volk zu erhöhen ${ }^{172}$.

Die nationalsozialistische Diktatur bedeutete nicht nur das Ende für die Reformvorhaben Schiffers, sie brachte auch den ehemaligen Justizminister selbst wegen seiner jüdischen Herkunft in große Gefahr. Es war vornehmlich der Fürsprache seiner Bekannten Johannes Popitz, Erich Seeberg und Lutz Graf Schwerin von Krosigk bei Himmler zuzuschreiben, daß er vor dem Konzentrationslager verschont blieb und das Kriegsende im jüdischen Krankenhaus in Berlin erleben konnte ${ }^{173}$. Er resignierte jedoch nicht, sondern hielt sich während des Dritten Reiches zur Rückkehr in die Politik bereit ${ }^{174}$. Indem er mit seinem Schwiegersohn Waldemar Koch bereits seit 1944 die Bildung einer liberalen Partei nach dem Zusammenbruch erörterte und sich an der Gründung der Liberal-Demokratischen Partei Deutschlands (LDP) maßgeblich beteiligte, zeigte er einen trotz seines hohen Alters ungebrochenen politischen Gestaltungswillen ${ }^{175}$.

Dies ließ ihn wohl auch auf das Angebot Ulbrichts zur Mitarbeit am „antifaschistisch-demokratischen" Neuaufbau eingehen, das dieser ihm in der ersten Maihälfte 1945 unterbreitete. Ulbricht war damals gemäß den Grundsätzen kommunistischer Bündnispolitik ${ }^{176}$ auf der Suche nach sozialdemokratischen und bürgerlichen Kräften, die er zunächst für die Mitarbeit im Berliner Magistrat gewinnen wollte. Nachdem er am 5. Mai bei Andreas Hermes mit Erfolg vorgesprochen hatte ${ }^{177}$, suchte er Schiffer in den darauffolgenden Tagen im jüdischen Krankenhaus auf. Im Verlauf der zweitägigen Verhandlungen verwies Schiffer zwar auf die unterschiedliche Herkunft und die unterschiedlichen Ziele der beiden Gesprächs-

171 Schiffer, Rechtssicherheit, S. 45. Diese Äußerung stammt zwar vom Oktober 1945, sie wird jedoch rückblickend angewandt und fügt sich nahtlos in Schiffers Gedanken der zwanziger Jahre ein.

172 Diese Ausführungen weitgehend nach Schiffer, Deutsche Justiz, 1. Aufl.

173 Ramm, Schiffer und die Reform, S. 171.

174 Ders., Schiffer. Wegbereiter der Justizreform, S. 464.

175 Koch an LDP-Landesverband Berlin, 5. 7. 1948, in: Berlin. Quellen und Dokumente, S. 997. Schiffer hatte demzufolge die Gründung der LDP am 16.6.1945 mit vorbereitet, war aber nicht bei der Gründungssitzung anwesend; vgl. auch Louis/Sommer, Neue Dokumente, S. $35 \mathrm{f}$.

176 Siehe dazu u. a. Sywottek, Volksdemokratie, und Erler/Laude/Wilke, Nach Hitler.

177 Ulbricht an Generaloberst Serow, 6. 5. 1945, in: Keiderling, Gruppe Ulbricht, S. 298-301. 
partner, erklärte sich aber bereit, „ein Stück des Weges gemeinsam zu gehen“178. Später bezeichnete Ulbricht Schiffer als denjenigen unter den LDP-Parteiführern mit der größten Bereitschaft zur Kooperation im „Block“ und fügte hinzu: "Schiffer hat als Demokrat einen Namen in Deutschland."179 Für Ulbricht entsprach der ehemalige Justizminister als bürgerlicher, im Dritten Reich verfolgter Reformpolitiker mit Renommee dem Idealbild eines Bündnispartners im Rahmen der Blockpolitik.

Schiffer trug seine Bereitschaft zur Kooperation mit den deutschen Kommunisten im nachhinein Vorwürfe ein ${ }^{180}$. Überschätzte er also seine Wirkungsmöglichkeiten, oder verleitete ihn gar sein Geltungsdrang dazu, die Risiken einer solchen Zusammenarbeit zu übersehen? In seinen Memoiren verwies Schiffer in diesem Zusammenhang darauf, daß trotz der Gegensätze von Liberalismus und Kommunismus „besondere Verhältnisse es erfordern oder doch rechtfertigen können, daß beide Parteien ein Stück Weges auf einzelnen Gebieten zusammengehen “181; über seine Motive zur Kooperation schwieg er jedoch. Der Schlüssel für sein Verhalten ist daher wohl bei der Festlegung des Blocks auf die „Herstellung voller Rechtssicherheit auf der Grundlage eines demokratischen Rechtsstaates" ${ }^{182}$ zu suchen. Dieser Grundsatz war auf Schiffers Antrag hin aufgenommen worden, der im Verlauf der Gründungssitzung auf rechtsstaatlichen Verfahren auch bei Enteignungen beharrt hatte ${ }^{183}$. Damit verband er offensichtlich die Hoffnung, die Kommunisten auf Rechtssicherheit und Rechtsstaatlichkeit festgelegt zu haben.

Erst unter dieser Voraussetzung war er bereit, die Leitung der DJV zu übernehmen. Dieses Amt schien ihm - und darin muß das stärkste Motiv für sein Engagement in der SBZ gesehen werden - die Möglichkeit zu bieten, seine Reformvorstellungen für das Justizwesen zu realisieren ${ }^{184}$. Sein „Programm“ hatte sich nur unwesentlich geändert. Angesichts des Mißbrauchs von Recht und Justiz im Nationalsozialismus hatte sich die Vertrauenskrise der Justiz über die Weimarer Republik hinaus verstärkt und verlängert, so daß er am 3. Oktober 1945 schrieb: "Jetzt ist die Stunde gekommen, in der es sich nicht um Umkehr und Rückkehr, sondern um ein Vorwärtsschreiten auf neuen Wegen und zu neuen Zielen handelt." ${ }^{185}$ Die von ihm angestrebte Justizreform besaß zwei Aspekte: einen rückwärtsgewandten, der die Entnazifizierung der Gesetze und des Justizpersonals betraf, und einen vorwärtsweisenden, bei dem es um die Überwindung der Trennung von Volk und Justiz ging 186 . Die Rezepte, die Schiffer vorschlug, waren im

178 Zit. nach Ulbricht, Geeinte Arbeiterklasse, S. 218. An anderer Stelle (Geschichtliche Lehren) führt Ulbricht an, daß sich beide noch aus dem Reichstag kannten, was aufgrund Schiffers Ausscheiden aus der Politik im Jahre 1924 und Ulbrichts erstem Reichstagsmandat von 1928 nicht möglich ist.

179 Bericht Ulbrichts vom Juli 1945, zit. nach Keiderling, Scheinpluralismus, S. 284.

180 Lüders, Fürchte Dich nicht, S. 175; P[aul] L[öbe], Eugen Schiffer 90 Jahre, in: Telegraf, 14. 2. 1950.

181 Schiffer, Leben, S. 243.

182 Gründungs-Erklärung des zentralen Einheitsfront-Ausschusses vom 14.7. 1945, in: Suckut, Blockpolitik, S. 64 f.

183 Verlauf der Gründungssitzung nach dem Gedächtnisprotokoll von Erich W. Gniffke, ebenda, S. 62 f.; Schiffer, Leben, S. 254.

184 So auch Ramm, Schiffer und die Reform, S. 175, sowie Anders, Demokratisierung, S. 30 f.; vgl. dazu auch Melsheimer, Dem scheidenden Chef, S. 147.

185 Schiffer, Rechtssicherheit, S. 44.

186 Ders., Justizreform. 
wesentlichen die der zwanziger Jahre: ein neuer, besser qualifizierter Richtertyp mit „vollem Verständnis für das praktische Leben und lebendiger Teilnahme für alles Menschliche“, ein neuer Typ Laienrichter, der „aus einem bloßen Zierstück“ zu einem "vollwertig Mitwirkende[n] an der Rechtsprechung" werden sollte, dreistufiger Gerichtsaufbau, Abbau der Hypertrophie des Rechts durch Beschränkung der Rechtsmittel, Einschränkung der Gesetzgebung, verständlichere Gesetze. Hinzu kam bereits 1945 der Gedanke, daß zum Rechtsstaat auch ein "Rechtsvolk“ gehöre, in dessen Herzen „die Achtung vor Recht und Gerechtigkeit [...] wie ein rocher de bronze stabilisiert werden " müßte187. Vor diesem Hintergrund überrascht es wenig, daß die zweite Auflage seines Werks „Die deutsche Justiz“ von 1949 inhaltlich kaum von der ersten Auflage abweicht, sieht man einmal von den Ausführungen zum „Rechtsvolk“ und zum Thema „Volksrichter“ $a b^{188}$. Schiffer war bis zu seinem Lebensende darauf bedacht, seine Reformvorstellungen zu realisieren, worauf auch seine in anderem Zusammenhang veröffentlichte Schrift „Ein Sofortprogramm für die deutsche Justiz“ von $1953^{189}$ hindeutet.

Schiffer hatte 1945 nichts von jenem Engagement verloren, das ihn auch in den zwanziger Jahren umtrieb. Er war keineswegs ein altersschwacher Greis, der nur ein Aushängeschild für eine vermeintlich demokratische Blockpolitik abgab, hinter deren Fassade die Kommunisten die Fäden ziehen konnten. Die SMADRechtsabteilung wandte sich bereits 1946 wiederholt an den Politischen Berater mit der Forderung, Schiffer zu entfernen, und begründete dies unter anderem mit folgenden Argumenten: „Schiffer ist Anhänger der bürgerlichen Schule des Naturrechts, er hält das Recht für eine über den Klassen stehende Erscheinung. Er verfehlt die politisch-wirtschaftlichen Maßregeln. Schiffer fällt es im Alter von 86 Jahren schwer, demokratische Ideen anzunehmen; letztendlich verbreitet er die Behauptung, daß eine Einmischung in die Gerichtsorgane unmöglich sei." Die Absetzung Schiffers erschien jedoch weder Generalleutnant Bokow vom Kriegsrat der SMAD noch Ulbricht einstweilen opportun ${ }^{190}$. Zeitgenossen und Untergebene hoben Schiffers Ungeduld, seine hohe geistige Präsenz, seine Arbeitskraft und seine Intelligenz hervor ${ }^{191}$. Die einzige Gegenstimme in diesem Konzert stammt von dem späteren kommunistischen Abteilungsleiter in der DJV, Hans Nathan, der im nachhinein von dem „Ehrgeiz dieses senilen, egozentrischen Mannes“ schrieb, der „aus der Justizverwaltung ein Ministerium im alten Stil“ machen wollte. Freilich mußte Nathan zugeben, daß Schiffer genau dies in den ersten Jahren nach 1945 gelungen war: „Was sich irgend an ,unbelasteten' Ministerialbeamten auftreiben ließ, das hatte er herangeholt" ${ }^{192}$.

187 Zitate ebenda; siehe auch Schiffer, Recht und Wirtschaft, S. 8, $17 \mathrm{f}$., $23 \mathrm{f} ., 28 \mathrm{ff}$.

188 Schiffer, Deutsche Justiz, 2. Aufl.; vgl. Ramm, Schiffer und die Reform, S. 194 f. Zu Schiffers geänderter Einstellung zu den Volksrichtern siehe Abschnitt A.III.1.

${ }^{189}$ Schiffer, Sofortprogramm; vgl. Ramm, Schiffer und die Reform, S. 197 ff.

190 Vgl. Nikitin, Sowjetische Militäradministration und die Justiz (Manuskript), S. 4 f.

191 Vgl. die Charakteristik aus der Feder von Erich Wende in: BAK, Kl. Erw. Nr. 116, Bl. 22; Güstrow, In jenen Jahren, S. 171.

192 Hans Nathan, Aus der Geschichte der zentralen Justizverwaltung, BAB, DP1 VA Nr. 6832, Bl. 9, teilweise zit. bei Amos, Justizverwaltung, S. 19. 


\section{Die Vizepräsidenten: Karl Kleikamp und Paul Bertz}

Auf die Auswahl der Vizepräsidenten nahm Schiffer keinen Einfluß, sondern akzeptierte die Personalvorschläge der CDU, der SPD und der KPD ${ }^{193}$. Von seiten der Unionsführung war zunächst offensichtlich Dr. Stenig, Oberstaatsanwalt in Moabit, vorgesehen ${ }^{194}$; dann fiel die Wahl auf den ehemaligen preußischen Justizminister Hermann Schmidt (ehemals Zentrum) ${ }^{195}$. Dieser strebte ebenfalls „eine wirkungsvolle Vereinfachung und Verbesserung des gesamten Rechts" an ${ }^{196}$ und wurde von Schiffer als Leiter einer besonderen Abteilung ins Auge gefaßt, die das Zivil- und Strafrecht reformieren sollte ${ }^{197}$. Dieses Vorhaben ließ sich freilich nicht realisieren, da Schmidt aufgrund von Gerüchten einer Mitgliedschaft im „Stahlhelm" und von Interventionen von Melsheimer nicht eingestellt wurde ${ }^{198}$.

Der Kandidat der SPD, Karl Kleikamp, konnte auf einen für einen Sozialdemokraten ungewöhnlichen Lebenslauf zurückblicken. Geboren 1894, schlug er zunächst eine militärische Laufbahn ein, wurde seit 1911 zum Offizier ausgebildet und nahm am Ersten Weltkrieg als Leutnant teil, zunächst bei der Infanterie, dann als Flieger, bis er 1915 in russische Kriegsgefangenschaft geriet. Nach seiner Flucht aus dem Gefangenenlager im März 1918 zum Oberleutnant befördert, ging er von Mai bis November 1919 in den angesichts der polnischen Aufstände gebildeten "Grenzschutzdienst"199. Am 31. März 1920 wurde er aus dem Dienst als einer "der besten und beliebtesten Offiziere seines Regiments" entlassen; ihm wurden neben guten Führungsqualitäten „recht gute[.] militärische[.] Anlagen“, „ernste Dienstauffassung und altpreußische Pflichttreue“ bescheinigt ${ }^{200}$. Nach diesem so wohl nicht geplanten Ende seiner militärischen Laufbahn studierte Kleikamp in Berlin und Greifswald Rechtswissenschaft und trat nach seiner großen Staatsprüfung 1929 in den preußischen Staatsdienst ein ${ }^{201}$. Während er bis Mai 1932 als Regierungsassessor beim Polizeipräsidium in Altona Dienst tat, war er danach als Regierungsrat bei der preußischen Bau- und Finanzdirektion in Berlin tätig202.

Weder der Zeitpunkt noch die Motive für Kleikamps Eintritt in die SPD sind bekannt. Aus Zeugnissen der Nachkriegszeit geht lediglich hervor, daß er im Dritten Reich aufgrund seiner SPD-Mitgliedschaft den Staatsdienst verlassen mußte und unter Observation der Gestapo stand. Deren Eingreifen war es auch zu verdanken, daß Kleikamp seine von 1936 bis 1938 bekleidete Stellung bei der Firma

193 Vgl. Schiffer an ZK der KPD, z.H. Pieck, 3. 12. 1945, SAPMO, NY 4182/1118, Bl. 172.

${ }^{194}$ Bericht über die Aussprache mit Oberstaatsanwalt Stenig am 11.8. 1945 [von Bertz], SAPMO, NY 4174/5 Bl. $5 \mathrm{f}$.

195 Hermann Schmidt, geb. 1880, gest. 1. 12. 1945, preußischer Justizminister vom 5. 3. 1927 bis zum 21. 5. 1932 .

196 Schmidt, Rechtserneuerung.

197 Bericht Melsheimer, August 1945, SAPMO, NY 4182/1118, Bl. 51.

198 Aufstellung von bei der DJV nicht eingestellten Personen von Benjamin, Januar 1947, BAB, DP1 VA Nr. 7852 (undatiert auch in Nr. 1009, Bl. 63-65, hier 65).

199 Kriegsranglisten-Auszug des Oberleutnant Karl Kleikamp, Materialien Kleikamp. Diese und die folgenden Schriftstücke wurden dem Verfasser von Frau Gertrud Kleikamp, einer angeheirateten Nichte von Karl Kleikamp, freundlicherweise überlassen.

200 Dienstleistungszeugnis, 6. 5. 1920, gez. v. Lossow, Materialien Kleikamp.

201 Inskriptionsurkunden und Zeugnisse Kleikamps, ebenda.

202 Ernennungsurkunden des Preußischen Innenministeriums vom 5. 6. 1931 und 27. 5. 1932, ebenda. 
E. Hoyer \& Co. KG verlor ${ }^{203}$. Auch bei der Einstellung Kleikamps in der Reichsstelle für Eisen und Metalle Ende 1940/Anfang 1941 ergaben sich aufgrund von dessen ablehnender Haltung gegenüber dem Regime Schwierigkeiten, die der Leiter der Dienststelle nur "nach längeren Verhandlungen“ aus dem Weg räumen konnte 204 .

Nach der Eroberung Berlins durch die Rote Armee ernannte die zuständige sowjetische Kommandantur Kleikamp zum Richter am Amtsgericht Tiergarten ${ }^{205}$. Neben seiner Tätigkeit als Jurist wurde er auch parteipolitisch bei der Neugründung der SPD in deren Programmausschuß aktiv und regte bei Max Fechner die Bildung eines Rechtsausschusses beim Parteivorstand an ${ }^{206}$. Vor diesem Hintergrund schlug ihn die Partei als Vizepräsident der DJV vor ${ }^{207}$. Die Einweisung in die entsprechende Planstelle erfolgte am 21. August, seine förmliche Ernennung zum Vizepräsidenten am 17. Oktober $1945^{208}$.

Kleikamp war - ähnlich wie Schiffer - an einer Reform des Rechtswesens gelegen. Bei der Erläuterung einer Entschließung des SPD-Rechtsausschusses attestierte er den Deutschen zunächst ein mangelndes Rechtsbewußtsein - ein Defizit, das er auf die fatale Entwicklung seit der Niederlage des deutschen bürgerlichen Liberalismus in der Auseinandersetzung mit dem preußischen Obrigkeitsstaat zurückführte. Seit dieser Zeit habe „sich das deutsche Volk in immer steigendem Maße dem Wahn hingegeben, daß es wohl so sein müsse, wenn Macht vor Recht ginge“, und Kleikamp fuhr fort: „Von den Wortbrüchen der deutschen Fürsten nach 1815 und in den Jahren 1848/49 und der Niederknüttelung der 48er Revolution durch die preußische Militärmacht führt ein gerader Weg zu den Gaskammern von Auschwitz und Belsen." Angesichts des totalen Zusammenbruchs und der damit einhergehenden Erschütterung des Rechtslebens war seine Zielsetzung darauf gerichtet, den Menschen erneut den Vorrang des Rechts vor der Macht zu vermitteln. Von daher war es nur konsequent, wenn er - in Auseinandersetzung mit dem Marxismus - nur die Entstehung des Rechts auf bestimmte gesellschaftliche Interessenlagen zurückführte, diesem aber eine „eigengesetzliche Existenz und Wirkungsweise“ zugestand ${ }^{209}$. Daß seine Überlegungen, wenngleich nicht mit denen Schiffers identisch, dennoch in hohem Maße mit diesen kompatibel waren, zeigt ein Artikel von 1946210, in dem Kleikamp das deutsche Rechtswesen vor 1933 als durchaus brauchbar verteidigte. Dessen Versagen führte er darauf zurück, daß Recht als „Obrigkeitsrecht" Teil und Funktion der Staatsgewalt gewesen sei, woraus sich „die Trennung, ja die Feindschaft zwischen Recht und Volk und Richter und Volk" ergeben habe. Auch wenn Kleikamp die Justizkrise anders

203 Ewald Hoyer an Katharine Kleikamp, 14. 10. 1953, ebenda.

204 Eidesstattliche Erklärung Hans Söhlke, 29. 9. 1953, ebenda.

205 Dienstausweis Kleikamp, 5. 6. 1945, ebenda.

206 Vgl. Gniffke, Jahre, S. 29; Fechner an Kleikamp, 10. 7. 1945, SAPMO, NY 4101/13, Bl. 2.

207 Vgl. Gniffke, Jahre, S. 64, der den Namen Kleikamps aber hier nicht nennt.

208 Chef der DJV an Kleikamp, 17. 10. 1945, Materialien Kleikamp.

209 Karl Kleikamp, Einführung und Erläuterung zu der Entschließung des rechtspolitischen Ausschusses über die Grundlagen der Rechtspolitik der SPD vom 31. 10. 1945, 13. 11. 1945, SAPMO, DY 30/IV 2/13/404.

210 Kleikamp, Krise. 
herleitete als Schiffer, stimmte er in seiner Diagnose mit diesem überein, womit die Ausgangslage für eine Zusammenarbeit gegeben war.

Der andere Vizepräsident, der von der KPD nominierte Paul Bertz, war von seinem biographischen Hintergrund her denkbar ungeeignet für dieses Amt. Geboren 1886, absolvierte er eine Lehre als Werkzeugschlosser. Seit 1910 in der SPD, trat er nach Mitgliedschaft im Spartakusbund mit ihrer Gründung 1919 in die $\mathrm{KPD}$ ein. In der $\mathrm{Zwischenkriegszeit} \mathrm{entwickelte} \mathrm{er} \mathrm{sich} \mathrm{zu} \mathrm{einem} \mathrm{reinen} \mathrm{Partei-}$ funktionär. Ab 1922 saß er im sächsischen Landtag und ab 1924 im Reichstag, wurde aber 1930 parteiintern wegen „linker Abweichung“ angegriffen und nicht mehr ins Parlament gewählt. In der Emigration, die ihn 1934 zunächst nach Frankreich, dann in die Schweiz und die Niederlande führte, wurde er 1935 und 1939 ins ZK der KPD berufen und spielte ab Mai 1937 eine wesentliche Rolle als Sekretär des ZK in Paris. Nach Kriegsausbruch in Frankreich interniert, gelang ihm im Juli 1940 die Flucht in die Schweiz, wo er zwar inaktiv blieb, dennoch bis 1943 als Führer der Exil-KPD anerkannt war. 1944 kam es zwischen der offiziellen Parteileitung in der Schweiz und Bertz zum Bruch, da dieser Vorbehalte gegen die Bewegung Freies Deutschland und die Verstärkung der "Massenarbeit“ in Deutschland hatte ${ }^{211}$. Bald nach seiner Rückkehr nach Berlin Anfang August 1945 wurde er zum Vizepräsidenten in der DJV nominiert ${ }^{212}$ und am 1. September in seine Planstelle als Stellvertreter des Chefs der DJV eingewiesen ${ }^{213}$. Daß die Wahl auf Bertz als einen Nicht-Juristen und einen wenig linientreuen Genossen fiel, zeigt zum einen, wie dünn die Personaldecke - insbesondere an leitenden „Justizkadern" - war, über die die Kommunisten verfügten, und zum anderen die zweitrangige Rolle, die die Justiz und die DJV damals für die KPD-Führung spielten.

\section{Die fübrenden "Justizkader" der KPD in der DJV: Ernst Melsheimer und Hilde Benjamin}

Im Unterschied zu Bertz verfügten die Kommunisten Ernst Melsheimer und Hilde Benjamin, die in den fünfziger Jahren das Erscheinungsbild der DDR-Justiz maßgeblich mitbestimmten, über eine solide juristische Ausbildung und eine mehrjährige Berufspraxis. Sie gelangten 1945 jedoch noch nicht in Führungspositionen, weil sie bei der Begründung der DJV der KPD-Führung noch weitgehend unbekannt waren. $\mathrm{Da}$ es jedoch an juristisch ausgebildeten Kommunisten in der DJV mangelte, stiegen sie mit Unterstützung der SMAD-Rechtsabteilung und der Partei in der Zentralverwaltung rasch auf und legten hier die Grundlage ihrer späteren Laufbahn ${ }^{214}$.

211 Zur Biographie von Bertz siehe u.a. Weber, Wandlung, Bd. 2, S. 73 f.; Biographisches Handbuch, S. 60; zum Exil in der Schweiz Bergmann, Bewegung, S. $28 \mathrm{f}$.

212 Bertz schrieb am 6. 12. 1945 an die Kaderabteilung des ZK, daß er sich „seit Anfang August" in Berlin befinde, SAPMO, NY 4174/1, Bl. 7; am 11.8. 1945 besprach er bereits mit Oberstaatsanwalt Stenig die Möglichkeit einer Kooperation zwischen CDU und KPD in Justizangelegenheiten, SAPMO, NY 4174/5 Bl. 5 f.

${ }^{213}$ Besetzungsliste DJV, 17. 10. 1945, BAB, DP 1 VA Nr. 1, Bl. 21.

214 Für die Vermutung Werkentins, Richter und Ankläger, S. 5 f., daß Melsheimer bereits vor 1945 insgeheim für die Sowjetunion gearbeitet haben könnte, gibt es nach wie vor keine Belege. 
Die Bewertung von Ernst Melsheimer schwankt unter den Zeitgenossen in Ost und West: Galt er in der DDR als wackerer Antifaschist, der „von den Faschisten wegen seiner politischen Überzeugung und seiner politischen Tätigkeit in der SPD und später der KPD gemaßregelt" 215 worden war, unterstellte man ihm in der Bundesrepublik aufgrund seines Justizdienstes im Dritten Reich, seiner angeblichen Freundschaft mit Roland Freisler und seiner Aktivität als Generalstaatsanwalt der DDR einen schrankenlosen Karrierismus ${ }^{216}$. Geboren 1897 im saarländischen Neunkirchen als Sohn eines „stramm nationale[n]“ Abteilungsleiters in den Stummschen Eisenwerken, wuchs Melsheimer in einem bürgerlich-nationalistisch geprägten Milieu auf217. Bei Ausbruch des Ersten Weltkriegs meldete er sich als Freiwilliger, erhielt jedoch im Oktober 1914 bei Langemarck eine so schwere Verwundung, daß er im April 1915 als „dienstunbrauchbar“ entlassen wurde ${ }^{218}$. Danach studierte er Rechts- und Staatswissenschaften an den Universitäten Marburg und Bonn. Während er in Marburg „in nationalistischer Begeisterung der Burschenschaft ,Arminia“" beigetreten war, fiel sein „erstes ,politisches Erwachen“" in das Jahr 1917, als er, zusammen mit anderen Studenten, seine Registrierung für den „Vaterländischen Hilfsdienst" verweigert habe. In dieser Zeit sei er das erste Mal mit sozialistischer Literatur bekannt geworden, und er habe auf seinen ersten Referendariatsstationen in den Jahren 1919 und 1920 im Saarland als „Roter" und "Radikalinski“ gegolten 219.

Seiner Karriere, die Melsheimer nach der Doktorprüfung sowie der ersten und zweiten Staatsprüfung (1918 und 1921) antrat, tat dies keinen Abbruch. Ursprünglich habe er sich mit der Absicht getragen, eine akademische Laufbahn einzuschlagen, er sei jedoch wegen seiner „besonders guten Examina am Tage nach dem Assessorexamen ins [Preußische] Justizministerium berufen " worden, wo er zunächst als „Hilfsarbeiter" tätig war 220 . Am 1. Mai 1924 zum Landgerichtsrat am Landgericht I in Berlin ernannt, war er auch weiterhin mit nur kurzen Unterbrechungen im preußischen Justizministerium tätig, wo er am 1. November 1932 zum Oberjustizrat avancierte 221 . Während seiner ersten Berliner Jahre betätigte er sich nicht politisch und trat erst am 23. Juni 1928 in die SPD ein 222. Melsheimers Begründung für diesen Schritt ist aufschlußreich, auch im Hinblick auf seinen weiteren Werdegang: „Der in den Berliner Ministerien der Weimarer Zeit ganz besonders herrschende ,Geheimrats-Geist' und mein opportunistisches Streben, Karriere zu machen und ,nicht aufzufallen', ließen den Gedanken, mich politisch

215 Nachruf des Ministerrats zum Tode Ernst Melsheimers, in: Neues Deutschland, 28. 3. 1960.

216 Pfefferkorn, Melsheimer; Kappelt, Braunbuch DDR, S. 299 f.; ders., Entnazifizierung, S. 125.

217 Lebenslauf Melsheimer, 4. 3. 1951, SAPMO, DY 30/IV 2/11/175, Bl. 371. Melsheimers Mutter sei jedoch „freiheitlich eingestellt" gewesen, habe sich als „überzeugte Demokratin“ bezeichnet und sei nach 1945 Sozialistin und Mitglied der Nationalen Front im Saarland geworden, ebenda.

218 Militärpaß Melsheimers, SAPMO, NY 4105/1, Bl. 15; vgl. Erklärung Melsheimers vom 6. 7. 1933, BADH, R 22 Pers. 68035.

${ }_{219}$ Lebenslauf Melsheimer, 4. 3. 1951, SAPMO, DY 30/IV 2/11/175, Bl. $371 \mathrm{f}$.

220 Lebenslauf Melsheimer, 18. 6. 1945, BAB, DP1 SE Nr. 3596, Bl. 747.

221 Personalbogen Melsheimers, BADH, R 22 Pers. 68055; die Ernennungsurkunden in: BAB, DP1 SE Nr. 3596, Bl. 1112, $1131 \mathrm{f}$.

222 So in seinem Lebenslauf vom 4. 3. 1951, SAPMO, DY 30/IV 2/11/175, Bl. 372; laut Lebenslauf vom 18.6.1945, BAB, DP1 SE Nr. 3596, Bl. 747, hatte er sich schon lange vor 1928 im sozialistischen Sinne betätigt, was unglaubwürdig erscheint. 
zu organisieren, nicht ernsthaft aufkommen (obwohl ich oft daran gedacht habe). [...] Erst als die ersten Sozialdemokraten (Siegfr[ied] Rosenfeld, Her[r]mann) auf dem Wege der Weimarer Kuhhandelspolitik in das Ministerium eingeschleust worden waren, entschloß ich mich, endgültig mit dem äußeren Schein des ,NurGelehrten', des unparteiischen, ,objektiven' Juristen zu brechen und ein für jeden erkennbar politischer Mensch zu werden“223. Demzufolge war ihm sein beruflicher Aufstieg wichtiger als das offene Eintreten für seine sozialistische Überzeugung; der Eintritt in die SPD erfolgte erst, als diese bei den Reichstagswahlen und den preußischen Landtagswahlen die besten Wahlergebnisse seit 1919 erzielte ${ }^{224}$ und eine SPD-Mitgliedschaft einer Karriere nicht länger abträglich zu sein schien. Als Parteigenosse nahm er Funktionen in seinem Bezirksverband wahr und trat darüber hinaus 1928 dem „Reichsbanner Schwarz-Rot-Gold“ und 1929 dem Republikanischen Beamtenbund bei ${ }^{225}$.

Nach Melsheimers eigener Darstellung wurde er in der Endphase der Weimarer Republik „zu einem begeisterten Anhänger der Idee der Einheitsfront“, woraufhin die von ihm geleitete Abteilung Steglitz der SPD als „oppositionell“ galt und sein Kollege Rosenfeld im Justizministerium von seiner Beförderung zum Oberjustizrat abgeraten habe. Die letzte rote und die letzte schwarz-rot-goldene Fahne in Steglitz hätten 1933 von seiner Wohnung geweht ${ }^{226}$. Während sein Engagement für die Einheitsfront nachträglich erfunden sein kann, ist sein Bekenntnis zur Sozialdemokratie mehrfach belegt. 1932 oder 1933 erklärte er seinen Austritt aus der "Vereinigung alter Marburger Arminen in Berlin“, die sich in ihren schriftlichen „Mitteilungen" äußerst nationalistisch, rassistisch und antisozialistisch geäußert hatte. All dies, so Melsheimer, lasse sich mit seiner „sozialistischen Weltanschauung nicht länger vereinbaren "227. Außerdem wurde er in zwei Denunziationsschreiben vom April 1933 als Jude und Sozialdemokrat bezeichnet, der an den Umzügen der SPD und des Reichsbanners teilgenommen sowie anläßlich von Wahlen und am Verfassungstag die "Dreipfeilchenfahne“ (des Reichsbanners Schwarz-Rot-Gold) gezeigt habe 228 .

Im Unterschied zu anderen leitenden Beamten 229 mußte Melsheimer das Justizministerium nach dem 30. Januar 1933 nicht verlassen. Daß er, wie er 1945 schrieb, „einmal verhaftet, aber alsbald wieder freigelassen “ 230 wurde, erscheint angesichts eines Schreibens des preußischen Justizministers Hanns Kerrl vom Mai 1933 unwahrscheinlich. Darin bezeichnet dieser Melsheimer als „ehrliche[n] Sozia-

223 Lebenslauf Melsheimer 4. 3. 1951, SAPMO, DY 30/IV 2/11/175, Bl. 372.

${ }^{224}$ Bei den Reichstagswahlen vom 20.5. 1928 erhielt die SPD 29,8\%, bei den preußischen Landtagswahlen vom selben Tag 29,0\% der Stimmen.

${ }^{225}$ Mitgliedsbuch Reichsbanner Schwarz-Rot-Gold, SAPMO, NY 4105/1, Bl. 2; Fragebogen betr. $\$ 4$ des Gesetzes und Nr. 3 der 1. Durchführungsverordnung vom 11.4. 1933, BADH, R 22 Pers. 68055.

${ }^{226}$ Lebenslauf Melsheimer 4. 3. 1951, SAPMO, DY 30/IV 2/11/175, Bl. 373.

${ }^{227}$ Melsheimer an Rechtsanwalt Brom, Vorsitzender der Vereinigung alter Marburger Arminen in Berlin, BAB, DP1 SE Nr. 3596, Bl. 1117 f. Die Abschrift des Briefes trägt auf der ersten Seite das Datum 6. 2. 1932, auf der letzten Seite das Datum 6.1.1933.

${ }^{228}$ Erich Böer an Gauleitung Berlin der NSDAP, 2. 4. 1933, R.R. Hinz an Reichsminister des Innern, 5. 4. 1933, BADH, R 22 Pers. 68055.

229 Siehe dazu Gruchmann, Justiz, S. 222-224.

${ }^{230}$ Lebenslauf vom 18.6. 1945, BAB, DP1 SE Nr. 3596, Bl. 747. 
list[en]“, der in seiner Naivität geglaubt habe, ,in der SPD als Sozialist wirken zu können“. Nunmehr sei er jedoch aus der SPD ausgetreten ${ }^{231}$, und Kerrl habe bei einer Unterhaltung mit Melsheimer „über den Irrtum der materialistischen Weltanschauung [...] die Überzeugung gewonnen, daß er diesen Irrtum völlig begriffen“ habe. Außerdem sah er in dem Oberjustizrat einen ,außerordentlich fähige[n] Jurist[en]", auf dessen Mitarbeit er nicht gern verzichten wollte. Kerrl hoffte daher, „daß in ihm ein ebenso treuer Mitkämpfer für die Bewegung erwachsen wird, wie es sein Bruder seit langen Jahren ist“"232. Melsheimer war nicht nur rechtzeitig vor ihrem Verbot am 22. Juni 1933 aus der SPD ausgetreten; er hatte Kerrl auch den Eindruck vermittelt, daß man ihn unter Umständen für die NSDAP gewinnen konnte 233 .

Wenngleich Melsheimer im Justizministerium verblieb, behielt er nicht seine Planstelle als Oberjustizrat, sondern wurde am 1. Juli 1933 zum Landgerichtsdirektor am Landgericht III in Berlin ernannt ${ }^{234}$. Beschäftigt in der für bürgerliches Recht zuständigen Abteilung IV, bearbeitete er im Justizministerium „Kostenund Stempelgesetzgebung" sowie "Zivilrechtliche Einzelsachen aus Berlin und Königsberg i.Pr. " ${ }^{235}$. Nach eigenem Bekunden erstellte er auf dieser Stelle im Zuge der "Verreichlichung“ des Justizwesens 1935/36 die "Reichskostenordnung“, in der das landesgerichtliche Gerichtskostenwesen vereinheitlicht wurde ${ }^{236}$. Zum 1. Oktober 1937 erfolgte schließlich - gegen seinen Willen - Melsheimers Versetzung an das Berliner Kammergericht, wo er bis 1945 als Kammergerichtsrat dem Zivilsenat 1a angehörte, der höchstrichterliche Entscheidungen in Angelegenheiten der freiwilligen Gerichtsbarkeit und des Kostenrechts traf237.

Die Versetzung war, wie Melsheimer es zutreffend darstellt, zwar eine Degradierung, aber sie ermöglichte immerhin eine berufliche Existenz an einem Gericht mit Renommee, ohne die Notwendigkeit, in politischen Verfahren urteilen zu müssen. Melsheimer, der gemeinsam mit seiner Frau Kontakt mit einem kleinen Kreis früherer Sozialdemokraten hielt und in Bedrängnis geratene Genossen sowie verfolgte Juden unterstützte ${ }^{238}$, trat nie der NSDAP bei, wohl aber dem RDB (1934), dem NSRB (1937) sowie der NSV (1938). Schließlich war er ab dem 22. Februar 1940 als Kreis-Rechtsberater der NSV tätig239. Diese Signale gegenüber dem Regime zeigen, wie weit Melsheimer zu gehen bereit war, um seinen

231 Der Austritt aus der SPD erfolgte am 28. 2. 1933: Fragebogen betr. $₫ 4$ des Gesetzes und Nr. 3 der 1. Durchführungsverordnung vom 11.4. 1933, BADH, R 22 Pers. 68055.

232 Kerrl an Böer, 26. 5. 1933, ebenda. Kerrl kannte Melsheimers älteren Bruder Rudolf, der Provinziallandtagsabgeordneter der NSDAP für Koblenz-Trier war.

233 Vgl. auch den Lebenslauf vom 4. 3. 1951, SAPMO, DY 30/IV 2/11/175, Bl. 373.

234 Personalbogen Melsheimers, BADH, R 22 Pers. 68055.

${ }^{235}$ Gruchmann, Justiz, Geschäftsverteilungsplan Reichs- und Preußisches Justizministerium, Stand vom 22. 10. 1934 , S. 1163.

${ }^{236}$ Lebenslauf vom 4. 3. 1951, SAPMO, DY 30/IV 2/11/175, Bl. $373 \mathrm{f}$.

${ }_{237}$ Vgl. Vermerk vom 24. 3. 1937, und Beurteilung Melsheimers, 23. 10. 1938, BADH, R 22 Pers. 68055.

238 Vgl. dazu die erhaltenen Lebensläufe Melsheimers, sein SED-Fragebogen vom 10.10. 1950 und seine eidesstattliche Versicherung vom 26. 7. 1945, BAB, DP1 SE Nr. 3596, Bl. 1056-1061, 672674. Da er auch Namen und Anschriften der von ihm unterstützten Personen nannte, waren die Angaben von der SED überprüfbar und sind daher glaubwürdig.

239 Personalbogen Melsheimers, Rechnungsamt beim Kammergericht an Kalkulatur des RJM, 28. 3. 1940, BADH, R 22 Pers. 68055. 
Posten nicht zu verlieren. Am Kammergericht selbst machte Melsheimer nicht nur eigenen Angaben zufolge aus seinen kritischen Ansichten über das Regime kein Hehl240 und traf dort anscheinend auf Sympathie; ja, Kammergerichtspräsident Heinrich Hölscher soll ihm persönlich geraten haben, Rechtsberater der NSV zu werden, „um nicht als alter SPD-Führer den Nazis mißliebig zu sein“241. Dies ist zu bedenken, wenn Senatspräsident Krieg Melsheimer als einen „der besten Mitglieder meines Senats" bezeichnete und ebenfalls bemerkte: „Ich glaube, daß M. jetzt dem heutigen Staat durchaus bejahend gegenübersteht." ${ }^{242}$ Auf dieser Beurteilung aufbauend, wurde er 1940 - wohl vom Kammergerichtspräsidenten zur Beförderung zum Reichsgerichtsrat vorgeschlagen. Die Begründung dazu bescheinigt zunächst Melsheimers fachliche Qualitäten, bevor sie ihn als „feste[n] Charakter mit anständiger Gesinnung und ausgeprägtem Pflichtgefühl, strebsam und selbstbewußt" charakterisiert. Seine SPD- und Reichsbanner-Mitgliedschaft werden genannt, im Anschluß daran aber auf seine Zugehörigkeit zu RDB, NSV und NSRB verwiesen, woraus auf seine den „nationalsozialistischen Staat durchaus bejahend[e]" Haltung geschlossen wird. Auch die Rechtsberatertätigkeit wird angeführt, um anschließend festzustellen: „Bei seinem ernsten geraden Charakter sehe ich darin ein Zeichen aufrichtiger Einsatzbereitschaft und glaube, daß Melsheimer an jeder Stelle tatkräftig und in vollem Maße dem Gedankengut des neuen Staates Rechnung tragen wird." 243 Es scheint, daß durch die übermäßige Betonung dieser untergeordneten Tätigkeit nur überdeckt werden sollte, daß Melsheimer nach wie vor nicht der NSDAP angehörte. Ziel des Vorschlags war, einen ausgewiesenen Fachmann zu befördern und dabei zu verhindern, daß seine SPD-Vergangenheit und seine Weigerung, in die Partei einzutreten, negativ zu Buche schlugen. Trotz dieser Begründung blieb die Beförderung indes aus.

Sofort nach dem Einmarsch der sowjetischen Truppen in Berlin stellte sich Melsheimer Anfang Mai 1945 „dem Kommandanten in Steglitz und Friedenau und dem kommandierenden General zur Verfügung " und nahm Verbindung zu den Antifa-Ausschüssen in beiden Stadtbezirken auf. Nach mehreren Rücksprachen mit dem Kommandanten von Friedenau unterzeichnete Melsheimer zunächst „vor dem russischen Gerichtsoffizier, Oberst Maschkow, auf der Kommandantur [seine] Verpflichtungserklärung“244 und wurde am 16. Mai „auf Befehl des Kommandanten der Stadt Berlin, Generaloberst Bersarin“ zum Oberstaatsanwalt des Bezirksgerichts Friedenau bestellt ${ }^{245}$. Damit erhielt er die Verantwortung für die Einrichtung des Gerichts. Voller Stolz berichtete Melsheimer dem Gene-

240 Vgl. Seibert, Beim Kammergericht, S. 97.

${ }^{241}$ Eidesstattliche Versicherung Melsheimers vom 26. 7. 1945, BAB, DP1 SE Nr. 3596, Bl. 672.

242 Beurteilung Melsheimers, 23. 10. 1938, BADH, R 22 Pers. 68055.

243 Begründung, nicht unterzeichnet, 1940, ebenda. Bereits Pfefferkorn, Melsheimer, S. 231, zitiert daraus; ebenfalls Werkentin, Richter und Ankläger, $\mathrm{S}$. $3 \mathrm{f}$.

${ }^{244}$ Melsheimer an Bürgermeister in Friedenau, 4. 6. 1945, BAB, DP1 SE Nr. 3596, Bl. 666. Die ersten russischen Panzer erschienen Ende April 1945 in den Straßen von Schöneberg und Friedenau, und ab dem 5. 5. 1945 wurde die neue Verwaltung dort aufgebaut: vgl. Wiedereingliederung Friedenau in Schöneberg, LAZ 2638.

245 Ausweis Melsheimers vom 20. 5. 1945, BAB, DP1 SE Nr. 3596, Bl. 344. Am 16. 5. 1945 fand eine Besprechung aller in Berlin eingesetzten Richter und Staatsanwälte bei Stadtkommandant Bersarin im Amtsgericht Lichtenberg statt: vgl. Benjamin, Von nun an, S. 105. Amos, Justizverwaltung, S. 13, schreibt unzutreffend, daß Melsheimer Staatsanwalt in Lichterfelde wurde. 
ralstaatsanwalt von Berlin, daß bei der Personalauswahl „von vornherein Faschisten oder verkappte Faschisten überhaupt nicht in Frage kamen “, und fügte hinzu: „So soll es auch in Zukunft bleiben. So muß es überall sein, wenn die neue deutsche Justiz vor dem Volke und der Welt bestehen soll." Während er damit jedoch nur sowjetische Forderungen erfüllte, ging er in seinem Brief an Maschkow erheblich weiter, indem er sich - wohl aus Karrieregründen - bei den Besatzern anbiederte: „Das Volk von Friedenau ist, wie die ganze Berliner Bevölkerung, der Roten Armee und dem großen Marschall Stalin von Herzen dankbar für all das, was bisher in so umfangreichem Maße für die Ernährung, für die Sauberkeit der Stadt und die Rückkehr zum normalen Leben geschehen ist."246 Unmittelbar nach der Verkündung des KPD-Aufrufs am 11. Juni 1945 beteiligte er sich an der KPDGründung in Friedenau, wo er die Funktion des Agitations- und Propagandaleiters erhielt ${ }^{247}$. Daß der alte Sozialdemokrat nicht den SPD-Gründungsaufruf vom 15. Juni abwartete, deutet darauf hin, daß die Entscheidung für die Kommunisten schon länger feststand. Auch dabei dürfte der Gedanke, eine führende Position im Berliner Justizwesen zu erhalten, eine erhebliche Rolle gespielt haben.

Seine „Bewährungsprobe“ bestand Melsheimer bereits im Juni 1945, als er in einem der ersten NS-Prozesse vor einem deutschen Gericht die Anklage vertrat. Oberpostinspektor Karl Kieling, NSDAP-Mitglied, hatte am 24. April 1945 ein Handgemenge zwischen einem uniformierten Parteigenossen und einem "Zivilisten“ beobachtet. Zur Verteidigung des Parteigenossen schoß Kieling den „Zivilisten" nieder, der an den Folgen der Verletzung starb. Nachdem Melsheimer die Angelegenheit am 2. Juni mitgeteilt worden war, beantragte er beim Bezirksrichter die Voruntersuchung; tags darauf forderte ein russischer Oberst die Festnahme des Täters, und Melsheimer kam der Aufforderung persönlich nach ${ }^{248}$. Die Besatzungsmacht entschied einige Tage später, den Fall von dem zuständigen deutschen Gericht aburteilen zu lassen249. Nach fünfstündiger Verhandlung des Falles am 27. Juni im Rathaus Friedenau verurteilte das Gericht Kieling gemäß dem Antrag Melsheimers zum Tode250.

Ab Anfang Juli 1945 übernahmen amerikanische Truppen die Befehlsgewalt in den ihnen zugesprochenen Bezirken Berlins, unter anderem am 12. Juli 1945 in Friedenau251. Da die Amerikaner die Berliner Gerichtsorganisation aus der Zeit vor 1933 wiederherstellen wollten, lösten sie das Bezirksgericht Friedenau auf und übertrugen dessen Funktionen wieder auf das Amtsgericht Schöneberg252. Als diese Entscheidung auf einer Dezernentensitzung am 16. Juli mitgeteilt wurde,

246 Melsheimer an Generalstaatsanwalt, 26. 5. 1945; Melsheimer an Maschkow, 25. 5. 1945, BAB, DP1 SE Nr. 3596, Bl. 773, 774.

247 Melsheimer an Generalstaatsanwalt in Berlin, 14.6. 1945, ebenda, Bl. $749 \mathrm{f}$.

${ }^{248}$ Zum Tathergang Bericht Melsheimers, 5. 6. 1945, BAB NY 4105/3, Bl. 174-177, Melsheimer an Oberst Maschkow, 3. 6. 1945, BAB, DP1 SE Nr. 3596, Bl. 756; Scholz, Berlin, S. 83.

249 Melsheimer an Generalstaatsanwalt in Berlin, 14. 6. 1945, BAB, DP1 SE Nr. 3596, B1. 749.

250 Melsheimer an Generalstaatsanwalt in Berlin, 28.6. 1945, ebenda, Bl. 726. Auch die inzwischen eingetroffene amerikanische Besatzungsmacht beschäftigte der Fall, der noch mehrere Instanzen durchlief, bis Kieling am 21. 8. 1946 hingerichtet wurde: vgl. Scholz, Berlin, S. 83-87; Günther, Kammergericht, S. 73-75.

251 Aktennotiz, Berlin-Friedenau, 12. 7. 1945, LAZ 2650.

252 Vgl. Scholz, Berlin, S. 44; die Angabe bei Wetzel, Office, S. 714, dessen Funktionen seien auf das Amtsgericht Steglitz übergegangen, ist unzutreffend. 
erhob Melsheimer zunächst heftigen Einspruch ${ }^{253}$; nachdem er eingesehen hatte, daß Widerstand zwecklos war, ging es ihm darum, das Friedenauer Gerichtspersonal, das nicht übernommen werden sollte, unterzubringen. Die größte Sorge galt freilich der eigenen Person. Am 17. Juli empfahl er sich dem amerikanischen Kommandanten in Schöneberg als Oberstaatsanwalt und strich dabei seine Verdienste über Gebühr hervor. Unter anderem bezeichnete er sich als "the only judge in Berlin, perhaps in whole Germany [sic], who actively fought against the Nazis before Hitler came“. Er sei der einzige Jurist, der trotz seiner SPD-Mitgliedschaft aufgrund seiner fachlichen Qualitäten nach 1933 in einem deutschen Ministerium habe verbleiben können, bis er wegen seiner kompromißlosen $\mathrm{Hal}$ tung gegenüber dem Regime schließlich doch entlassen worden sei. Daß er am Kammergericht sein weiteres Auskommen gefunden hatte, verschwieg er bezeichnenderweise 254 .

Freilich bestand für Melsheimer nicht die Gefahr, arbeitslos zu werden - im Gegenteil: Ihm wurde zur gleichen Zeit der Vorsitz einer Strafkammer am Berliner Stadtgericht angeboten ${ }^{255}$. Dennoch hätte er eine leitende Stellung im Gerichtswesen des amerikanischen Sektors bevorzugt. In einem Schreiben an den stellvertretenden Berliner Generalstatsanwalt Günter Greffin legte er dar, daß dies sicherlich auch den Intentionen der zentralen, im Ostsektor ansässigen Berliner Justizorgane entgegenkäme, "weil so absolut[e] Gewähr für ein gemeinsames Handeln und einen gemeinsamen Aufbau der neuen deutschen Justiz gegeben wäre"256; zudem, so äußerte er sich einige Tage darauf, entspräche dies „auch der Ansicht und den Wünschen meiner pol[itischen] Freunde" 257 . Waren seine Bemühungen also allein auf die übergeordnete, (partei-)politische Überlegung zurückzuführen, im Justizwesen des amerikanischen Sektors einen Fuß in der Tür zu behalten, oder rechnete Melsheimer mit besseren Aufstiegschancen im Westen? Anhand seiner erhaltenen Briefe vom Juli 1945 läßt sich dies nicht eindeutig beantworten. Daraus geht indes hervor, daß er nicht bereit war, die Kommunistische Partei zu verlassen; andererseits wollte er sich nicht aufgrund seiner Parteizugehörigkeit „der Gefahr aussetzen, von den Amerikanern abgelehnt oder auf einen minderwichtigen Posten abgedrückt zu werden"258. Am 23. Juli richtete er ein weiteres Bewerbungsschreiben an den für Schöneberg zuständigen Gerichtsoffizier ${ }^{259}$, das jedoch - wie die anderen diesbezüglichen Bemühungen auch - nicht zu der gewünschten Einstellung führte 260 . Melsheimer erhielt daraufhin im August eine Oberstaats-

253 Protokoll über dic Sitzung vom 16. 7. 1945 betr. Übergabe von Friedenau an Schöneberg, LAZ 2586.

${ }^{254}$ Melsheimer an den Kommandanten in Schöneberg, 17. 7. 1945, BAB, DP1 SE Nr. 3596, Bl. 696698.

255 Vgl. Greffin an Melsheimer, o.D.; Melsheimer an Greffin, 18. 7. 1945, BAB, DP1 SE Nr. 3596, Bl. $687,690 f$.

256 Melsheimer an Greffin, 19. 7. 1945, ebenda, Bl. 686.

257 Melsheimer an Greffin, 21. 7. 1945, ebenda, Bl. 679.

258 Melsheimer an Greffin, 19. 7. 1945, ebenda, Bl. 686.

259 Melsheimer an Scheinemann, 23. 7. 1945, ebenda, Bl. 675.

260 Nach Bukofzer, Justiz, lehnte die amerikanische Kommandantur ab, da die Oberstaatsanwaltsstelle in Schöneberg bereits besetzt gewesen sei; aber auch andere Gründe hätten gegen Melsheimers Weiterbeschäftigung gesprochen. In einem Vermerk „Organisation und Besetzung der Berliner Justiz“, SAPMO, NY 4182/1118, Bl. 1-3, vom Juli/August 1945 heißt es hingegen: „Die 
anwaltsstelle am Amtsgericht Berlin-Mitte, wo er fast einen zweiten NS-Prozeß geführt hätte, wenn die sowjetische Besatzungsmacht das Verfahren nicht in letzter Minute noch an sich gezogen hätte ${ }^{261}$. Damals war er jedoch bereits von seiner Partei zur Mitarbeit in der DJV vorgesehen ${ }^{262}$. Die endgültige Einweisung in seine Abteilungsleiterstelle erfolgte schließlich am 13. September 1945, nachdem er kurz zuvor bereits den Dienst in der DJV angetreten hatte 263 .

Melsheimer war somit kein reiner Karrierist, der politische Überzeugungen und politische Freunde zugunsten seiner Laufbahn bedenkenlos geopfert hätte. Denn er trat nicht in die NSDAP ein, hielt Kontakt zu ehemaligen SPD-Genossen und schützte verfolgte Juden. Er war jedoch auch kein Idealist, der sich bis zuletzt zu seinen Überzeugungen bekannt und dafür erhebliche berufliche Nachteile in Kauf genommen hätte. Insgesamt erscheint er eher als Opportunist, der sich zu präsentieren wußte und bereit war, dem Regime so weit entgegenzukommen, daß er zunächst seine Stellung im Justizministerium behielt und auch nach 1937 an einem der renommiertesten deutschen Gerichte verbleiben konnte. Hinzu kam, daß er als hochqualifizierter Jurist um seine Qualitäten wußte. Er sah sich somit nach den Jahren des Dritten Reiches für eine leitende Stellung im Justizwesen prädestiniert, sei es im amerikanischen, sei es im sowjetischen Sektor. Seine frühzeitige Entscheidung für die KPD machte er zwar nicht rückgängig; aus Sicht der SED hatte er 1951 jedoch seine „kleinbürgerliche[n] Überlieferungen, die sich in einer übermäßigen Empfindlichkeit, einem spießerhaften Geltungsbedürfnis in der Öffentlichkeit ausdrücken " 264 , noch nicht überwunden.

Seit seiner Zeit als Oberstaatsanwalt in Friedenau war Melsheimer mit Hilde Benjamin, die die gleiche Position in Steglitz bekleidete, eng befreundet ${ }^{265}$. Dies verwundert zunächst angesichts des völlig anderen, von politischer Verfolgung gekennzeichneten Lebenswegs der späteren Justizministerin ${ }^{266}$. Geboren 1902 als Tochter des kaufmännischen Angestellten Walter Lange, wuchs sie seit ihrem siebten Lebensjahr in Berlin auf, wo sie nach Privatschule, Lyzeum und Studienanstalt 1921 das Abitur ablegte267. Geprägt von einem politisch liberal eingestellten Elternhaus - der Vater gehörte der DDP an ${ }^{268}$ - engagierte sie sich, wie viele ihrer Altersgenossen, im Wandervogel, ohne sich organisatorisch zu binden ${ }^{269}$. Von 1921 bis 1924 studierte sie Rechtswissenschaften in Berlin, Heidelberg und Hamburg mit dem Ziel, Rechtsanwältin zu werden; das Referendariat beendete sie

Gründe sind klar: Die Amerikaner und Engländer wollen keinen KPD-Mann in einem leitenden Posten haben!“

261 Vermerk Melsheimers, 8.9.[1945], SAPMO, NY 4182/1118, Bl. 55.

262 Siehe Bericht von Bertz über Sitzung im Amtsgericht Wedding am 21. 8. 1945, in: Amos, Justizverwaltung, S. 215.

263 Besetzungsliste DJV, 17. 10. 1945, BAB, DP 1 VA Nr. 1, Bl. 21; Kleikamp an Melsheimer, 6. 9. 1945, Melsheimer an Schiffer, 7. 9. 1945, BAB, DP1 SE Nr. 3596, Bl. 650, 1094.

264 Protokoll der Sonderkommission, 14. 3. 1951, SAPMO, DY 30/IV 2/11/175, Bl. 370.

${ }^{265}$ Vgl. u. a. Benjamin, Aus den ersten Jahren, S. 387.

266 So u. a. Feth, Benjamin, S. 81; Werkentin, Benjamin, S. 4; dieser datiert die Anfänge der Freundschaft auf deren gemeinsame Zeit in der DJV.

267 Vgl. Feth, Benjamin, S. 19f.; Lebenslauf Benjamin, 24. 4. 1951, SAPMO, DY 30/IV 2/11/171, Bl. 160.

268 Vgl. Brief Benjamins, 17. 2. 1966, zit. bei Sorgenicht, Benjamin, S. 9; Protokoll der Sonderkommission, 26. 4. 1951, SAPMO, DY 30/IV 2/11/171, Bl. 159.

269 Vgl. Feth, Benjamin, S. $20 \mathrm{f}$. 
1928 in Berlin. Benjamins nachträglichen Äußerungen zufolge war bei ihrer Berufswahl der Wunsch ausschlaggebend, „als Rechtsanwalt allen, denen Unrecht geschah, helfen zu können“. Sie nannte auch das Vorbild Karl Liebknecht, über dessen und Rosa Luxemburgs Ermordung im Jahre 1919 sie empört gewesen sei $^{270}$. Ihr politisches Interesse erwachte freilich erst mit Beginn ihres Studiums, als sie anfing, sich "mit den Problemen des Sozialismus zu befassen“. Dabei habe es sich, wie Benjamin 1951 schrieb, um eine "gefühlsmäßige[.] Stellungnahme“ gehandelt; ihre Haltung sei „entschieden beeinflußt [gewesen] vom ,bürgerlich schlechten Gewissen“" 271 . In ihrem Studium, das sie sich teilweise selbst verdienen mußte, da die Inflation das väterliche Vermögen vernichtet hatte, sei sie in Kontakt mit Arbeitern und sozialistischen Studentengruppen ${ }^{272}$ gekommen. In diesen Jahren befaßte sich Hilde Lange ebenfalls mit Fragen des Strafvollzugs und begann 1924 mit einer Dissertation aus diesem Themengebiet, die sie aber nach ihrer Heirat nicht fortsetzte273. Für ihr soziales Engagement sprach, daß sie während ihrer juristischen Ausbildung in Erziehungsheimen, auf dem Jugendamt, bei der Jugendgerichtshilfe und in einem Berliner Frauengefängnis arbeitete ${ }^{274}$. Schließlich trat sie 1924 in Berlin-Steglitz in die SPD ein, "ohne ein ideologisches und theoretisches Wissen zu besitzen“275. Bei diesem Schritt sei sie von einem eher „unbestimmte[n] Suchen“ und dem „Bedürfnis, aus der Vereinzelung heraus zu kommen [sic]“ bestimmt gewesen; sie habe kaum mehr getan, als ihre Beiträge zu zahlen ${ }^{276}$. Insgesamt war Hilde Lange bis 1925 eine zwar sozial, jedoch wenig politisch engagierte angehende Juristin, die zudem kaum über menschliche Kontakte verfügte.

All dies änderte sich mit ihrer engen Beziehung zu Georg Benjamin, einem kommunistischen Arzt aus einer großbürgerlichen jüdischen Familie, dem Bruder des bekannten Philosophen und Schriftstellers Walter Benjamin ${ }^{277}$. Nachdem sie durch Georg Benjamin in nähere Berührung mit der KPD gekommen war, trat sie bereits Ende 1925 wieder aus der SPD aus. Nach ihrer Heirat am 26. Februar 1926 orientierte sie sich in politischer Hinsicht stark an ihrem Mann, so daß sie im November 1927 schließlich in die KPD eintrat. Der Einfluß Georg Benjamins auf die nach Orientierung suchende 24jährige Referendarin kann ihrer eigenen Aussage nach kaum überschätzt werden: „Ich stand menschlich und politisch stark unter dem Einfluß der Überlegenheit meines Mannes; wenn ich etwas scharf formuliere, könnte ich sagen, daß er für mich mit der Partei identisch war, jedenfalls mein Ver-

270 Brief Benjamins, 17. 2. 1966, zit. bei Sorgenicht, Benjamin, S. 9; nachträglich berichtete sie auch von einer "starken naturwissenschaftlichen Neigung" und daß sie sich erst unmittelbar bei der Immatrikulation für das Jura-Studium entschieden habe: vgl. Feth, Benjamin, S. 23.

271 Lebenslauf Benjamin, 24. 4. 1951, SAPMO, DY 30/IV 2/11/171, Bl. 161.

272 Ebenda; Feth, Benjamin, S. 23, schreibt irrtümlicherweise, daß sie dem Sozialistischen Studentenbund beigetreten sei.

273 Benjamin, Georg Benjamin, S. 189.

${ }^{274}$ Lebenslauf Hilde Benjamin, 19. 8. 1945, BAB, DP1 VA Nr. 6827, Bl. 4; vgl. Feth, Benjamin, S. 37.

275 Protokoll der SED-Sonderkommission, 26. 4. 1951, SAPMO, DY 30/IV 2/11/171, Bl. 158.

276 Hilde Benjamin, Bemerkungen zu meinem Lebenslauf, SAPMO, DY 30/IV 2/11/171, Bl. 163; Lebenslauf Benjamin, 24. 4. 1951, ebenda, Bl. 161.

$277 \mathrm{Zu}$ seiner Biographie siehe Benjamin, Georg Benjamin. 
hältnis zur Partei wesentlich über ihn ging." 278 In ihren frühen Ehejahren war Hilde Benjamin dann auch - gemeinsam mit ihrem Mann - politisch für die KPD tätig und übernahm verschiedene Funktionen im Rahmen ihrer Parteiarbeit ${ }^{279}$.

Die Politik bestimmte nicht nur die private, sondern auch die berufliche Existenz von Hilde Benjamin, die als eine der wenigen Juristinnen ihrer Zeit im April 1929 zur Rechtsanwaltschaft vor den Berliner Landgerichten zugelassen wurde. Unmittelbar nach Eröffnung ihrer Kanzlei im Wedding vertrat sie Arbeiter, die im Zusammenhang mit den Berliner Unruhen von Anfang Mai 1929 wegen Widerstands gegen die Staatsgewalt oder Landfriedensbruchs angeklagt wurden. Wenngleich sie ebenfalls eine Angeklagte im Prozeß gegen die Mörder Horst Wessels verteidigte, war sie insgesamt weniger in politischen als in arbeitsrechtlichen Verfahren aktiv. Finanziert von der "Roten Hilfe Deutschlands“, trat sie im Auftrag der kommunistischen Gewerkschaft RGO vor dem Landes- und dem Reichsarbeitsgericht auf, um Arbeiter zu unterstützen, die ihre Entlassung gerichtlich anfochten ${ }^{280}$. „Wenn ich an diese Zeit zurückdenke“, so Benjamin 1965, „so muß ich doch sagen, daß gerade diese Tätigkeit auf dem Gebiet des Arbeitsrechts in einer Verbindung mit dem revolutionären Arbeiter, mit den roten Betriebsräten von Berlin eine Zeit war, die mich sehr stark gebildet und geformt hat." Erst als Rechtsanwältin und in ihrer Tätigkeit für die RGO sei sie „zum bewußten Marxisten" geworden281. Obgleich diese für die Öffentlichkeit gedachten Aussagen quellenkritisch zu betrachten sind, ist es sehr plausibel, daß ihre sozialistische Einstellung sowie ihr späteres Denken in Freund-Feind-Schemata durch ihre Erfahrungen mit den Klassenunterschieden und den Klassenkonflikten der Weimarer Zeit nachhaltig geprägt wurden 282 .

Nach der Machtübernahme durch Hitler wurde gegen Hilde Benjamin am 6. Mai 1933 aufgrund des Gesetzes über die Zulassung zur Rechtsanwaltschaft ein Vertretungsverbot erlassen ${ }^{283}$. Im Unterschied zu ihrem Mann, der im April 1933 in "Schutzhaft" genommen worden war und erst Ende Dezember aus dem Konzentrationslager Sonnenburg entlassen wurde, konnte sich Hilde Benjamin der Verhaftung entziehen. Anfang 1934 wurde sie, dank ihrer russischen Sprachkenntnisse und durch Vermittlung des Rote-Hilfe-Anwalts Eduard Alexander, Mitarbeiterin in der Rechtsabteilung der sowjetischen Handelsvertretung, die sie insbesondere mit der Führung von Schiedsgerichtssachen am deutsch-russischen Schiedsgericht betraute. Am 30. September 1936 mußte sie „wegen Verringerung der Arbeit" aus ihrem festen Anstellungsverhältnis ausscheiden, war jedoch noch bis 1939/40 in freier Mitarbeit als Prozeßbevollmächtigte für ihren früheren Arbeitgeber tätig. Anfang $1937 \mathrm{kam}$ sie als Buchhalterin bei einer jüdischen Konfektionsfirma unter - eine Tätigkeit, die mit der Liquidation des Betriebes am 31. März 1939 endete. Danach beendete sie ihre Berufstätigkeit und konnte mit

278 Hilde Benjamin, Bemerkungen zu meinem Lebenslauf, SAPMO, DY 30/IV 2/11/171, Bl. 163; vgl.

Benjamin, Georg Benjamin, S. 185.

279 Vgl. ebenda, S. 185, 189 und Lebenslauf Benjamin, SAPMO, DY 30/IV 2/11/171, Bl. 161.

${ }_{280} \mathrm{Zu}$ Benjamins Tätigkeit als Anwalt vgl. Feth, Benjamin, S. 31-40.

281 Rundfunkinterview mit Hilde Benjamin, BAB, DP1 VA Nr. 6834, Bl. 62f. Vgl. auch Feth, Benja$\min$, S. 37.

282 Vgl. ebenda, S. 234.

283 Brentzel, Machtfrau, S. 60-62. 
der Begründung, den Haushalt ihrer alten Eltern führen zu müssen, ihr Arbeitsbuch schließen und sich somit einer Arbeitsverpflichtung im Dritten Reich entziehen 284 .

Hilde Benjamin hatte ihren Mann nach dessen Rückkehr aus dem KZ in seiner illegalen Tätigkeit mit Übersetzungen aus ausländischen Zeitungen und Schreibmaschinenarbeiten unterstützt, bis dieser im Mai 1935 erneut verhaftet wurde. Im November 1936 folgte seine Verurteilung zu sechs Jahren Zuchthaus. Nach Verbüßung seiner Haft im Mai 1942 ergriff ihn erneut die Gestapo, die ihn im August 1942 ins KZ Mauthausen überführte, wo er ermordet wurde 285 . Abgesehen davon, daß sie Kontakte zu kommunistischen Genossen hielt, war Hilde Benjamin seit der Verhaftung ihres Mannes nicht im kommunistischen Widerstand aktiv. Dies hing nach ihrer eigenen Aussage damit zusammen, daß ihr Verhältnis zur KPD wesentlich über Georg Benjamin ging. Außerdem besaß für sie die Sorge um ihren 1931 geborenen Sohn Michael (der als „Mischling“ besonders gefährdet war) Priorität; sie habe, wie sie selbstkritisch einräumte, ,also letzten Endes Persönliches über die Partei“ gestellt. Rückblickend formulierte sie: „Wenn ich auch, seitdem ich wieder allein war, also seit 1936 [sic], Schritt für Schritt - notgedrungen politisch selbständiger und von meinem Mann unabhängiger wurde, so stand ich doch auch nach 1945 noch lange unter dem Eindruck, daß ein großer Teil des Vertrauens, das die Partei mir entgegenbrachte, zurückzuführen war auf Georg Benjamin." ${ }^{286}$ Hilde Benjamins Beziehung zu ihrem Mann und zu ihrer Partei waren für sie untrennbar miteinander verknüpft: Hatte sie zur Partei erst durch Georg Benjamin gefunden, so war ihr Ansehen in der Partei erst durch ihn begründet worden. Nach dessen Tod und nach dem Ende des Dritten Reiches sah sie in ihrem Engagement für die Partei eine Verpflichtung dem Toten gegenüber. Die Partei wiederum ging ihr über alles und gab ihrem Leben den nötigen Halt: „Jetzt“, so schrieb sie 1951, „steht die Partei in meinem Leben an erster Stelle. Es gibt keine Bindung, keine Beziehung, die dem vorgingen. Von meinem Verhältnis zu meinem Jungen kann ich wohl sagen, daß unsere stärkste Bindung in unserer $\mathrm{Ge}-$ meinsamkeit in der Partei liegt." 287

Indem sie in den Jahren nach 1935 wieder ihren Mädchennamen Lange annahm, konnte sie sich dem Zugriff der Gestapo entziehen und das Dritte Reich bei ihren Eltern in Berlin-Steglitz überleben ${ }^{288}$. Als überzeugte Kommunistin stellte sie sich nach der Besetzung des Bezirks durch die Rote Armee Ende April/Anfang Mai 1945 der neuen Bezirksverwaltung zur Verfügung, und der sowjetische Kommandant erteilte ihr am 12. Mai den Auftrag, in Steglitz das Gericht wiederaufzubauen. Ähnlich wie Melsheimer, wählte sie drei unbelastete Richter aus, die am 14. Mai vom Kommandanten eingesetzt wurden. Sie selbst wurde zum Ober-

${ }^{284} \mathrm{Zu}$ Benjamins beruflicher Tätigkeit im Dritten Reich ebenda, S. 43, 44f., sowie ihre Lebensläufe vom 19. 8. 1945, BAB, DP1 VA Nr. 6827, Bl. 4, und vom 24. 4. 1951, SAPMO, DY 30/IV 2/11/ 171, Bl. 160 f.

285 Vgl. Benjamin, Georg Benjamin, S. 238, 290.

${ }^{286}$ Hilde Benjamin, Bemerkungen zu meinem Lebenslauf, SAPMO, DY 30/IV 2/11/171, Bl. 164.

287 Hilde Benjamin, Bemerkungen zu meinem Lebenslauf, SAPMO, DY 30/IV 2/11/171, Bl. 165; vgl. dazu Brentzel, Machtfrau, S. $117 \mathrm{f}$.

288 Vgl. Schöneburg, Berger, S. 469; Feth, Benjamin, S. 43. 
staatsanwalt ernannt ${ }^{289}$. Neben ihrer Tätigkeit am Gericht beteiligte sie sich seit Juni 1945 am Wiederaufbau der KPD in Steglitz ${ }^{290}$. Als die Amerikaner in ihrem Sektor die alte Berliner Gerichtsorganisation wiederherstellen wollten, stand auch ihre Stelle zur Disposition ${ }^{291}$. Benjamin blieb vorläufig noch im Amt, so daß der Generalstaatsanwalt bei dem von den Amerikanern neu gebildeten Landgericht II sie förmlich entlassen mußte, damit sie im September 1945 als Vortragender Rat in der Personalabteilung der DJV ihre Tätigkeit aufnehmen konnte ${ }^{292}$.

Die Lebenswege von Hilde Benjamin und Ernst Melsheimer weisen beachtliche Unterschiede auf: hier die Anwältin der Arbeiter, dort der Ministerialbeamte im Justizministerium, hier die vom Schicksal Geschlagene, im Dritten Reich Verfolgte, dort der Geschickte, eher Angepaßte, auch unter dem Nationalsozialismus gut Gestellte, hier die glühende Kommunistin, dort der Ehrgeizige, Geltungsbedürftige, politisch zwischen Sozialdemokratie und Kommunismus Schwankende. Diese Lebenswege kreuzten sich jedoch unter Bedingungen, die eine enge Zusammenarbeit der beiden nahelegten: 1945 in zwei benachbarten Berliner Bezirken mit der gleichen Aufgabe betraut, zählten sie zu den wenigen kommunistischen Richtern und Staatsanwälten mit einer juristischen Ausbildung. Dies prädestinierte sie aus der Sicht der KPD für die DJV, wo sie zunächst, abgesehen von Bertz, Gentz ${ }^{293}$ und Otto Türksch ${ }^{294}$, die einzigen Kommunisten im höheren Dienst waren und angesichts der Übermacht der Nicht-Kommunisten geradezu konspirative Kontakte pflegten, um die Linie ihrer Partei durchzusetzen ${ }^{295}$. Die Notwendigkeit ständiger Abstimmung untereinander wirkte sich auch auf ihre persönlichen Beziehungen aus. Insofern band die Gegenwart sie enger aneinander, als die Vergangenheit sie trennen konnte.

\section{Die Zusammensetzung des höheren Dienstes in der DJV}

Auch wenn sie die Abteilungsleiterstellen der DJV nicht mit Kommunisten besetzen konnte, wollte die KPD-Führung doch maßgeblichen Einfluß auf die Stellenbesetzungen nehmen. Ulbricht hatte am 17. August diesen Anspruch mit den Worten bekräftigt: „Über die Besetzung der Abt[eilungs]-Leiterposten entscheidet nicht Dr. Schiffer." Dieser wollte jedoch seine personalpolitischen Entschei-

$289 \mathrm{Vgl}$. Benjamin, Von nun an, S. $103 \mathrm{f}$.

290 Lebenslauf Benjamin, 24. 4. 1951, SAPMO, DY 30/IV 2/11/171, Bl. 162.

291 Siehe das Papier „Organisation und Besetzung der Berliner Justiz“, SAPMO, NY 4182/1118, Bl. 2.

292 Generalstaatsanwalt beim Landgericht Berlin an Benjamin, 17. 9. 1945, BAB, DP1 VA Nr. 6827,

Bl. 11; zum 19. 9. 1945 wurde sie förmlich in ihre Stelle eingewiesen, Besetzungsliste DJV, 17. 10.

1945, BAB, DP 1 VA Nr. 1, Bl. 21. Sie war jedoch schon seit August in der DJV tätig.

293 Über die Parteizugehörigkeit von Gentz besteht Unklarheit: Bertz bezeichnete ihn in seinem Bericht vom 23. 8. 1945 an das KPD-Sekretariat als der KPD politisch nahestehend (in: Amos, Justizverwaltung, S. 215). Polak schrieb am 23.3. 1946: „Er [Gentz] trat nach dem Sturz Hitlers der KPD bei, wird aber aus taktischen Gründen nicht in einer Betriebs- und Ortsgruppe geführt." (SAPMO, NY 4182/1185, Bl. 42.) Gentz sagte gegenüber einer Parteiüberprüfungskommission im Frühjahr 1951 aus, „daß ihm von den Genossen nahegelegt worden sei, aus Gründen der Zusammenarbeit mit dem bürgerlichen Minister Dr. Schiffer aus der Partei [der KPD] auszuscheiden“ (SAPMO, DY 30 IV 2/11/172, Bl. 247).

${ }^{294}$ Türksch wurde aufgrund seiner Russisch-Kenntnisse als Dolmetscher und persönlicher Referent von Schiffer eingestellt; vgl. Türksch an ZK der KPD, 3.1. 1946, SAPMO, NY 4182/1119, Bl. 1-4, und Amos, Justizverwaltung, S. $14 \mathrm{f}$.

295 Vgl. Nathan, Aus der Geschichte der zentralen Justizverwaltung, BAB, DP1 VA Nr. 6832, Bl. 7. 
dungen weitgehend autonom und nur in Absprache mit der SMAD treffen. Gegenüber Bertz erklärte er sich zwar bereit, die Personalabteilung seinem ersten Stellvertreter - also Bertz - zu unterstellen, weigerte sich jedoch, als Leiter der Abteilung einen Kommunisten auszuwählen. Auch Melsheimer und Gentz sollten nach Schiffers Willen keine Abteilung leiten. Schließlich lehnte er auch den Vorschlag von Bertz ab, Hilde Benjamin zu dessen persönlicher Mitarbeiterin zu bestellen. Nach einer Sitzung mit den kommunistischen Vertretern am 21. August erklärten Melsheimer und Benjamin, daß sie auf eine Mitarbeit in der DJV verzichten wollten, wenn Schiffer seine Vorstellungen durchsetze. Bertz wandte sich daraufhin an das Sekretariat des KPD-Zentralkomitees, mit der Bitte, „diese Vorgänge an anderer Stelle [also bei der SMAD] zu behandeln und eine Entscheidung im Sinne unserer Vorschläge [...] herbeizuführen“296. Die Entscheidung, die schließlich herbeigeführt wurde - ob unter Einschaltung der SMAD ist nicht bekannt -, beinhaltete einen Kompromiß, der weitgehend zugunsten Schiffers ausfiel: Melsheimer wurde Leiter der Abteilung V (Gesetzgebung), Gentz erhielt zunächst keine Abteilungsleiterstelle, ein Parteiloser kam an die Spitze der Personalabteilung, und ein persönlicher Mitarbeiter für Bertz wurde nicht vorgesehen. Als Zugeständnis Schiffers muß schließlich noch die Besetzung der Referentenstelle in der Personalabteilung mit Hilde Benjamin gewertet werden ${ }^{297}$.

Dies blieb nicht die einzige Personalangelegenheit, über die es 1945 zum Konflikt kam. Abgesehen vom ehemaligen preußischen Justizminister Schmidt, war Schiffer bestrebt, Oberstaatsanwalt Fuhrmann in die DJV zu übernehmen. Anfänglich schien dies zu gelingen, und dieser nahm sogar an einer internen Besprechung am 3. September 1945 teil298. Man konnte ihm zwar keine NSDAP-Mitgliedschaft nachweisen, Benjamin und Melsheimer, für die er ein „Vertreter der alten reaktionären Juristenschicht " 299 war, verhinderten jedoch, daß er in eine Planstelle eingewiesen wurde. Weitere Erfolge verbuchten sie im Hinblick auf den ehemaligen Oberlandesgerichtspräsidenten von Königsberg, Hugo Holthöfer ${ }^{300}$, und Kammergerichtspräsident Heinrich Hölscher, die Schiffer ebenfalls als Mitarbeiter vorgesehen hatte: Holthöfer wiesen sie nach, daß er einen Antrag auf Aufnahme in die NSDAP gestellt hatte, und bei Hölscher, der kein Parteimitglied geworden war, reichte ein Verweis auf dessen Position aus, in der er für „die Strafrechtspolitik der Hitlerjustiz" mitverantwortlich geworden sei301. In den Auseinandersetzungen um die Stellenbesetzung in der DJV lassen sich jedoch auch Erfolge Schiffers nachweisen. Beispielsweise verhinderte er, daß der Kommunist und spätere ADN-Korrespondent Max Kahane, den Bertz vorgeschlagen hatte, als

296 Dieser Abschnitt beruht auf den Darlegungen von Bertz gegenüber dem Sekretariat der KPD, 23. 8. 1945, in: Amos, Justizverwaltung, S. 215-217, die Zitate S. 217.

297 Bericht von Bertz, mit Begleitbrief vom 5. 11. 1945 an Ulbricht, SAPMO, NY 4182/1185, Bl. 7.

298 DJV, Besetzung nach dem Stande vom 20. 9. 1945, BAB, DP1 VA Nr. 1, Bl. 1-7 (vgl. Amos, Justizverwaltung, S. 14-17); Niederschrift über die Besprechung am 3.9. 1945 über das Arbeitsprogramm der Abteilung I, SAPMO, NY 4174/5, Bl. 7-9.

299 Aufstellung von bei der DJV nicht eingestellten Personen von Benjamin, Januar 1947, BAB, DP1 VA Nr. 7852.

300 Lebenslauf Holthöfers im ADL, Gummersbach. Holthöfer hatte vor 1933 der DDP angehört.

301 Ebenda, und Bericht von Bertz, mit Begleitbrief vom 5. 11. 1945 an Ulbricht, SAPMO, NY 4182/ $1185, \mathrm{Bl} .10$. 
Pressereferent eingestellt wurde ${ }^{302}$. Bei der Besetzung der Abteilung IV konnte Schiffer gegen den Widerstand von Bertz und Kleikamp seinen Kandidaten, den ihm aus der Zeit des Dritten Reiches bekannten Hermann Kuenzer (LDP), als Abteilungsleiter durchsetzen. Kuenzer, ein 73jähriger Jurist aus Baden, hatte in den zwanziger Jahren die Polizeiabteilung des Reichsinnenministeriums geleitet und war 1940 als Kriegsgerichtsrat zum Zentralgericht des Heeres in Berlin eingezogen worden ${ }^{303}$. Dort soll er „wegen der Schärfe seiner Anträge und Stimmungsschwankungen unangenehm aufgefallen sein " 304 . Kuenzer konnte dies richtigstellen: Normalerweise mit Verwaltungsaufgaben betraut, wurde er von seinem Vorgesetzten, dem in die Verschwörung vom 20. Juli 1944 verwickelten Generalrichter Karl Sack, „nur dann als Richter eingesetzt, wenn es galt, unschuldig Verfolgte vor Strafe zu retten oder höhere Offiziere einer Strafe zuzuführen, auch wenn sie von der Partei oder SS gedeckt wurden" ${ }^{305}$. Dabei fällte er auch Todesurteile und scheute sich nicht, gegen den Willen von Goebbels dessen Verbindungsoffizier zur Wehrmacht wegen eines Korruptionsfalles zu verurteilen, woraufhin er im Januar 1945 „als politisch unzuverlässig entlassen“ wurde ${ }^{306}$. Insgesamt lassen sich daher bei den Konflikten um die Stellenbesetzung in der DJV keine eindeutigen Sieger und Verlierer ausmachen: Weder konnte Schiffer alle seine Vorstellungen durchsetzen, noch war der Einfluß der Kommunisten so bestimmend, wie sich insbesondere Bertz dies stets wünschte.

Dies hängt auch damit zusammen, daß die nicht-kommunistischen Parteien über weitaus größere Personalressourcen als die KPD verfügten und die persönlichen Verbindungen der bürgerlichen Juristen untereinander die Rekrutierung der DJV-Mitarbeiter aus diesen Kreisen erheblich begünstigte. Dies gilt insbesondere für die sozialdemokratischen Volljuristen Karl Kleikamp, Erich Rosenthal-Pelldram (Leiter der Abteilung I), Fritz Corsing (Leiter der Abteilung III), Egon Büchs und Karl Guski (beide Referenten in der Abteilung V), die sich vom rechtspolitischen Ausschuß der SPD kannten. Kleikamp nutzte zudem seine Position als Vizepräsident, um, wie im Falle Guskis, seine Parteigenossen zu fördern ${ }^{307}$. Parteipolitische und persönliche Verbindungen existierten nachweislich auch zwischen Schiffer und Kuenzer sowie vermutlich zu Wilhelm Eickhoff (LDP), dem Leiter des Zentralbüros ${ }^{308}$. Darüber hinaus konnten persönliche Empfehlungen eine Rolle bei den Einstellungen spielen, wie bei Erich Wende (CDU), der aufgrund eines Schreibens von Schiffers Schwiegersohn, Waldemar Koch, den Weg

302 Über den diesbezüglichen Versuch vgl. Bericht von Kahane, o.D., SAPMO, NY 4182/1118, Bl. 53 sowie Bertz gegenüber dem Sekretariat der KPD, 23. 8. 1945, in: Amos, Justizverwaltung, S. 216.

${ }^{303}$ Lebenslauf von Kuenzer, 22. 11. 1945 in: Personalakte Kuenzer, BAB, DP1 SE Nr. 91, Bl. 12.

304 Bericht von Bertz, mit Begleitbrief vom 5. 11. 1945 an Ulbricht, SAPMO, NY 4182/1185, Bl. 11.

305 Kuenzer an Schiffer, 6. 10. 1945, in: Personalakte Kuenzer, BAB, DP1 SE Nr. 91, Bl. 9; diese Angaben von Kuenzer wurden in einer Bescheinigung von Präses Kurt Scharf bestätigt, der von August 1941 bis Ende 1943 dem Kriegsgericht in Berlin als Schreiber zugeteilt war, ebenda, Bl. $15 \mathrm{f}$.

306 Vgl. Kuenzer an Schiffer, 6. 10. 1945, ebenda, Bl. 10; vgl. auch Tagebücher von Joseph Goebbels, II, Bd. 12, S. 409 (Eintragung vom 6. 6. 1944) und Bd. 13, S. 200 (Eintragung vom 2. 8. 1944).

307 Vermerk vom 21.9. 1945, Personalakte Guskis, BAB, DP1 SE Nr. 13, Bl. 65.

${ }^{308} \mathrm{Zu}$ Eickhoff siehe Personalliste DJV, o.D., BAB, DP1 VA Nr. 1, Bl. 98; vgl. Amos, Justizverwaltung, S. 15. 
zur DJV fand ${ }^{309}$. Wende wiederum scheint den parteilosen Martin Fenner nach sich gezogen zu haben, der unter seinem Vorsitz von 1938 bis 1940 in der Beschlußkammer für Familienrechtssachen am Berliner Landgericht tätig gewesen war ${ }^{310}$. Alle bis Mitte November 1945 rekrutierten Mitarbeiter für den höheren Dienst der DJV ${ }^{311}$ wiesen - abgesehen von Paul Bertz - eine bürgerliche Herkunft und eine juristische Ausbildung auf. Weitgehend noch im Kaiserreich sozialisiert - 12 der hier zugrunde gelegten 17 Personen waren vor 1900 geboren -, gehörten sie fast ausnahmslos der generell als konservativ eingeschätzten Juristenschicht an, die mehrheitlich die Weimarer Republik bekämpft, sich in den Dienst des Dritten Reiches gestellt und in der Regel den an sie gestellten Anforderungen entsprochen hatte ${ }^{312}$.

Die Karrieren der 1945 in die DJV eingestellten Abteilungsleiter entsprachen freilich nicht denen der angepaßten NS-Juristen, wenngleich die Abweichung von der ,Norm' unterschiedlich stark ausgeprägt war. Rosenthal-Pelldram wurde 1933 genötigt, aus dem politischen Dezernat der Staatsanwaltschaft III in Berlin auszuscheiden, da er nicht der NSDAP beitrat. Seine konstante Weigerung, Nationalsozialist zu werden - er wurde lediglich Mitglied des NSRB und der NSV -, führte von 1942 bis 1944 zu seiner Abordnung zum Reichskommissar für Preisbildung. Nach einer mehrmonatigen Verwendung bei der Militärverwaltung in Frankreich ab Mai 1944 kehrte er schließlich im November als Staatsanwalt an das Berliner Landgericht zurück ${ }^{313}$. Sehr viel härter traf das Schicksal Fritz Corsing, der als Ministerialrat von 1920 bis Februar 1933 im preußischen Staatsministerium und anschließend bis zu seiner Entlassung im Juni 1933 im preußischen Justizministerium gedient hatte. Als Jude und Sozialdemokrat im Dritten Reich erheblichen Schikanen ausgesetzt, tauchten er und seine Frau 1943 in die Illegalität unter, um dem $\mathrm{KZ}$ und dem Holocaust zu entgehen ${ }^{314}$. Werner Gentz, der als Ministerialrat seit 1928 in der Strafvollzugsabteilung des preußischen Justizminsteriums arbeitete, wurde 1933 wegen seiner Zugehörigkeit zum Republikanischen Richterbund, seiner "politischen Linkseinstellung“ und seines "Strebens nach Humanisierung des Strafvollzuges" entlassen ${ }^{315}$. Zum Amtsrichter degradiert, war er bis 1945 am Amtsgericht Berlin-Mitte tätig ${ }^{316}$. Erich Wende, seit 1926 im preußischen Kultusministerium zunächst als Ministerialdirigent, ab 1932 als Ministerialdirektor tätig, wurde im April 1933 im Zuge der Übernahme des Ministeriums durch die Nationalsozialisten unter dem Vorwurf, er sei „als verkappter Zentrumsmann

${ }^{309}$ Koch an Schiffer, 19. 8. 1945, in: Personalakte Wende, BAB, DP1 SE Nr. 2492; vgl. auch Bericht von Bertz, mit Begleitbrief vom 5. 11. 1945 an Ulbricht, SAPMO, NY 4182/1185, Bl. 9.

310 Anlage 1 zum Personalfragebogen, in: Personalakte Fenner, BAB, DP1 SE Nr. 13, Bl. 65.

311 Hierzu werden die beiden Stellvertreter Schiffers (Kleikamp und Bertz), die Abteilungsleiter und der Leiter des Zentralbüros (Rosenthal-Pelldram, Winkelmann, Corsing, Kuenzer, Gentz, Melsheimer, Wende, Lentz, Eickhoff) sowie die in den Abteilungen tätigen Referenten (Hirschfeld, Benjamin, Hartwig, Fenner, Guski, Büchs, Paech) gerechnet, nicht aber die Dolmetscher und persönlichen Referenten Schiffers.

312 Vgl. dazu insbesondere Angermund, Richterschaft.

313 Personalbogen und Lebenslauf in: Personalakte Rosenthal-Pelldram, BAB, DP1 SE Nr. 59. In seiner Personalakte findet sich nichts, was auf eine „halbjüdische Abstammung “ (so Nathan, Aus der Geschichte der zentralen Justizverwaltung, BAB, DP1 VA Nr. 6832, Bl. 10) hindeutet.

314 Lebenslauf Corsing, 1. 8. 1945, SAPMO, DY 30/IV 2/13/404.

315 Lebenslauf Gentz, o.D. [Frühjahr 1951], SAPMO, DY 30/IV 2/11/172, Bl. 249 f.

316 Personalbogen Gentz, in: Personalakte Gentz, BAB, DP1 VA Nr. 854. 
tätig gewesen", in den einstweiligen Ruhestand versetz $\mathrm{t}^{317}$. Freilich konnte er weiterhin berufstätig bleiben und wurde zum 1. November 1933 zum Landgerichtsdirektor in Berlin ernannt; in dieser Funktion war er bis 1945 als Vorsitzender von Ehe-, Berufungs- und Beschwerdekammern und schließlich der Kammer für Patent- und Warenzeichenprozesse tätig. Er kam dem Regime durch den Beitritt zum NSRB und zur NSV entgegen, wurde aber nicht Parteimitglied ${ }^{318}$. Baptist Lentz, seit 1925 im preußischen Justizministerium, behielt trotz seiner Zugehörigkeit zum Zentrum vor 1933 zunächst seine Stellung in der für Personal und Gerichtsorganisation zuständigen Abteilung I. Er trat dem NSRB und der NSV, nicht aber der NSDAP bei. 1942 aus dem Justizministerium entfernt, war er bis 1945 beim Reichskommissar für die Behandlung feindlichen Vermögens tätig319. Über die Karriere von Paul Winkelmann sind in Ermangelung von dessen Personalakte keine verläßlichen Aussagen möglich, außer daß er seit 1933 in der Verwaltung des Amtsgerichts Berlin-Mitte tätig und von 1938 bis 1939 Zellenwalter in der NSV war ${ }^{320}$.

Auch bei dem Leiter des Zentralbüros und vier der sieben 1945 eingestellten Referenten hatte das Dritte Reich nachweislich zu Einbrüchen unterschiedlichen Ausmaßes in der jeweiligen Berufslaufbahn geführt. Wilhelm Eickhoff hatte seine Stelle als Amtmann im Finanzministerium verloren ${ }^{321}$; Benjamin war die Anwaltszulassung entzogen worden; Otto Hartwig, Ministerialdirektor und Abteilungsleiter im preußischen Justizministerium, wurde 1933 entlassen ${ }^{322}$. Hermann Hirschfeld hatte 1932 sein Assessor-Examen bestanden, wurde als „Mischling“ jedoch 1933 aus dem Justizdienst entlassen ${ }^{323}$. Fritz Paech, seit 1920 Landgerichtsdirektor am Landgericht I in Berlin, mußte, da er mit einer Jüdin verheiratet war, 1933 seine Stelle aufgeben und sollte an das Amtsgericht Berlin-Wedding versetzt werden, nahm aber daraufhin seinen Abschied aus dem Justizdienst ${ }^{324}$. Karl Guski hingegen, der vor 1933 der SPD und danach dem NSRB und der NSV angehört hatte, blieb von 1927 bis 1944 Landgerichtsrat in Berlin und wurde erst 1944 an das Amtsgericht Rathenow versetzt ${ }^{325}$. Etwas komplizierter liegt der Fall des parteilosen Martin Fenner, der bis zu seiner Einberufung zur Wehrmacht 1943 in Berlin und Hohensalza als Landgerichtsrat tätig war ${ }^{326}$. Fenner - ebenfalls NSRBund NSV-Mitglied - betonte zwar nachträglich seine antinazistische Gesinnung, aus der ihm Nachteile erwachsen seien, gab aber auch zu, sich Ende 1937 oder 1938 um Aufnahme in die NSDAP bemüht zu haben, um den gegen ihn gerichte-

\footnotetext{
317 Autobiographischer Bericht Wendes, BAK, Kl. Erw. Nr. 116, Bl. $19 \mathrm{f}$.

318 Personalbogen und Lebenslauf Wendes, in: Personalakte Wende, BAB, DP1 SE Nr. 2492.

319 Personalbogen und Lebenslauf von Lentz, in: Personalakte Lentz, BAB, DP1 SE Nr. 91, B1. 599602. Zu seiner Tätigkeit im preußischen und Reichsjustizministerium siehe auch die bei Gruchmann, Justiz, abgedruckten Geschäftsverteilungspläne von 1934 und 1941, insb. S. 1153, 1163, $1167,1169,1174,1196,1209$.

320 Bericht von Bertz, mit Begleitbrief vom 5.11. 1945 an Ulbricht, SAPMO, NY 4182/1185, Bl. 8; Chef der DJV an Rechtsabteilung der SMAD, 13.6. 1947, BAB, DP1 VA Nr. 823, Bl. 61.

321 Personalliste DJV, o.D., BAB, DP1 VA Nr. 1, Bl. 98.

322 Ebenda, Bl. 99; Gruchmann, Justiz, S. 223.

${ }^{223}$ Charakteristiken der Vortragenden Räte in der DJV, BAB, DP1 VA Nr. 821, Bl. 104.

324 Personalbogen und Lebenslauf Paech in: Personalakte Paech, BAB, DP1 SE Nr. 518, Bl. 310 f., 315.

325 Lebenslauf Guski, in: Personalakte Guski, BAB, DP1 SE Nr. 13, Bl. 67.

326 Personalbogen Fenner und Anlage 1 in: Personalakte Fenner, ebenda, Bl. 61 f., 65.
} 
ten Denunziationen ein Ende zu bereiten. Er sei kurz darauf zum Landgerichtsrat befördert worden, habe auf seine Anfrage bei der Partei jedoch nie eine Antwort erhalten ${ }^{327}$. Trotz allem akzeptierte ihn die SMAD-Rechtsabteilung als Referenten für die DJV328.

Nur zwei der 1945 in die Zentralverwaltung eingestellten Mitarbeiter des höheren Dienstes - Corsing und Benjamin - waren im Dritten Reich aufgrund ihrer politischen Überzeugung oder ihrer „Rasse“ verfolgt worden. Die große Mehrzahl hatte zwar berufliche Nachteile erlitten, war jedoch im Justizdienst verblieben. Dazu trug auch bei, daß insgesamt sechs von ihnen zwar nicht in die NSDAP, wohl aber in den NSRB und die NSV eintraten und zum Teil dort untergeordnete Funktionen übernahmen - Melsheimer war demnach kein Einzelfall. Da sie sich von der Partei ferngehalten hatten, waren sie in den Augen der sowjetischen Besatzungsmacht indes für die Übernahme in die Justiz prädestiniert. Dies zeigte sich bereits bei der Besetzung der Berliner Gerichte und Staatsanwaltschaften im Mai 1945. Neben Benjamin und Melsheimer waren Gentz, Hirschfeld und Rosenthal-Pelldram als Staatsanwälte, Kleikamp, Lentz, Wende und Winkelmann als Richter eingesetzt worden. Aufgrund der Herkunft, den parteipolitischen Präferenzen ${ }^{329}$ und den negativen Erfahrungen der leitenden Mitarbeiter der DJV im Dritten Reich kann 1945 insgesamt von einem reformfreundlichen, nicht aber von einem revolutionären Klima in dieser Zentralverwaltung ausgegangen werden. Schiffer stand, auch wenn er nicht jeden seiner Kandidaten gegenüber der KPD und möglicherweise auch der SMAD - hatte durchsetzen können, ein Apparat zur Verfügung, mit dem er zu Recht hoffen konnte, seine Reformvorstellungen durchzusetzen.

\section{Personalbewegungen in der DJV 1945 bis 1947}

Schiffer vermochte die DJV nur auf Reformkurs zu halten, wenn deren personelle Zusammensetzung im wesentlichen erhalten blieb. Dies setzte unter anderem voraus, daß sich die Kommunisten mit ihren geringen Einflußmöglichkeiten zufriedengaben, womit freilich angesichts des kommunistischen Machtanspruchs kaum zu rechnen war. Schon im September 1945 kam es daher zu einem Konflikt in der DJV, in dessen Verlauf der 1. Vizepräsident Schiffer heftig angriff. Bertz wollte vor allem die "Kaderpolitik“ der DJV maßgeblich bestimmen, um auf diese Weise die weitere Entwicklung zu beeinflussen. Daß die Kommunisten auch dabei - zumindest vorläufig - auf Kooperation mit anderen "antifaschistisch-demokratischen“ Kräften setzten, hatte der „Linksabweichler“ der zwanziger Jahre anscheinend nicht begriffen. Er fühlte sich bei den Personalentscheidungen der ersten Wochen

327 Anlage 2, ebenda, Bl. 66.

${ }^{328} \mathrm{Zu}$ den sieben Referenten zählte auch Egon Büchs (SPD), über dessen Leben vor 1945 nichts bekannt ist.

${ }^{329}$ Zur Herkunft und zum politischen Organisationsgrad im höheren Dienst der DJV im September 1945 siehe Amos, Justizverwaltung, S. $19 \mathrm{ff}$. Von den hier zugrunde gelegten 18 Personen gehörten drei der KPD (wozu Gentz als vierter wahrscheinlich hinzugerechnet werden kann), fünf der SPD, drei der CDU und zwei der LDP an, während vier parteilos waren. 
übergangen und wies daher den Leiter der Personalabteilung am 23. Oktober 1945 an, ihn in Zukunft rechtzeitig und umfassend über alle anstehenden Stellenbesetzungen zu unterrichten ${ }^{330}$. Außerdem übersandte Bertz Ulbricht und der SMAD-Rechtsabteilung am 5. November 1945 einen „Bericht über die in der Zentralen Justizverwaltung bisher übliche Praxis in Personaldingen“. Aufgrund der „völlig selbstherrlich[en]" Entscheidungen Schiffers habe die DJV auch Mitarbeiter aufgenommen, die "aufs schwerste kompromittiert" seien. Eine Fortsetzung dieser Personalpolitik müsse "unweigerlich“ dahin führen, „daß der Aufbau eines einwandfrei antifaschistischen Justizapparates unmöglich gemacht wird“. Schiffer umgehe dabei seinen Stellvertreter, indem er sich stets direkt an die Abteilungsleiter wende und darüber hinaus zur Informationsbeschaffung seine persönlichen Referenten einsetze ${ }^{331}$. Vor diesem Hintergrund versuchte der Vizepräsident KPD und SMAD zu aktivieren, um seine Position in der DJV zu verbessern.

Bertz, der sich auch in anderer Hinsicht übergangen fühlte ${ }^{332}$, scheute die direkte Konfrontation mit Schiffer nicht. Dabei ging es einmal um einen Dienstwagen, den Bertz für sich persönlich beanspruchte, so daß Schiffer an einem Novemberabend den Weg von der DJV zu seiner Wohnung in Charlottenburg zu Fuß zurücklegen mußte ${ }^{333}$. Größere Wellen schlug seine Privatfehde gegen Schiffers persönlichen Referenten, Erich Glüse, dem Bertz vorwarf - im Gegensatz zu dessen eigener Darstellung - nie KPD-Mitglied gewesen zu sein, sich bei Schiffer eingeschmeichelt, gegen die Kommunisten in der DJV intrigiert, Verbindungen zu den Westalliierten unterhalten und sich an Schiebereien von Lebensmitteln und anderen Gütern beteiligt zu haben ${ }^{334}$. All dies veranlaßte Schiffer, am 3. Dezember 1945 Wilhelm Pieck mitzuteilen, daß er nicht länger mit Bertz zusammenarbeiten werde. Dieser bringe kein „Verständnis für die Eigenart eines behördlichen Organismus" auf, verfüge nicht über die für die Justiz notwendigen Fachkenntnisse und sei daher "stets ein Fremdkörper in [seinem] Amte gewesen und geblieben“. „Seine wirkliche Tätigkeit“, so Schiffer weiter, „beschränkte sich auf die politische Untersuchung der in Betracht kommenden Personen - eine Tätigkeit, die gewiß von Wert und Bedeutung ist, indes nicht wohl für das hohe Amt ausreicht, das Herr Bertz in der Justizverwaltung bekleidet." Mit der Bitte um Vorschläge für die Wahl eines Nachfolgers beendete Schiffer seinen Brief335.

Mit einer Reaktion ließ sich die KPD-Führung Zeit. In einem Gespräch am 11. Dezember zwischen Ulbricht und Bertz konnte noch keine endgültige Klarheit geschaffen werden ${ }^{336}$. Dies gab dem Vizepräsidenten Gelegenheit, gegenüber

330 Bertz an Winkelmann, 25. 10. 1945, BAB, DP1 VA Nr. 1, Bl. 26; zur Umsetzung siehe den Vermerk Winkelmanns, 25. 10. 1947, ebenda, Bl. 27.

331 Bericht von Bertz, am 5. 11. 1945 an Ulbricht, SAPMO, NY 4182, Bl. 6-17.

332 Erklärung von Bertz, 3. 11. 1945, SAPMO, NY 4182/1118, Bl. 72: Darin beschwerte er sich darüber, daß ihm nicht rechtzeitig vor einer Besprechung Schiffers Entwurf zur Gerichtsverfassung zugegangen sei.

333 Vermerk Schiffers, 28. 11. 1945, ebenda, Bl. 74 f.; vgl. Amos, Justizverwaltung, S. 72.

${ }_{334}$ Betrifft: Glüse, o.D., ebenda, Bl. 181-186; dieser Vermerk wurde von Bertz am 14. 12. 1945 an das Sekretariat des ZK der KPD übersandt. Ulbricht persönlich meldete am 27. 5. 1946 an die SMAD, daß Glüse "sehr eng mit französischen Stellen zusammenarbeitet“: SAPMO, NY 4182/1191, Bl. $75 \mathrm{f}$.

335 Schiffer an das ZK der KPD, z.H. Wilhelm Pieck, 3. 12. 1945, ebenda, Bl. 172-175.

336 Bertz an das Sekretariat des ZK der KPD, 17. 12. 1945, ebenda, Bl. 191-196, hier 191. 
dem ZK-Sekretariat seine eigenen Verdienste in der Diskussion um die Ausbildung der „Volksrichter“ hervorzuheben und in einem weiteren Schreiben den DJV-Präsidenten zu diskreditieren, unter anderem dadurch, daß er ihn aufgrund seines Verhaltens beim Kapp-Putsch als "politisch nicht ganz einwandfrei“ bezeichnete 337 . Er verstieg sich in dem Schreiben sogar zu dem Satz: „Wenn ich privat mit Schiffer zu tun hätte, dann würde ich ihm die Worte eines Götz von Berlichingen als Antwort geben." Da ihm eine weitere Arbeit unter dem DJV-Präsidenten nicht länger möglich erschien, stellte Bertz das Sekretariat abschließend vor die Entscheidung, entweder ihn abzuberufen oder den Rücktritt Schiffers herbeizuführen, wohl ahnend, daß die Blockpolitik Vorrang vor anderen Überlegungen besaß338. Dennoch fuhr er fort, Schiffer vor seinen KPD-Genossen zu disqualifizieren. Bei einer Besprechung im Januar 1946 spielte er nicht nur dessen Verdienste bei der Wiederaufnahme der Justizarbeit herunter, sondern bezeichnete darüber hinaus dessen juristische Qualitäten als „schwach“. Ulbricht ließ sich davon nicht beirren und beharrte auf seinem Standpunkt: „Schiffer entfernen, heißt der ganzen Welt demonstrieren, die 4-Parteien-Einheitsfront ist hin." ${ }^{339}$ Kurze Zeit darauf fiel die endgültige Entscheidung über das Schicksal von Bertz, dessen Verhalten auch von einem anderen kommunistischen DJV-Angestellten heftig kritisiert wurde ${ }^{340}$. Am 27. Januar beschloß das Sekretariat des ZK der KPD, daß Bertz aus der DJV ausscheiden und „eine Polizeifunktion in Dresden übernehmen" solle ${ }^{341}$.

Wenngleich das Sekretariat bereits bei dieser Gelegenheit Melsheimer als Nachfolger vorschlug, wurde Bertz erst am 16. April 1946 von der SMAD mit Befehl Nr. 121 formell aus der DJV entlassen und der Leiter der Gesetzgebungsabteilung an seine Stelle gesetzt ${ }^{342}$. Dies deutet bereits darauf hin, daß der Übergang von Bertz zu Melsheimer keineswegs so reibungslos vor sich ging, wie es in manchen Darstellungen erscheint ${ }^{343}$. Zwischen Ulbricht und Melsheimer gab es zunächst keine Differenzen über die Besetzung der Vizepräsidentenstelle. Denn im Anschluß an eine Besprechung der beiden am 16. Februar stellte Melsheimer bereits

${ }^{337}$ Schiffer habe angeblich den Putschisten Straffreiheit zugesichert. Vgl. dagegen Ramm, Schiffer und die Reform, S. 52-55.

338 Bertz an das Sekretariat des ZK der KPD, 17. 12. 1945, SAPMO, NY 4182/1118, Bl. 191-196, hier $194 \mathrm{ff}$. (Hervorhebung im Original).

339 Protokoll über die Sitzung der Genossen der Berliner Justiz und der Zentralverwaltung für Justiz in der sowjetischen Zone bei Ulbricht am 19.1. 1946, SAPMO, DY 30/IV 2/13/404; vgl. Amos, Justizverwaltung, S. 85.

340 Siehe den Brief des Dolmetschers Türksch an das ZK der KPD, z.H. Dahlem, 3. 1. 1946, SAPMO, NY 4182/1119, Bl. 1-4, zit. bei Amos, Justizverwaltung, S. 73.

341 Protokoll Nr. 8/65 der Sitzung des Sekretariats am 27. 1. 1946, in: Dokumente zur Geschichte der kommunistischen Bewegung, Bd. 1, S. 161. Bertz wurde jedoch nach seiner endgültigen Entlassung stellvertretender Leiter der Werkstättenabteilung der Deutschen Zentralverwaltung für Verkehr, war von Mai 1948 bis Februar 1949 stellvertretender Abteilungsleiter im Zentralausschuß der Sozialhilfe Groß-Berlin und ab Mai 1949 Direktor des Kommunal-Wirtschafts-Unternehmens in Chemnitz. Am 19. April 1950 nahm er sich unter dem Druck der ZPKK - er wurde im Zusammenhang mit der Noel-Field-Affäre der Agententätigkeit beschuldigt - das Leben. Siehe Biographisches Handbuch, S. 60.

342 Vgl. Inventar, S. 98.

${ }^{343}$ So Rößler, Programm, S. 145; Amos, Justizverwaltung, S. 74, die die Schwierigkeiten „nicht bei der Auswahl des Nachfolgekandidaten, sondern beim ungünstiger werdenden Proporz für die KPD“ sieht. Lorenz, Zentralverwaltung, S. 135, nennt zwar drei der Nachfolgekandidaten, geht jedoch auf den Entscheidungsprozeß nicht weiter ein. 
Überlegungen an, wie man den KPD-Einfluß in der DJV trotz des Abgangs von Bertz erhalten könne. Als Leiter der Abteilung $\mathrm{V}$ wollte er zwar einen parteilosen Juristen ${ }^{344}$ einstellen, diese aber aus dem Zuständigkeitsbereich Kleikamps herauslösen und sich selbst unterstellen. Zudem sollten die Kompetenzen Hilde Benjamins erweitert werden, indem man ihr die Zuständigkeit für „die gesamten Angelegenheiten der Volksrichter (Personalien und Ausbildung) "übertrug ${ }^{345}$. Außerhalb des engen Parteiführungszirkels war jedoch die Nachfolge von Bertz noch keineswegs geklärt. Auf einer am 15./16. Februar von der DJV einberufenen Konferenz der Oberlandesgerichtspräsidenten und Leiter der Landesjustizverwaltungen kursierte nämlich das Gerücht, daß als Vizepräsident Landgerichtspräsident Willy Lange aus Magdeburg ausersehen sei. Die provinzsächsische KPD-Bezirksleitung, die davon erfahren hatte, richtete daraufhin ein Schreiben an Franz Dahlem, in dem Lange als „etwas weich“ bezeichnet wurde. Er sei Schiffer, mit dem er „von früher her sehr gut bekannt" sei, wohl nicht gewachsen ${ }^{346}$. Schiffer, der sich gegenüber Pieck am 3. Dezember 1945 noch bereit erklärt hatte, als Nachfolger von Bertz „einen in meinem Amt bereits tätigen, Ihrer Partei angehörigen oder nahestehenden Herrn anzunehmen "347, versuchte anscheinend, anstelle von Melsheimer einen ihm von früher bekannten und genehmen Kommunisten auf die Vizepräsidentenstelle zu setzen.

Als das Sekretariat des KPD-Zentralkomitees am 11. März entschied, „das Rücktrittsgesuch von Bertz anzunehmen und einen Vorschlag für einen neuen Vizepräsidenten der Zentralverwaltung für Justiz zu machen"348, war von Melsheimer nicht mehr die Rede. Am selben Tag unterbreitete Ulbricht dem nach Berlin gereisten sächsischen Generalstaatsanwalt John Ulrich Schroeder den Vorschlag, das Vizepräsidentenamt zu übernehmen ${ }^{349}$. Warum die KPD-Führung nun nach einem anderen Kandidaten suchte, läßt sich nicht eindeutig beantworten; es ist jedoch zu vermuten, daß die SMAD Melsheimer nicht zum Vizepräsidenten ernennen wollte 350 - möglicherweise, weil ihr dessen Vergangenheit aufklärungsbedürftig erschien. Schroeder lehnte freilich das Angebot Ulbrichts ab ${ }^{351}$. In dieser Situation griff die KPD-Führung auf Vorschlag von Bertz ${ }^{352}$ und Polak auf Werner Gentz zurück. Letzterer empfahl ihn, da Gentz Volljurist, 1933 „wegen seiner

${ }^{344}$ Melsheimer wollte Georg Brühl, den er als einen der Richter des Bezirksgerichts Friedenau eingestellt hatte: siehe Melsheimer an Stadtgerichtspräsiden und Generalstaatsanwalt von Berlin, 26.5. 1945, BAB, DP1 SE Nr. 3596.

${ }^{345}$ Melsheimer an Ulbricht, 18. 2. 1946, SAPMO, NY 4182/1119, Bl. 12.

${ }^{3+6}$ KPD-Bezirksleitung Provinz Sachsen an Dahlem, 26. 2. 1946, ebenda, Bl. 13. Zur Vorliebe Schiffers für Lange siehe auch die Mitteilung Rosenthal-Pelldrams vom 27. 3. 1946 im Vermerk: Besprechung in Karlshorst bei der SMAD-Rechtsabteilung am 27.3. 1946, SAPMO, NY 4182/1185, Bl. 45.

${ }^{347}$ Schiffer an das ZK der KPD, z.H. Wilhelm Pieck, 3. 12. 1945, SAPMO, NY 4182, Bl. 175.

${ }_{348}$ Protokoll Nr. 15/72 der Sitzung des Sekretariats am 11. 3. 1946, in: Dokumente zur Geschichte der kommunistischen Bewegung, Bd. 1, S. 184.

${ }^{349}$ Dies geht aus dem Schreiben Schroeders an Ulbricht vom 11.3. 1946, SAPMO, NY 4182/1119, Bl. 15 , hervor.

350 Schiffer teilte am 21. 3. 1946 Melsheimer mit, daß in Karlshorst „die Frage der Wiederbesetzung von Bertz' Stelle“ seit 14 Tagen "schwebe“, Melsheimer an Polak, 21. 3. 1946, ebenda, Bl. 26.

351 Schroeder an Ulbricht, 11.3. 1946, ebenda, Bl. 15. Als Gründe nannte er sein Alter, seinen Gesundheitszustand sowie die gegenüber einem Generalstaatsanwalt eingeschränkten Einflußmöglichkeiten eines DJV-Vizepräsidenten.

352 Erinnerungen Werner Gentz, SAPMO, SgY 30 1684, Bl. 3. 
sozialistischen Einstellung aus dem Staatsdienst und von der Universität entfernt worden" und ein ehrlicher Kommunist sei ${ }^{353}$. Bei einer daraufhin von Ulbricht herbeigeführten Unterredung lehnte Gentz jedoch ab und schlug erneut Melsheimer vor ${ }^{354}$.

Dem Abteilungsleiter, der inzwischen seine Felle davonschwimmen sah, kam das entgegen. Am 21. März hatte Schiffer ihm eröffnet, daß er der SMAD-Rechtsabteilung Melsheimer, Gentz und Lange (in dieser Reihenfolge) als Nachfolger für Bertz vorgeschlagen habe. Lange sei in den vergangenen Tagen in der DJV gewe$\operatorname{sen}^{355}$. Wenngleich Schiffer mitteilte, daß für diesen ,auch die Stelle eines Generalstaatsanwaltes in Halle in Frage" komme, vermutete Melsheimer eine gegen ihn gerichtete Intrige. Außerdem erfuhr er bei dieser Gelegenheit auch von dem Vorschlag, John Ulrich Schroeder zum Vizepräsidenten zu ernennen. Auf Anordnung der SMAD-Rechtsabteilung wurde dieser zwecks Vorstellung in Karlshorst einbestellt, sein Besuch jedoch krankheitshalber verschoben. Der von Melsheimer und Benjamin verfaßte Bericht an Polak schloß daher mit den Worten: „Wir haben hier den Eindruck, fortgesetzter andauernder [sic] Schiebung und halten größte Eile für geboten." 356

Ulbricht teilte daraufhin am 25. März dem Leiter der SMAD-Rechtsabteilung mit, er habe erfahren, daß Schroeder zum Vizepräsidenten ernannt werden solle. In Verhandlungen mit der KPD-Führung habe Schroeder aber „wegen seines schlechten Gesundheitszustandes“ abgelehnt. „Wir haben deshalb“, so Ulbricht weiter, „dem Gen. Bokow vorgeschlagen, den Gen. Melsheimer zum ersten Vizepräsidenten zu ernennen, der gegenwärtig als Leiter der Abteilung für Gesetzgebung in der Justizverwaltung tätig ist." 357 Während Ulbricht mangels anderer Alternativen wieder auf den ursprünglichen KPD-Vorschlag zurückkam, war die SMAD-Rechtsabteilung noch nicht bereit, sich auf Melsheimer festzulegen. Dieser wurde zwar aufgefordert, mit einem ausführlichen Lebenslauf am 27. März in Karlshorst zu erscheinen. Auch nach einer dreistündigen Unterredung mit Major Nikolajew und Karassjow fiel dort jedoch keine Entscheidung. Die wurde nun von einer Äußerung der KPD-Führung abhängig gemacht - der Brief Ulbrichts lag anscheinend noch nicht vor. Außerdem bestanden die sowjetischen Vertreter weiterhin auf einem Treffen mit Schroeder 358 . Bis zur Ernennung Melsheimers durch SMAD-Befehl vergingen jedenfalls noch weitere drei Wochen ${ }^{359}$. Wenn-

${ }^{353}$ Vermerk Polak, 23. 3. 1946, SAPMO, NY 4182/1185, Bl. 42.

354 Erinnerungen Werner Gentz, SAPMO, SgY 30 1684, Bl. 3.

355 Dies wird von Polak bestätigt, der Ulbricht mitteilte, Lange sei am 20.3. 1946 in Berlin gewesen, habe sich aber nicht persönlich gemeldet, sondern ihm lediglich eine Nachricht hinterlassen, die den Satz enthielt: „Ich muß sofort noch einmal zu Minister Schiffer und dann eiligst nach Magdeburg zurück, konnte deshalb nicht warten, obwohl ich Dich gern einmal gesehen hätte." SAPMO, NY 4182/1119, Bl. 25, 27.

356 Melsheimer an Polak, 21. 3. 1946, ebenda, Bl. 26. Daß Benjamin den Brief mitverfaßte, geht einmal aus den Korrekturen in ihrer Handschrift und zweitens daraus hervor, daß Polak in seinem Vermerk für Ulbricht von einem „Brief der Genossin Benjamin“ sprach.

357 Ulbricht an Karassjow, 25. 3. 1946, SAPMO, NY 4182/1185, Bl. 44.

358 Vermerk: Besprechung in Karlshorst bei der SMAD-Rechtsabteilung am 27.3. 1946, ebenda, Bl. 45. Ob Schroeder sich noch in Karlshorst vorstellte, ist nicht überliefert.

359 Der Befehl vom 16. 3. 1946 wurde Melsheimer anscheinend erst zwei Tage später eröffnet: vgl. Polak an Ulbricht, 18. 4. 1946, SAPMO, NY 4182/119, Bl. 33; siehe dazu auch Amos, Justizverwaltung, S. 74. 
gleich die Ursachen für die Verzögerungen nicht aktenkundig sind, deutet vieles darauf hin, daß in der SMAD Melsheimer keineswegs von Anfang an als der ideale Nachfolger von Bertz galt. Sein Aufstieg ist daher nicht nur auf Ehrgeiz und Befähigung zurückzuführen, sondern auch darauf, daß die anderen zur Verfügung stehenden Kandidaten zurücktraten oder für die SMAD nicht in Frage kamen.

Melsheimer konnte bereits im Mai 1946 seine Position in der DJV verbessern, als ihm auf Drängen des Leiters der SMAD-Rechtsabteilung neben der Abteilung II die Abteilungen V und VI unterstellt wurden ${ }^{360}$. Er profitierte auf diese Weise von der Verdrängung des zweiten Vizepräsidenten Kleikamp, der sich seit Jahresanfang als heftiger Gegner der Kommunisten und der SED profiliert hatte ${ }^{361}$. Er wie auch die anderen SPD-Mitglieder in der DJV traten nach dem Vereinigungsparteitag im April 1946 nicht der Einheitspartei bei, sondern hielten der Sozialdemokratischen Partei die Treue. Die SED-Führung strebte daher Kleikamps Entfernung aus seinem Amt an und wollte gleichzeitig die Situation zu einem Revirement an der DJV-Spitze nutzen. Ulbricht schlug am 31. Oktober 1946 Bokow vor, der Bürgermeister von Leipzig, Erich Zeigner (SED), solle das Präsidenten- und der Vizepräsident der sächsischen Landesverwaltung, Reinhard Uhle (LDP), das Vizepräsidentenamt übernehmen ${ }^{362}$. Die SMAD-Rechtsabteilung wollte Schiffer zwar noch halten; Kleikamp wurde indes seit Frühjahr 1946 systematisch aus seinem Wirkungskreis verdrängt. Am 17. Mai kritisierte Karassjow, daß Kleikamp in der DJV zu passiv, in seiner eigenen Partei hingegen sehr "aktiv und energisch“ auftrete; Melsheimer sollten daher "die wichtigeren Abteilungen“ für Personal, Gesetzgebung und Ausbildung unterstellt werden. Schiffers Argumente zugunsten des 2. Vizepräsidenten vermochten Karassjow nicht von seinem Vorhaben abzubringen ${ }^{363}$, so daß Kleikamp die Gruppenleitung über die Abteilungen I, III, IV, IV A und VII, die inneren Verwaltungsgeschäfte des Amtes und - als Sonderaufgabe - die Geschäftsführung der von der DJV herauszugebenden Zeitschrift übertragen wurde 364 . Dennoch hatte Karassjow ausdrücklich die Gleichberechtigung der beiden Vizepräsidenten betont und die Regelung der Vertretungsfrage dem Amtschef überlassen ${ }^{365}$. Am 31. Juli befahl er jedoch, daß Melsheimer die Gesamtvertretung Schiffers während dessen vierwöchigen Urlaubs übernehmen solle ${ }^{366}$. Am 19. September schließlich wies Major Nikolajew den DJV-Präsidenten an, Kleikamp die Leitung des Redaktionsausschusses der DJV-Zeitschrift zu entziehen und ihn verstärkt mit Revisionsfahrten in die Provinzen und Länder zu

360 Verfügung Schiffers, 21. 5. 1946, DP1 VA Nr. 1, Bl. 135; am 17.5. hatte Karassjow Schiffer eine enstprechende Anweisung erteilt, Aktenvermerk von Stackelbergs, 18. 5. 1946, BAB, DP1 VA Nr. 11, Bl. 40.

$36 !$ Siehe dazu Kap. A.I.1.

362 Ulbricht an Bokow, 31. 10. 1946, SAPMO, NY 4182/1192, Bl. 174; vgl. Amos, Justizverwaltung, S. 85.

${ }^{363}$ Ergänzende Bemerkung zum Aktenvermerk vom 18.5. über die Rücksprache Schiffers mit Karassjow, 20. 5. 1946, BAB, DP1 VA Nr. 11, Bl. 42.

364 Verfügung Schiffers, 21. 5. 1946, BAB, DP1 VA Nr. 1, Bl. 135.

365 Aktenvermerk von Stackelbergs, 18. 5. 1946, BAB, DP1 VA Nr. 11, Bl. 41.

366 Aktenvermerk über den Besuch Schiffers in Karlshorst am 31.7. 1946, 2. 8. 1946, ebenda, Bl. 62; die entsprechende Verfügung Schiffers vom 2. 8. 1946, BAB, DP1 VA Nr. 1, Bl. 139. 
betrauen ${ }^{367}$. Angesichts seiner Demontage bemühte sich Kleikamp um eine andere Aufgabe und wurde am 16. Dezember 1946 zum stellvertretenden Bürgermeister des Bezirks Tiergarten gewählt ${ }^{368}$. Wenngleich Karassjow in einer Unterredung mit Schiffer am 20. Dezember die Mitteilung über Kleikamps Ausscheiden zum 1. Januar 1947 mit einem Ausdruck förmlichen Bedauerns quittierte ${ }^{369}$, konnte er insgesamt zufrieden sein: Mit dem Rücktritt des zweiten Vizepräsidenten war das prominenteste SPD-Mitglied aus der DJV ausgeschieden, und die Gegner der SED-Zwangsvereinigung hatten an Boden verloren.

Am 20. Dezember billigte Karlshorst auch einen Vorschlag Schiffers zur Reorganisation der DJV, demzufolge der Posten des zweiten Vizepräsidenten gestrichen, die Abteilungen IV und VI aufgelöst und deren Geschäfte den Abteilungen II und III übertragen werden sollten: Dabei hätte die Abteilung II „alle Personalien der Rechtsanwälte und die Sache der Richterkurse" und die Abteilung III die anderen in Abteilung IV bearbeiteten Angelegenheiten zu übernehmen ${ }^{370}$. Schiffer hatte wahrscheinlich im Verlauf des Jahres 1946 gesehen, daß einem weiteren Vizepräsidenten ohnehin keine nennenswerten Kompetenzen zugewiesen worden wären, und mit der Streichung der Leitungspositionen wollte er Karlshorst dazu bewegen, drei neue Vortragende Räte und drei Oberjustizräte in die DJV einzustellen, um den gestiegenen Arbeitsanfall bewältigen zu können ${ }^{371}$. Aufgelöst wurde schließlich nur die Abteilung IV. Schiffer verfügte, daß ab dem 1. Februar 1947 "die Personalien und die sonstigen auf die Rechtsanwälte und Notare sich beziehenden Angelegenheiten sowie das Gerichtsvollzieherwesen" auf Abteilung II und „die Tätigkeit der Staatsanwaltschaften“ auf Abteilung III übertragen wurde ${ }^{372}$. Abteilung VI blieb jedoch erhalten und büßte keine Kompetenzen ein, obwohl Oberstleutnant Jakupow von der SMAD-Rechtsabteilung am 23. Januar 1947 den „Wunsch“ äußerte, „die Ausbildungsangelegenheiten sofort der Abteilung II anzuvertrauen" ${ }^{373}$. Indem Schiffer von seinem ursprünglichen Vorhaben abrückte, erreichte er, daß Hilde Benjamins Einfluß nicht weiter gestärkt wurde.

Diese war am 21. August 1946 in Schiffers Abwesenheit mit Verfügung Melsheimers „zeitweilig mit der Wahrnehmung der Geschäfte des Abteilungsleiters II“ beauftragt worden, während Winkelmann „einstweilen die Leitung der Abteilung $V^{\text {“ }}$ übernahm ${ }^{374}$. Nach Schiffers Rückkehr aus dem Urlaub behielten Benjamin und Winkelmann ihre Posten; der DJV-Präsident unternahm jedoch nichts, um

367 Aktenvermerk über die Besprechung Schiffers mit Nikolajew beim Besuch des Letzteren in der DJV am 19. 9. 1946, 20. 9. 1946, BAB, DP1 VA Nr. 11, Bl. $70 \mathrm{f}$.

368 Neuwahl der Bezirksbürgermeister auf Grund der Berliner Wahlen am 20. Oktober 1946, LAZ 2138/3. Kleikamps Tätigkeit in der Verwaltung des Bezirks Tiergarten ist bis 1949 bezeugt, LAZ 5685/14; Kleikamp starb im Jahre 1953 (Mitteilung Gertrud Kleikamps vom 30. 8. 1995).

369 Aktenvermerk über die Besprechung Schiffers mit Karassjow am 20.12. 1946, BAB, DP1 VA Nr. 11, Bl. 88.

370 Ebenda. Die Abteilung IV war seit dem Tod von Kuenzer am 26. Juni 1946 ohne einen Leiter.

371 Dieser Wunsch Schiffers erfüllte sich anscheinend nicht: auf Karassjows Aufforderung hin stellte er einen formellen schriftlichen Antrag am 31.12. 1946, BAB, DP1 VA Nr. 1025, Bl. 26-28. Eine Antwort auf das Schreiben ist nicht überliefert; eine Stellenvermehrung blieb jedenfalls aus.

372 Verfügung Schiffers, 13.1. 1947, BAB, DP1 VA Nr. 5777.

373 Aktenvermerk über ein Telefonat Jakupows am 23. 1. 1947, BAB, DP1 VA Nr. 11, Bl. 99.

374 Verfügung Melsheimers, 21. 8. 1946, BAB, DP1 VA Nr. 1, Bl. 143. 
Benjamin zu befördern. Erst aufgrund eines Telefonats von Oberstleutnant Jakupow mit Schiffer am 23. Januar 1947 wurde sie tags darauf zum Direktor ernannt ${ }^{375}$. Als Leiterin der Personalabteilung kam ihr eine von den Kommunisten seit 1945 angestrebte Schlüsselposition zu. Schiffer wollte Benjamin nicht auch noch die Verantwortung für die Volksrichterausbildung übertragen, sondern beließ diese bei der Abteilung VI, deren Leitung damals ebenfalls wechselte. Denn Erich Wende hatte gegen den Willen der SMAD-Rechtsabteilung ${ }^{376}$ das Angebot eines Staatssekretärspostens im niedersächsischen Kultusministerium angenommen und kehrte im Januar 1947 nach Ablauf seines Urlaubs nicht wieder in die DJV zurück ${ }^{377}$. An seine Stelle trat Otto Hartwig (CDU), der nach dem Ausscheiden Fritz Corsings im Oktober 1946378 „bis auf weiteres“ mit der Geschäftsführung der Abteilung III beauftragt worden war ${ }^{379}$.

Hartwig wurde jedoch nicht - wie von Schiffer geplant ${ }^{380}$ - in der Abteilung III, sondern in der Abteilung VI befördert ${ }^{381}$. Dies war auf das Eingreifen der SEDFührung zurückzuführen, die die Umbruchssituation in der DJV dazu nutzen wollte, um ihre Stellung in dieser Zentralverwaltung zu stärken. Dazu wurde, entgegen den Wünschen Schiffers und mit Hilfe der sowjetischen Militärverwaltung, einer der wenigen kommunistischen "Justizkader" aus dem Moskauer Exil, der ehemalige Reichstagsabgeordnete Fritz Löwenthal, als Leiter der Abteilung III in die DJV eingeschleust ${ }^{382}$. Löwenthal, der bereits im Januar 1946 in der KPD-Führung als Leiter der Abteilung V im Gespräch gewesen war ${ }^{383}$, erwies sich jedoch keineswegs als treuer Parteigänger der SED. Denn sein Exil in der Sowjetunion ließ ihn angesichts der politischen Verhaftungswellen der Jahre 1935 bis 1938 von einem Bewunderer zu einem Kritiker des sowjetischen Systems werden. Während er bei seiner Rückkehr nach eigenem Bekunden noch gehofft hatte, ,in der Sozialistischen Einheitspartei eine Vertreterin der wahren Interessen des deutschen

375 Aktenvermerk über ein Telefonat Jakupows am 23. 1. 1947, BAB, DP1 VA Nr. 11, Bl. 99; Chef der DJV an Chef der SMAD-Rechtsabteilung, 24. 1. 1947, BAB, DP1 VA Nr. 1025, Bl. 32.

376 Aktenvermerk über die Besprechung Schiffers mit Karassjow am 20.12. 1946, BAB, DP1 VA Nr. 11, Bl. 88; Aktenvermerk über Telefonat von Jakupow am 30. 12. 1946, ebenda, Bl. 93.

377 Wende an Schiffer, 18. 1. 1947, in: Personalakte Wende, BAB, DP1 SE Nr. 2492. Vgl. auch den autobiographischen Bericht Wendes, BAK, Kl. Erw., Nr. 116, Bl. 24. Wende war bis 1950 Staatssekretär im niedersächsischen Kultusministerium und von 1950 bis 1953 Leiter der Abteilung für kulturelle Angelegenheiten im Bundesinnenministerium, ebenda, Bl. 1 .

${ }^{378}$ Corsing schied mit Ablauf des 15. 10. 1946 auf eigenen Wunsch aus der DJV aus: siehe Verfügung Schiffers, 19. 10. 1946, BAB, DP1 VA Nr. 7489. Corsing emigrierte 1947 in die Vereinigten Staaten, war von 1949 bis 1953 Direktor der Beratungsstelle für Wertpapierbereinigung in New York und starb im Dezember 1962: siehe Deutsches Literatur-Lexikon, Bd. 2, S. 776.

374 Verfügung Schiffers, 19. 10. 1946, DP1 VA Nr. 7489.

380 Aktenvermerk über ein Telefonat Jakupows am 23. 1. 1947, BAB, DP1 VA Nr. 11, Bl. 99; Chef der DJV an Leiter der SMAD-Rechtsabteilung, 24. 1. 1947, BAB, DP1 VA Nr. 1025, Bl. 31.

381 Am 4. 2. 1947 erteilte Jakupow die diesbezügliche Genehmigung: siehe Aktenvermerk über ein Telefonat mit Jakupow, BAB, DP1, VA Nr. 11, Bl. 101. Am 5. 2. 1947 wurde Hartwig daraufhin die Leitung der Abteilung VI und des Justizprüfungsamts übertragen: siehe Verfügung Schiffers, 5. 2. 1947, BAB, DP1 VA Nr. 5777.

382 Löwenthal, Geist, S. 9. Löwenthals Name befand sich bereits auf einer Liste von KPD-Genossen, die zum Einsatz in Berlin bestimmt waren: siehe Ergänzungsliste für Berlin zur Liste vom 5.6. 1945, SAPMO, NY 4182/851a, Bl. 45; vgl. Keiderling, Gruppe Ulbricht, S. 508. Am 5. 2. 1947 wurde er zum DJV-Abteilungsleiter ernannt.

383 Protokoll Nr. 8/65 der Sitzung des Sekretariats am 27. 1. 1946, in: Dokumente zur Geschichte der kommunistischen Bewegung, Bd. 1, S. 161. 
Volkes zu finden“, wurde er rasch eines Besseren belehrt. Nach weniger als vier Monaten entschloß er sich, am 25. Mai 1947 die SBZ zu verlassen ${ }^{384}$. In seinem Abschiedsbrief an Schiffer schrieb er, daß „die Zustände in der Ostzone [...] fast noch schlimmer als in der Sowjetunion" seien; da er keiner fremden Macht dienstbar sein wolle, bleibe ihm „kein anderer Ausweg, als den Weg dorthin zu nehmen, wo die persönliche Freiheit der Staatsbürger besser geachtet wird“" 385 .

Die Abteilungen in der DJV blieben also, abgesehen von der Personalabteilung (II) und der Abteilung für den Strafvollzug (IV386), in der Hand nichtkommunistischer Juristen. Dies gilt auch für die Abteilung V, die von Winkelmann geführt wurde, bis Schiffer ihn zum 7. Juli 1947 mit der Leitung der Abteilung III beauftragte. Die Abteilung V unterstellte er vorläufig Karl Guski (SPD) ${ }^{387}$. Auch die anderen Angehörigen des höheren Dienstes rekrutierte die DJV bis Ende 1947 mehrheitlich aus nichtkommunistischen Juristenkreisen. Neben Melsheimer, Benjamin und Gentz gehörten Ende 1947 nur noch drei weitere Angestellte auf der Leitungsebene der SED an: Otto Türksch, Wolfgang Weiß und Hans Nathan. Türksch, Gewerkschaftsfunktionär und ehemaliges KPD-Mitglied, diente Schiffer seit Gründung der DJV als persönlicher Referent und Dolmetscher ${ }^{388}$. Weiß, Jahrgang 1910, hatte bis 1938 eine juristische Ausbildung absolviert und war seit 1942 als Rechtsanwalt tätig. Von 1932 bis 1933 Mitglied des „Roten Studentenbundes“, trat er 1945 der KPD bei ${ }^{389}$. Seit Ende Mai 1945 stellvertretender Bürgermeister von Berlin-Mitte, fand er den Weg zur DJV anscheinend über Melsheimer und Hilde Benjamin 390 . Ende Februar wurde er eingestellt, am 1. April $1946 \mathrm{der}$ Abteilung V zugeteilt und am 1. Juli als Vortragender Rat in eine Planstelle eingewiesen ${ }^{391}$. Nathan schließlich, geboren 1900 , hatte 1925 sein zweites juristisches Examen absolviert und anschließend eine Anwaltspraxis eröffnet. Von 1930 bis 1932 Mitglied der DDP, fand er den Weg zur KPD erst im Exil, das er von 1933 bis 1938 in Prag und danach in England verbrachte. 1938 stellte er einen Antrag auf Aufnahme in die KPD; diesem wurde erst 1944 formell entsprochen, da sein Aufnahmeschein auf dem Weg zum ZK in Paris verlorenging ${ }^{392}$. Anfang September 1946 nach Deutschland zurückgekehrt, wandte er sich an das ZK der SED, von wo ihn Karl Polak weiter an die DJV verwies. Nach seiner Vorstellung am 7. Sep-

${ }^{384}$ Löwenthal, Geist, S. 8-10, Zitat S. 9.

${ }^{385}$ Löwenthal an Schiffer, 24. 5. 1947, BAB, DP1 SE Nr. 13, Bl. 317; zit. bei Amos, Justizverwaltung, S. 91. Zu Löwenthal vgl. auch Güstrow, Jahre, S. 348-351. Er trat 1947 in die SPD ein, wurde Mitglied des Parlamentarischen Rates und im Mai 1949 nach Angriffen auf die kritische Haltung des Parteivorstands zu Grundgesetz und Westintegration aus der SPD-Fraktion ausgeschlossen. Er starb am 28. 8. 1956: siehe Biographisches Handbuch, S. $457 \mathrm{f}$.

${ }^{386}$ Mit Auflösung der Abteilung IV zum 1.2. 1947 ordnete Schiffer an, daß die Abteilung IV A die Nummer IV führen sollte: BAB, DP1 VA Nr. 5777.

387 Verfügung Schiffers, 2. 7. 1947, BAB, DP1 VA Nr. 1044, Bl. 33.

388 Türksch an das ZK der KPD, z.H. Dahlem, 3.1. 1946, SAPMO, NY 4182/1119, Bl. 1-4; vgl. Amos, Justizverwaltung, S. 14, 90.

389 Lebenslauf Weiß, 24. 4. 1951, SAPMO, DY 30/IV 2/11/177, Bl. 613-616.

390 Siehe das Bewerbungsschreiben von Weiß vom 25. 2. 1946, in dem er sich auf eine Besprechung mit Melsheimer bezog, sowie den Aktenvermerk Winkelmanns vom 28. 2. 1946, aus dem hervorgeht, daß Weiß von Benjamin eingeführt wurde. Beide Schriftstücke in: Personalakte Weiß, BAB, DP1 SE Nr. 2492.

391 Ebenda.

392 Lebenslauf Nathan, 24. 4. 1951, SAPMO, DY 30/IV 2/11/175, Bl. 547-552. 
tember bei Melsheimer und Benjamin wurde er neun Tage später als Vortragender Rat der Abteilung V zugeteilt ${ }^{393}$.

Wenngleich es dem SED-Justizapparat in Kooperation mit Melsheimer und Benjamin gelang, zwei Kommunisten in der Gesetzgebungsabteilung unterzubringen, war damit der kommunistische Einfluß nur unwesentlich erhöht worden. Von den 28 Angehörigen des höheren Dienstes in der DJV im Jahre 1947 gehörten neben den sechs SED-Vertretern zwei der SPD, drei der CDU, zwei der LDP und 15 gar keiner Partei an ${ }^{394}$. Wenn man darüber hinaus die Personalstatistik der DJV nach dem Stand vom 1. Oktober 1947 zugrunde legt, waren von den insgesamt 103 Angestellten 10 in der SED, 12 in der SPD, 7 in der CDU, 4 in der LDP und 70 parteilos ${ }^{395}$. Damit wies die DJV sowohl in absoluten Zahlen als auch in Prozent die niedrigste Quote von SED-Mitgliedern aller Zentralverwaltungen auf ${ }^{396}$. Zu Recht zählt der Bericht über die SED-Betriebsgruppen in den Zentralverwaltungen vom 11. November 1947 die DJV zu den Verwaltungen, die gezwungen waren, „eine große Zahl von früheren Beamten und Fachleuten zu übernehmen"; daher sei „dort das bürgerliche und indifferente Element sehr stark"397.

Der SED-Berichterstatter verwies damit auf ein zentrales Rekrutierungsproblem: Es mangelte nach wie vor an Juristen, die der SED angehörten und sich für eine leitende Stellung in der Zentralen Justizverwaltung eigneten. Dies kam zweifellos Schiffer in seinem Bestreben entgegen, die DJV von Kommunisten möglichst frei zu halten. Es wurde jedoch auch für ihn immer schwieriger, das geeignete Personal einzustellen. Dies wird deutlich an seinem Versuch, Ende Juli 1946 drei freie Stellen im höheren Dienst zu besetzen ${ }^{398}$. Zwei der in Aussicht genommenen Kandidaten, Oberstaatsanwalt Georg Brühl und Landgerichtsdirektor Wilhelm Schmitz, waren Juristen, die die Berliner Justizbehörden aufgrund der allgemeinen Personalknappheit nicht freigeben wollten. Wenngleich es der DJV gelang, im Fall Brühls die Unterstützung durch die SMAD-Rechtsabteilung zu erhalten, konnte der Berliner Generalstaatsanwalt die Zustimmung der Berliner Kommandantur zu dessen Freigabe verhindern ${ }^{399}$. Schiffer forderte daher im November 1946 die Landesjustizverwaltungen zweimal auf, ihm geeignete Mitarbeiter zu benennen ${ }^{400}$. Die Reaktionen aus den Ländern und Provinzen, die unter

393 Göhring, Nathan, S. 5 f.; Nathan, Aus der Geschichte der zentralen Justizverwaltung, BAB, DP1 VA Nr. 6832, Bl. 5-7; Verfügung Schiffers, 16. 9. 1946, BAB, DP1 VA Nr. 7489.

394 Amos, Justizverwaltung, S. 88.

395 Personalstatistik der DJV nach dem Stande vom 1. 10. 1947, BAB, DP1 VA Nr. 1009, Bl. 2. In der Statistik wird Gentz offensichtlich nicht zu den SED-Mitgliedern gezählt, da nur eine SED-Abteilungsleiterin aufgeführt wird. Rößler, Aspekte der Personalentwicklung, S. 141, schreibt irrtümlicherweise, daß die Mehrzahl der DJV-Mitarbeiter der SPD angehörte.

396 Vgl. Bericht über die Betriebsgruppe in den Zentralverwaltungen [2. Jahreshälfte 1947], SAPMO, DY 30/IV 2/2/234, Bl. 168-177, hier 176; ähnliche Vergleiche, freilich für September 1946 bei Amos, Justizverwaltung, S. $83 \mathrm{f}$.

397 Betr.: Betriebsgruppe Zentralverwaltungen, 11. 11. 1947, SAPMO, DY 30/IV 2/2/234, Bl. 155160 , hier 159.

398 Chef der DJV an SMAD-Rechtsabteilung, 29. 7. 1946, BAB, DP1 VA Nr. 1025, Bl. 5 f. Bei dem dritten Kandidaten handelte es sich um den Ministerialrat a.D. Erich Pritsch, der sich in der britischen Besatzungszone aufhielt.

399 Siehe dazu insgesamt die Akten zum Falle Brühl in: BAB, DP1 SE Nr. 3474, Bl. 582-600.

400 Protokoll über die Konferenz mit den Vertretern der Justizabteilungen der Landes- und Provinzialregierungen, 1./2. 11. 1946, BAB, DP1 VA Nr. 22, Bl. 65 f.; Chef der DJV an Landes- und Provinzialverwaltungen/Justizabteilung, 7. 11. 1946, BAB, DP1 VA Nr. 1025, Bl. 10. 
der durch die Entnazifizierung der Justiz hervorgerufenen extremen Personalknappheit litten ${ }^{401}$, waren für die DJV enttäuschend: Während aus Brandenburg und Thüringen überhaupt keine Antworten eingingen, sahen sich die Verwaltungen in Halle und Schwerin außerstande, geeignete Bewerber zu benennen ${ }^{402}$. Nur die sächsische Justizabteilung unterbreitete am 19. November zwei Personalvorschläge ${ }^{403}$. Beide Kandidaten, Bernhard Schreiber (CDU) und Otto Bürger (SED), wurden zum 1. Februar 1947 in die DJV eingestellt, auch wenn der sächsische Justizminister noch am 24. Dezember darum gebeten hatte, aufgrund der angespannten Geschäftslage Bürger einstweilen in Sachsen zu belassen ${ }^{404}$.

Insgesamt führten die Personalbewegungen in der DJV-Spitze nach dem Abgang von Paul Bertz und Karl Kleikamp daher durchaus zu einer Steigerung des kommunistischen Einflusses. Mit Melsheimer als einzigem Vizepräsidenten und Benjamin als Leiterin der Personalabteilung hatte die SED zwei Schlüsselstellungen besetzt. Schiffer war es somit nicht gelungen, die Kommunisten mit untergeordneten Funktionen in der DJV abzuspeisen. Freilich konnten Melsheimer und Benjamin ihren Einfluß in den Personalangelegenheiten der DJV in den Jahren bis 1947 kaum zur Geltung bringen, da es nach wie vor an geeigneten kommunistischen Juristen mangelte. Schiffers Handlungsspielraum wurde daher durch die Präsenz der beiden SED-Justizfunktionäre an der Spitze der DJV nur unwesentlich eingeschränkt.

401 Vgl. exemplarisch Tätigkeitsbericht der Justizabteilung der Provinzialverwaltung Sachsen (Mitte 1945-April 1946), 13. 5. 1946, und Tätigkeitsbericht der Justizabteilung der Provinzialverwaltung Mark Brandenburg (Mitte 1945-5.7.1946), Juli 1946, in: Berichte der Landes- und Provinzialverwaltungen, S. 221 f., 293.

402 Provinzialverwaltung Sachsen/Abt. Justiz an DJV, 18. 11. 1946, Landesverwaltung Mecklenburg/ Abt. Justiz an DJV, 2. 12. 1946, BAB, DP1 VA Nr. 1025, Bl. 12, 15.

${ }^{403}$ Landesverwaltung Sachsen/Abt. Justiz an DJV, 19. 11. 1946, ebenda, Bl. 13.

404 Vermerk 19.12. 1946, DJV an SMAD-Rechtsabteilung, 16.1. 1947, Kastner an Schiffer, 24. 12. 1946 (Telegramm), ebenda, Bl. 16, 29, 19. 